\title{
Epidemiological studies into prodromes and risk factors for cognitive decline and dementia
}

Citation for published version (APA):

Baars, M. A. E. (2009). Epidemiological studies into prodromes and risk factors for cognitive decline and dementia. [Doctoral Thesis, Maastricht University]. NeuroPsych Publishers. https://doi.org/10.26481/dis.20091217mb

Document status and date:

Published: 01/01/2009

DOI:

$10.26481 /$ dis. $20091217 \mathrm{mb}$

Document Version:

Publisher's PDF, also known as Version of record

\section{Please check the document version of this publication:}

- A submitted manuscript is the version of the article upon submission and before peer-review. There can be important differences between the submitted version and the official published version of record.

People interested in the research are advised to contact the author for the final version of the publication, or visit the DOI to the publisher's website.

- The final author version and the galley proof are versions of the publication after peer review.

- The final published version features the final layout of the paper including the volume, issue and page numbers.

Link to publication

\footnotetext{
General rights rights.

- You may freely distribute the URL identifying the publication in the public portal. please follow below link for the End User Agreement:

www.umlib.nl/taverne-license

Take down policy

If you believe that this document breaches copyright please contact us at:

repository@maastrichtuniversity.nl

providing details and we will investigate your claim.
}

Copyright and moral rights for the publications made accessible in the public portal are retained by the authors and/or other copyright owners and it is a condition of accessing publications that users recognise and abide by the legal requirements associated with these

- Users may download and print one copy of any publication from the public portal for the purpose of private study or research.

- You may not further distribute the material or use it for any profit-making activity or commercial gain

If the publication is distributed under the terms of Article $25 \mathrm{fa}$ of the Dutch Copyright Act, indicated by the "Taverne" license above, 
Epidemiological studies into prodromes and risk factors for cognitive decline and dementia 
(C) M.A.E. Baars, Maastricht, 2009

Lay-out Lia Baars, Jeroen Bleijerveld, Datawyse BV, Maastricht

Cover illustration Joke Plass

Publisher NeuroPsych Publishers

ISBN 978-90-75579-43-7

NeuroPsych Publishers is a non-profit organization, which aims at promoting the science of 'Brain and Behaviour' and improving the application of the products of this science in health care and education. NeuroPsych Publishers accomplishes these aims by publishing books, dissertations and other products of scientific activity, by disseminating educational material and publication of tests, assessment scales and other psychometric instruments in the field of Neuropsychology, Neuropsychiatry and other areas within the domain of Brain and Behaviour.

Neuropsych Publishers

Department of Psychiatry \& Neuropsychology

Maastricht University

P.O. Box 616

NL- 6200 MD Maastricht

www.np.unimaas.nl 


\title{
Epidemiological studies into prodromes and risk factors for cognitive decline and dementia
}

\author{
Proefschrift \\ Ter verkrijging van de graad van doctor aan de Universiteit Maastricht, \\ op gezag van de Rector Magnificus, Prof. mr. G.P.M.F. Mols, \\ volgens het besluit van het College van Decanen, \\ in het openbaar te verdedigen \\ op donderdag 17 december 2009 om 10:00 uur \\ door \\ Maria Amalia Engelina Baars
}

Geboren op 13 januari 1980 te Heerlen 
Promotores

Copromotor
Prof. dr. J. Jolles

Prof. dr. F.R.J. Verhey

Dr. M.P.J. van Boxtel

Beoordelingscommissie Prof. dr. J. F. M. Metsemakers (voorzitter)

Prof. dr. L. Fratiglioni (Karolinska Institutet, Sweden)

Dr. M. Jelicic

Em. Prof. dr. C. Jonker (Vrije Universiteit Amsterdam)

Prof. dr. G. I. J. M. Kempen

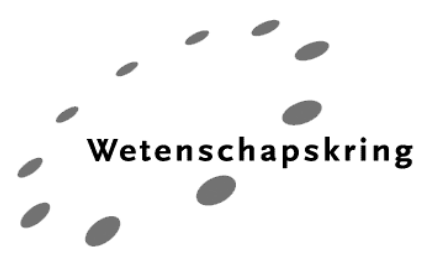

The research described in this thesis was performed at the Department of Psychiatry \& Neuropsychology, School for Mental Health and Neuroscience, Maastricht University, The Netherlands and at the Aging Research Center of Karolinska Institutet, Stockholm, Sweden.

Financial support for the publication of this thesis was kindly provided by Alzheimer Nederland, Danone Research B.V., Internationale Stichting Alzheimer Onderzoek (ISAO), Janssen-Cilag, Lundbeck B.V., Nutricia Advanced Medical Nutrition, Novartis Pharma B.V., and Wyeth Pharmaceuticals. 
Voor Oop en Oom, samen prachtig oud!

En voor Jeroen, de allerliefste... 
Waar je ook loopt, wie je ook bent, niemand vertelt jou wat goed is of slecht, niemand die weet wie verliest of wie wint, je komt op het eind bij jezelf terecht.

Jack Poels 


\section{Contents}

Chapter 1 Introduction

\section{Part I}

Chapter 2 Predictive value of Mild Cognitive Impairment for dementia. The influence of case definition and age.

Chapter 3 Long-term stability of Mild Cognitive Impairment. Results from a six-year longitudinal population study.

Chapter 4 Neuropsychological trajectories of preclinical dementia. Nine year follow up results from the Maastricht Aging Study.

\section{Part II}

Chapter 5 Migraine does not affect cognitive decline: results from the Maastricht Aging Study.

Chapter 6 Obesity, blood pressure and cognitive function.

Chapter 7 Effects of hypertension on cognitive decline: mediation by exposure duration, antihypertensive treatment and APOE-e4 genotype, but not diabetes.

Chapter 8 Effects of multimorbidity on the progression to dementia over nine years in older individuals with cognitive impairment, no dementia.

Chapter 9 Concluding remarks.

Summary

Samenvatting

Dankwoord

Publications

Curriculum Vitae 

1

Introduction 


\subsection{Background}

Mean life expectancy in Western countries has increased from 63 to 75 years over the past fifty years. This development has caused the number of people aged 60 years or older to grow steadily to 600 million in 2000, a number that will reach 1.2 billion in 2025 and is predicted to be 2 billion in 2050 (WHO, 2006).

Due to the baby boom after World War II, the proportion of people over 65 years old in the Netherlands is expected to increase from $15 \%$ in 2009 to $25 \%$ in 2050 (CBS, 2008). Due to these demographic trends age-related functional limitations and disease burden will hit our society hard in the next decades. (Wolfs et al., 2009). Old age is the primary risk factor for dementia and cognitive decline, and therefore the number of people with dementia in the Netherlands will increase from 200.000 in the year 2000 to 400.000 in 2050 (CBS, 2008).

At present, a curative treatment for dementia is unavailable. The development of effective (non)-pharmacological treatment options for dementia hinges on various factors, which are not fully understood. Dementia is a degenerative condition and therefore treatment in the earliest stages of the disease should be aimed for. However, especially in the preclinical stages of dementia, it is hard to distinguish the first signs of dementia from what should be considered as age-congruent decline in cognition. Both seem to exist along a continuum of cognitive aging in which pathological aging is present to some extent in older individuals even if they do not develop a clinical syndrome such as dementia. Studies into risk factors and predictors for cognitive decline may help in identifying those individuals who will show a rate of decline that is typical for pathological aging.

\subsection{Prodromes and risk factors for cognitive decline and dementia}

Recent studies have provided important new insights regarding prodromes and risk factors for dementia. Since no diagnostic procedures are currently available to identify future dementia patients with absolute certainty, identification of individuals who may be at risk for dementia seems to be an appropriate strategy. In the past decade, the concept of Mild Cognitive Impairment (MCI) (Petersen, Stevens et al., 2001) has received much attention in aging research. MCI refers to a state of cognitive functioning between normal cognitive performance and dementia. Original MCI criteria included the existence of memory complaints, disturbed memory performance compared on standard neuropsychological tests and normal global cognitive functioning (Petersen, Doody et al., 2001). Conversion from MCI to dementia has been investigated in many clinical (Mosconi et al., 2004; Rasquin et al., 2005) and population-based (Artero et al., 2006; Larrieu et al., 2002; Palmer et al., 2003) studies, which have shown large discrepancies in results. Conversion to dementia in these and other studies was dependent on many factors, which include study population characteristics, vascular disease, memory performance, genetic predisposition, psychopathology (i.e. depressive symptoms (Palmer et 
al., 2007)) and lifestyle (mental, social and physical fitness (Karp et al., 2006)). The following factors will be discussed in depth in the next chapters of this thesis:

1. Characteristics of the study population: the setting in which the study takes place (clinical vs. population-based) is an important determinant of conversion of MCI to dementia (Ganguli, 2006), as is the age of the study population (Visser \& Verhey, 2007).

2. Cognitive performance: a low level of memory performance, predicts conversion to dementia many years before diagnosis (Chen et al., 2000; De Jager et al., 2003; Masur et al., 1994), even when factors such as age and education are taken into account (Tabert et al., 2006).

3. Genetic factors: the Apolipoprotein-E-e4 genotype is a known genetic marker for Alzheimer's Disease (AD). Its relation to cognitive decline is somewhat controversial, with studies reporting increased risk of cognitive decline in carriers of this gene (Cosentino et al., 2008; Knopman et al., 2009) and other studies reporting no such effects (Bunce et al., 2004; Christensen et al., 2008).

4. Vascular disease: individuals with a history of cerebrovascular disease, such as stroke, are at increased risk for cognitive decline over time and dementia (Staekenborg et al., 2009). Other vascular factors, such as hypertension and diabetes have also been related to cognitive decline and dementia (Helzner et al., 2009; Launer et al., 2000; Xu et al., 2008). However, effects of long-term exposure to both hypertension and diabetes on cognitive change over time are not yet well defined. Studies into the effects of vascular risk factors may improve insight in the progression of cognitive decline and dementia, and may help find ways to slow down the pathological process causing dementia.

\subsection{Defining the problem}

The progression from normal or mildly disturbed cognitive functioning to cognitive decline and dementia is determined by a complex set of factors, that all may have primary effects in the aetiology of cognitive disorders but may interact as well.

MCI has been studied extensively, with varying results with respect to its predictive value for dementia diagnosis at a later stage. Unfortunately, the definition of MCI has been subject of much debate. At present, prevailing MCI definitions differ particularly with respect to the inclusion of cognitive domains. In amnestic MCI only memory performance is taken into consideration (Petersen et al., 1999), whereas in multiple domain MCI (Winblad et al., 2004), also other domains, such as executive functioning, are taken into consideration. The prevalence of amnestic and multiple domain MCI differs greatly, due to fact that the number of cognitive measures included in a study is directly related to identification of a score in the pathological range. For example, prevalence of amnestic MCI was found to be $4 \%$ in a large population sample (Ganguli et al., 2004) and in another large population sample, prevalence of multiple domain MCI was found to be 17\% (Artero et al., 2006). The status of subjective cognitive complaints in the MCI definition has also been subject to some debate. Presence of subjective complaints were 
part of the first MCI definition (Petersen et al., 1999). In the revised MCI criteria, subjective cognitive complaints expressed by the patient or partner are still included, but now either subjective complaints or objective cognitive impairment is sufficient for a diagnosis (Winblad et al., 2004). The setting in which MCI definitions are applied affects prevalence as well. In general, higher prevalence rates are found in clinical samples (Schmidtke \& Hermeneit, 2008; Visser \& Verhey, 2007) than in population-based samples (Busse et al., 2006; Ganguli et al., 2004). To date, little is known about the effects of differences in these definitions and in the setting they are applied, on the conversion of MCI to dementia.

To formulate a definition of the prodromal phase of dementia, we need to identify risk factors that may predict who will cognitively decline over time, and who will not. Both cognitive performance and exposure to the health-related risk factors should be followed over time, in order to study long-term associations between risk factors and conversion.

\subsection{Aim of this thesis}

The main aims of this thesis are to study the prodromal phase of cognitive decline and dementia, to explore cognitive domains with respect to their predictive value for conversion to dementia, and finally, to study the association between selected health-related factors and cognitive decline and dementia. These aims result in the following research questions:

1. What is the predictive value of currently employed Mild Cognitive Impairment definitions for the development of dementia at a later stage

2. Can Mild Cognitive Impairment be considered as a stable condition over time?

3. Which aspect of cognitive functioning has the largest predictive power for dementia and how do the cognitive profiles of individuals with preclinical dementia develop over time?

4. What is the relationship between selected health-related risk factors and cognitive decline or dementia?

5. What is the effect of risk factor exposure on cognitive change?

\subsection{Longitudinal databases used in this thesis}

The studies described in this thesis, were all conducted using data derived from longitudinal aging studies. The Maastricht Aging Study (MAAS) was the main data framework used for studies described in chapters two to seven. Data from the Kungsholmen Project $(\mathrm{KP})$ were used in chapter eight. Both datasets are to some extent complementary with respect to their age build-up: where age range in the MAAS was 24-84 years, the KP typically included individuals aged 75 and older. The datasets are in many respects comparable in design and methodology. In the next sections both studies will be described in more detail. 


\subsubsection{The Maastricht Aging Study}

The Maastricht Aging Study (MAAS) is a longitudinal study into the determinants of cognitive aging. Baseline assessment, involving 1,823 cognitively intact and healthy persons (aged 24-81 years), took place between 1993 and 1996 and participants were followed over a period of twelve years, with measurements after three (only participants aged 50 years and older), six, nine (questionnaires only) and twelve years. The main outcome variables of the MAAS are the cognitive measures taken (e.g. memory, processing speed, executive functioning) and the health status of the participants (e.g. bloodpressure, medical conditions and medication use). To date, MAAS has proven to be a rich source of information on the influence of health-related (Van Boxtel et al., 1998), psychosocial (Bosma et al., 2002) and psychological (Mol et al., 2006) factors on cognitive functioning. MAAS has also served as data framework for studies into standardization of neuropsychological tests and provision of normative data (Van der Elst et al., 2005, 2006a, 2006b, 2006c, 2006d). MAAS was chosen for its relatively long follow-up period and full adult age range, which serve as a sound base for studies into prodromes and risk factors for cognitive decline.

\subsubsection{The Kungsholmen Project}

The Kungsholmen Project (KP) is a longitudinal, population-based study on aging and dementia. In this study, all persons living in the Kungsholmen district of Stockholm, Sweden who were born before 1913 were invited to participate (Fratiglioni et al., 1992). The main outcome variables of KP were dementia diagnosis, neuropsychological test performance, health-related variables (e.g. blood-pressure measures, prevalent diseases, medication use) and information on engagement in social, physical and mental activities. Baseline assessment was conducted in $1987(\mathrm{~N}=1,700)$ and the last of four follow-up phases (every three years) has been completed in 2000. The KP has also been an invaluable data source for many studies into health-related risk factors (Marengoni et al., 2009; Marengoni et al., 2008), Mild Cognitive Impairment (Caracciolo et al., 2008; Palmer et al., 2003), or lifestyle (Karp et al., 2006; Wang et al., 2009), all related to dementia as primary outcome measure. Due to the high age range of participants, the conversion rate to dementia is relatively high and the Kungsholmen Project serves well as a database for investigations into risk factors for dementia.

\subsection{Outline of this thesis}

This thesis consists of seven chapters, of which the first three (chapters 2 to 4), focus on the conversion from normal cognitive performance to dementia. The second part of the thesis (chapters 5 to 8) deals with specific potential risk factors for cognitive decline or dementia and investigates the effect of exposure to these risk factors over time on cognitive efficiency.In chapter 2, a set of commonly used MCI definitions was compared, in order to investigate which definition predicts dementia at a later stage best. Conversion 
to dementia was expected to depend on the definition of cognitive impairment and on the age stratum studied.

Chapter 3 continues with the predictive value of MCI for dementia, by focusing on those participants who fulfilled the criteria for MCI at baseline but who did not convert to dementia. Stability of MCI was studied over a six-year time-interval, comparing different indicators of stability, which can take practice effects on neuropsychological tests or the effects of aging into account.

Chapter 4 deals with the prediction of dementia in healthy individuals based on the neuropsychological assessment. Cognitive performance was followed for six years in MAAS participants, 44 of whom were diagnosed with dementia within nine years after baseline. Part II of this thesis starts with chapter 5 deals with migraine as a risk factor for cognitive decline. Effects of migraine and migraine medication use on cognitive change over time were tested over a six-year interval.

In Chapter 6 effects of obesity and blood pressure on cognitive functioning were investigated. Interaction between obesity and blood pressure on cognitive performance over time was tested, based on an earlier study that strongly suggested the presence of such an effect but which was too small to provide a definite answer.

Effects of exposure to hypertension and diabetes on cognitive performance are discussed in chapter 7. Twelve-year follow-up data were used to test whether prolonged exposure to hypertension and diabetes leads to an increase in cognitive decline. ApoE genotype, anti-hypertensive medication use and body mass index served as control variables.

In chapter 8 , effects of multimorbidity on progression from cognitive impairment (no dementia) to dementia are studied in the Kungsholmen data. The prevalence of multimorbidity, defined as having two or more chronic diseases, and health-related functional decline tends to increase with age.

In chapter 9, the results described in the experimental chapters are discussed on a broader level, including the strengths and limitations of the studies and their implications for both future research and clinical practice. 


\section{References}

Artero, S., Petersen, R., Touchon, J., \& Ritchie, K. (2006). Revised criteria for mild cognitive impairment: validation within a longitudinal population study. Dement Geriatr Cogn Disord, 22(5-6), 465-470.

Bosma, H., van Boxtel, M. P., Ponds, R. W., Jelicic, M., Houx, P., Metsemakers, J., et al. (2002). Engaged lifestyle and cognitive function in middle and old-aged, non-demented persons: a reciprocal association? $Z$ Gerontol Geriatr, 35(6), 575-581.

Bunce, D., Fratiglioni, L., Small, B. J., Winblad, B., \& Backman, L. (2004). APOE and cognitive decline in preclinical Alzheimer disease and non-demented aging. Neurology, 63(5), 816-821.

Busse, A., Hensel, A., Guhne, U., Angermeyer, M. C., \& Riedel-Heller, S. G. (2006). Mild cognitive impairment: long-term course of four clinical subtypes. Neurology, 67(12), 2176-2185.

Caracciolo, B., Palmer, K., Monastero, R., Winblad, B., Backman, L., \& Fratiglioni, L. (2008). Occurrence of cognitive impairment and dementia in the community: a 9-year-long prospective study. Neurology, $70(19 \mathrm{Pt}$ 2), $1778-1785$.

CBS. (2008). Kerncijfers van de bevolkingsprognoses 2008-2050: Centraal Bureau voor de Statistiek (CBS).

Chen, P., Ratcliff, G., Belle, S. H., Cauley, J. A., DeKosky, S. T., \& Ganguli, M. (2000). Cognitive tests that best discriminate between presymptomatic $\mathrm{AD}$ and those who remain nondemented. Neurology, 55(12), 1847-1853.

Christensen, H., Batterham, P. J., Mackinnon, A. J., Jorm, A. F., Mack, H. A., Mather, K. A., et al. (2008). The association of APOE genotype and cognitive decline in interaction with risk factors in a 65-69 year old community sample. BMC Geriatr, 8, 14 .

Cosentino, S., Scarmeas, N., Helzner, E., Glymour, M. M., Brandt, J., Albert, M., et al. (2008). APOE epsilon 4 allele predicts faster cognitive decline in mild Alzheimer disease. Neurology, 70(19 Pt 2), 1842-1849.

De Jager, C. A., Hogervorst, E., Combrinck, M., \& Budge, M. M. (2003). Sensitivity and specificity of neuropsychological tests for mild cognitive impairment, vascular cognitive impairment and Alzheimer's disease. Psychol Med, 33(6), 1039-1050.

Fratiglioni, L., Viitanen, M., Backman, L., Sandman, P. O., \& Winblad, B. (1992). Occurrence of dementia in advanced age: the study design of the Kungsholmen Project. Neuroepidemiology, 11 Suppl 1, 29-36.

Ganguli, M. (2006). Mild cognitive impairment and the 7 uses of epidemiology. Alzheimer Dis Assoc Disord, 20(3 Suppl 2), S52-57.

Ganguli, M., Dodge, H. H., Shen, C., \& DeKosky, S. T. (2004). Mild cognitive impairment, amnestic type: an epidemiologic study. Neurology, 63(1), 115-121.

Helzner, E. P., Luchsinger, J. A., Scarmeas, N., Cosentino, S., Brickman, A. M., Glymour, M. M., et al. (2009). Contribution of vascular risk factors to the progression in Alzheimer disease. Arch Neurol, 66(3), 343-348.

Karp, A., Paillard-Borg, S., Wang, H. X., Silverstein, M., Winblad, B., \& Fratiglioni, L. (2006). Mental, physical and social components in leisure activities equally contribute to decrease dementia risk. Dement Geriatr Cogn Disord, 21(2), 65-73.

Knopman, D. S., Mosley, T. H., Catellier, D. J., \& Coker, L. H. (2009). Fourteen-year longitudinal study of vascular risk factors, APOE genotype, and cognition: the ARIC MRI Study. Alzheimers Dement, 5(3), $207-$ 214.

Larrieu, S., Letenneur, L., Orgogozo, J. M., Fabrigoule, C., Amieva, H., Le Carret, N., et al. (2002). Incidence and outcome of mild cognitive impairment in a population-based prospective cohort. Neurology, 59(10), 1594-1599.

Launer, L. J., Ross, G. W., Petrovitch, H., Masaki, K., Foley, D., White, L. R., et al. (2000). Midlife blood pressure and dementia: the Honolulu-Asia aging study. Neurobiol Aging, 21(1), 49-55.

Marengoni, A., von Strauss, E., Rizzuto, D., Winblad, B., \& Fratiglioni, L. (2009). The impact of chronic multimorbidity and disability on functional decline and survival in elderly persons. A community-based, longitudinal study. J Intern Med, 265(2), 288-295.

Marengoni, A., Winblad, B., Karp, A., \& Fratiglioni, L. (2008). Prevalence of chronic diseases and multimorbidity among the elderly population in Sweden. Am J Public Health, 98(7), 1198-1200.

Masur, D. M., Sliwinski, M., Lipton, R. B., Blau, A. D., \& Crystal, H. A. (1994). Neuropsychological prediction of dementia and the absence of dementia in healthy elderly persons. Neurology, 44(8), 1427-1432.

Mol, M. E., van Boxtel, M. P., Willems, D., \& Jolles, J. (2006). Do subjective memory complaints predict cognitive dysfunction over time? A six-year follow-up of the Maastricht Aging Study. Int J Geriatr Psychiatry, 21(5), 432-441. 
Mosconi, L., Perani, D., Sorbi, S., Herholz, K., Nacmias, B., Holthoff, V., et al. (2004). MCI conversion to dementia and the APOE genotype: a prediction study with FDG-PET. Neurology, 63(12), 2332-2340.

Palmer, K., Berger, A. K., Monastero, R., Winblad, B., Backman, L., \& Fratiglioni, L. (2007). Predictors of progression from mild cognitive impairment to Alzheimer disease. Neurology, 68(19), 1596-1602.

Palmer, K., Fratiglioni, L., \& Winblad, B. (2003). What is mild cognitive impairment? Variations in definitions and evolution of nondemented persons with cognitive impairment. Acta Neurol Scand Suppl, 179, 14-20.

Petersen, R. C., Doody, R., Kurz, A., Mohs, R. C., Morris, J. C., Rabins, P. V., et al. (2001). Current concepts in mild cognitive impairment. Arch Neurol, 58(12), 1985-1992.

Petersen, R. C., Smith, G. E., Waring, S. C., Ivnik, R. J., Tangalos, E. G., \& Kokmen, E. (1999). Mild cognitive impairment: clinical characterization and outcome. Arch Neurol, 56(3), 303-308.

Petersen, R. C., Stevens, J. C., Ganguli, M., Tangalos, E. G., Cummings, J. L., \& DeKosky, S. T. (2001). Practice parameter: early detection of dementia: mild cognitive impairment (an evidence-based review). Report of the Quality Standards Subcommittee of the American Academy of Neurology. Neurology, 56(9), 11331142.

Rasquin, S. M., Lodder, J., Visser, P. J., Lousberg, R., \& Verhey, F. R. (2005). Predictive accuracy of MCI subtypes for Alzheimer's disease and vascular dementia in subjects with mild cognitive impairment: a 2 year follow-up study. Dement Geriatr Cogn Disord, 19(2-3), 113-119.

Schmidtke, K., \& Hermeneit, S. (2008). High rate of conversion to Alzheimer's disease in a cohort of amnestic MCI patients. Int Psychogeriatr, 20(1), 96-108.

Staekenborg, S. S., Koedam, E. L., Henneman, W. J., Stokman, P., Barkhof, F., Scheltens, P., et al. (2009). Progression of mild cognitive impairment to dementia: contribution of cerebrovascular disease compared with medial temporal lobe atrophy. Stroke, 40(4), 1269-1274.

Tabert, M. H., Manly, J. J., Liu, X., Pelton, G. H., Rosenblum, S., Jacobs, M., et al. (2006). Neuropsychological prediction of conversion to Alzheimer disease in patients with mild cognitive impairment. Arch Gen Psychiatry, 63(8), 916-924.

Van Boxtel, M. P., Buntinx, F., Houx, P. J., Metsemakers, J. F., Knottnerus, A., \& Jolles, J. (1998). The relation between morbidity and cognitive performance in a normal aging population. J Gerontol A Biol Sci Med Sci, 53(2), M147-154.

Van der Elst, W., Van Boxtel, M. P., Van Breukelen, G. J., \& Jolles, J. (2005). Rey's verbal learning test: normative data for 1855 healthy participants aged 24-81 years and the influence of age, sex, education, and mode of presentation. J Int Neuropsychol Soc, 11(3), 290-302.

Van der Elst, W., Van Boxtel, M. P., Van Breukelen, G. J., \& Jolles, J. (2006a). Normative data for the Animal, Profession and Letter M Naming verbal fluency tests for Dutch speaking participants and the effects of age, education, and sex. J Int Neuropsychol Soc, 12(1), 80-89.

Van der Elst, W., Van Boxtel, M. P., Van Breukelen, G. J., \& Jolles, J. (2006b). The Concept Shifting Test: adult normative data. Psychol Assess, 18(4), 424-432.

Van der Elst, W., Van Boxtel, M. P., Van Breukelen, G. J., \& Jolles, J. (2006c). The Letter Digit Substitution Test: normative data for 1,858 healthy participants aged 24-81 from the Maastricht Aging Study (MAAS): influence of age, education, and sex. J Clin Exp Neuropsychol, 28(6), 998-1009.

Van der Elst, W., Van Boxtel, M. P., Van Breukelen, G. J., \& Jolles, J. (2006d). The Stroop color-word test: influence of age, sex, and education; and normative data for a large sample across the adult age range. $A s$ sessment, 13(1), 62-79.

Visser, P. J., \& Verhey, F. R. (2007). Mild cognitive impairment as predictor for Alzheimer's disease in clinical practice: effect of age and diagnostic criteria. Psychol Med, 1-10.

Wang, H. X., Karp, A., Herlitz, A., Crowe, M., Kareholt, I., Winblad, B., et al. (2009). Personality and lifestyle in relation to dementia incidence. Neurology, 72(3), 253-259.

WHO. (2006). The world health report 2006: working together for health: World Health Organization, WHO.

Winblad, B., Palmer, K., Kivipelto, M., Jelic, V., Fratiglioni, L., Wahlund, L. O., et al. (2004). Mild cognitive impairment--beyond controversies, towards a consensus: report of the International Working Group on Mild Cognitive Impairment. J Intern Med, 256(3), 240-246.

Wolfs, C. A., Dirksen, C. D., Kessels, A., Severens, J. L., \& Verhey, F. R. (2009). Economic evaluation of an integrated diagnostic approach for psychogeriatric patients: results of a randomized controlled trial. Arch Gen Psychiatry, 66(3), 313-323.

Xu, W., Qiu, C., Gatz, M., Pedersen, N. L., Johansson, B., \& Fratiglioni, L. (2008). Mid- and Late-life Diabetes in Relation to the Risk of Dementia: A Population-based Twin Study. Diabetes. 2 


\section{2}

Predictive value of Mild Cognitive Impairment for dementia: the influence of case definition and age 


\begin{abstract}
In population studies different MCI definitions have been used to predict dementia at a later stage. This study compared predictive values of different MCI definitions for dementia and the effect of age on the predictive values was investigated. This study was conducted as part of an ongoing longitudinal study into the determinants of cognitive aging, the Maastricht Aging Study. MCI predicted dementia best, when multiple cognitive domains were considered and subjective complaints were not (sensitivity: 0.66, specificity: 0.78). Age had a strong influence on the sensitivity of MCI for dementia (age $60-70$, sensitivity $=0.56$; age $70-85$, sensitivity $=0.70$ ).

The inclusion of multiple cognitive domains and participants aged 70 and older, leads to the best prediction of dementia, regardless of subjective complaints.
\end{abstract}




\section{Introduction}

Mild cognitive impairment is a transitional state between normal functioning and dementia (Petersen et al., 1999). Progression to dementia is one possible outcome for individuals classified as MCI. The rate of progression to dementia differs greatly between studies (Ganguli et al., 2004; Larrieu et al., 2002). Case definition is one reason for these differences. In the earlier studies amnestic and non-amnestic MCI subtypes were predominantly used as predictors of Alzheimer's Disease (Petersen et al., 1999; Ritchie et al., 2001). In the past years the discussion on the applicability of MCI as a prognostic marker has shifted towards a broader interpretation including several domains of cognition, such as memory and executive functioning, in one definition (Winblad et al., 2004). The predictive value of MCI for dementia has been found to be highest when a combination of complaints (reported by the patient or partner), cognitive performance in multiple domains, and preserved overall general functioning are taken into account (Artero et al., 2006). However, it has also been suggested that subjective complaints should not be included in the definition of MCI, because the predictive value for dementia does not increase when complaints are taken into account (Kliegel et al., 2005).

Age of the population studied is another possible reason for differences in progression rate. Aging is by far the most important risk factor for the development of both dementia and MCI (Petersen et al., 1997; Visser et al., 2006). However, the effect of age on conversion rate from MCI to dementia in population based studies remains unclear. Moreover, it is not clear whether the definition of MCI that predicts conversion rates best varies with age.

In the current study, the effect of age on the conversion rate of MCI to dementia is investigated for different MCI definitions in the Maastricht Aging Study, a large longitudinal study into the determinants of cognitive aging (Jolles et al., 1995).

Several MCI definitions used in the literature are compared in a sensitivity analysis, and the most useful set of criteria is defined. Based on findings from previous studies, we hypothesize, that the predictive value of MCI for the development of dementia, is highest when MCI is defined using broad cognitive criteria, and subjective complaints are left out of the definition. Second, we expect, that the predictive value of this type of MCI for dementia increases with age.

\section{Methods}

\section{Sample}

The participants included in this study were all part of the Maastricht Aging Study (MAAS), a longitudinal study into the determinants of cognitive aging (Jolles et al., 1995; Van Boxtel et al., 1998). Participants were tested neuropsychologically at baseline (19921994), after three years (only participants over 50) and after six years. The twelve years follow up is currently in progress. 10,396 potential participants were recruited from a patients register of collaborating general practitioners in the south of the Netherlands (RNH) (Metsemakers et al., 1992) by sending a prepaid postcard 4,490 agreed to partici- 
pate $(43.2 \%), 3,531$ refused participation $(34 \%)$ and 2,375 did not return the postcard $(22.8 \%)$.

Participants were excluded from participation when medical records from the general practitioner (GP) reported conditions that could interfere with cognitive functioning, including coma, all tumors of the nervous system, congenital malformations of the nervous system, history of stroke, parkinsonism, multiple sclerosis, dementia, organic psychosis (other than dementia), schizophrenia, affective psychosis and mental retardation. Health problems in the RNH database were recorded according to the International Classification Primary Care (ICPC) (Lamberts \& Wood, 1987). The 4,490 potential participants were additionally screened by telephone, for medical conditions not reported by the RNH (history of TIA, brain surgery, haemodialysis for renal failure, electroconvulsive therapy, and regular use of psychotropic drugs) and to update information reported by the RNH. In total, 301 potential participants were excluded from participation based on this interview. Of the remaining 4,189 participants, 1,856 were randomly selected from 12 equally sized age categories $(25+/-1$ years, $30+/-1$ years . . $.80 \mathrm{H} / \mathrm{-} 1$ years), stratified for sex and education level, ranging from primary education (1) to university degree (8) (De Bie, 1987). After baseline measurement, 27 participants were excluded with MMSE scores lower or equal to 24. Another six participants were excluded due to technical problems during baseline assessment $(n=4)$, or because their native language was not Dutch $(\mathrm{n}=2)$. After the baseline measurement 1,823 participants, aged 24 to 81 years at baseline, were admitted to the longitudinal part of the study.

In the current study only the participants over the age of sixty were included $(n=661)$. The comparison of the different MCI definitions was based on both the baseline and three-year follow-up assessments $(n=519)$, since one MCI definition depended on information taken from a proxy questionnaire, the DECO (Détérioration Cognitive Observée), which was not available at baseline.

\section{Definition of dementia cases at follow-up}

At baseline, persons with a diagnosis of dementia (based on RNH database information) or a MMSE score of 24 or less were excluded from participation. Nine years after baseline all participants who had developed dementia during the study were identified by their GP on the basis of data from the MAAS study that was send to the GP, and using the criteria of the DSM-IV (American Psychiatric Association, 1994) and the guidelines of the GP practice (Boomsma et al., 2004). The type of dementia was determined by an experienced neuropsychiatrist from the Memory Clinic of the Maastricht University Medical Center (FRJV) on the basis of the neuropsychological data, daily functioning and the participant's medical profile (vascular risk factors, comorbidity, course) and using the established criteria (Dubois et al., 2007).

\section{Instruments}

Several domains of cognitive functioning were screened using a battery of neuropsychological instruments. The domains included memory, executive functioning, mental speed and verbal fluency. 
The Visual Verbal Learning Test (Van der Elst et al., 2005) was included to test verbal memory. In this study the total immediate recall score of five trials and the delayed recall score after twenty minutes were used. The Stroop-Color Word Test (Stroop, 1935; Van der Elst et al., 2006c) and the Concept Shifting Task (Van der Elst et al., 2006a) were included to measure complex speed. The interference score of the Stroop was used in this study, as a measure of inhibition. This interference score was calculated by taking the time needed for the third card (naming ink colors of incongruent printed color names) and subtracting the mean of the time on the first (reading color names) and second (naming colors of patches) card. This calculation minimizes the effects of less complex executive functions and simple speed on the interference score. The Concept Shifting Test (CST) measures executive functioning, and is comparable to the Trail Making Test (Lezak et al., 2004). The shifting score on this task was calculated by subtracting the average time needed for version A (digits) and B (letters) from the total time needed for version $\mathrm{C}$ (letters and digits). This procedure separates time needed for complex shifting from time needed for simple reading and counting (Van der Elst et al., 2006c). Both the Stroop interference score and the concept shifting score are considered measures of executive functioning, calculated by correcting the more complex parts of the task for the relatively simple parts. Attention, visual recognition and working memory are important factors in all parts of the tasks, but the mental shifting between letters and digits (CST-C) and the inhibition of reading (Stroop-III) were the measures of executive functioning of interest. To make the screening of cognitive domains as complete as possible, a measure of general information processing speed, the Letter Digit Substitution Test (Van der Elst et al., 2006b) was included, which is based on the Digit Symbol Substitution Test (Wechsler, 1955). After completing the test battery, all participants filled out a questionnaire at home, which included questions on Activities of Daily Living (ADL, dressing, washing, grocery shopping), on self-perceived forgetfulness and worry and hindrance. The ADL questions were used to exclude participants from the MCI group, who had significant problems with performing these functions. Intact ADL function is a criterion that distinguishes MCI from probable dementia (Petersen et al., 2001). Questions on self-perceived forgetfulness were included to investigate whether participants experienced subjective memory complaints. The first question was: 'Do you consider yourself to be forgetful?' Then the amount of experienced worry about this forgetfulness was scored on a five-point scale ranging from 'no worry at all' to 'a lot of worry'. Finally, the amount of hindrance caused by the forgetfulness was measured on a five-point scale ranging from 'no hindrance at all' to 'a lot of hindrance'. A participant was considered to have subjective cognitive complaints when the forgetfulness question was answered positively and the worry and hindrance questions scored at least three out of five on either one or both. The DECO was included in this questionnaire (not at baseline) to probe close relatives about the changes in functioning of the respondent. The maximum score on the DECO was thirty-eight and a score of less than thirty-eight was considered a partner complaint.

\section{MCI definitions}

At baseline four possible MCI definitions were compared. These definitions had been applied in population samples before and their predictive values for dementia had been 
established. Intact ADL functions and no dementia diagnosis were two criteria applied in every definition mentioned below.

MCI-1, which refers to single domain amnestic MCI (Petersen et al., 1999) is defined as a score of 1.5 SD below the mean for a reference group on either the delayed recall score or the immediate recall score of the VVLT, subjective memory complaints and preserved general cognitive functioning (performance above 1.5 SD below the mean on all other cognitive measures).

The second definition was multiple domain amnestic MCI, or MCI-2 (Larrieu et al., 2002). The difference with the first definition is that cases are not excluded if more cognitive functions are impaired, as long as memory is also impaired.

The third and the fourth definition were based on the criteria developed by the working group on MCI (Winblad et al., 2004). MCI-3 included any cognitive decline, defined as performance equal to or below 1.5 SD on one or more cognitive domains, and did not include subjective complaints. Subjective memory complaints were left out in MCI-3 because it was one of our goals to find out what the influence was of including or excluding complaints from the criteria for MCI on its predictive value for dementia. Therefore MCI-4 was defined as performance equal to or below 1.5 SD on one or more cognitive domains as well, but it also included subjective complaints in the definition. Since MCI-4 was proven superior in predicting dementia when compared to MCI-1 or MCI-2 in previous studies (Amieva et al., 2005; Artero et al., 2006), the effect of excluding subjective complaints as a criterion was only tested for this broad cognitive definition.

A fifth definition could be included from the first follow-up onward. Proxy information was needed to define MCI-Revised criteria (MCI-5), as implemented in a study by Artero et al. (2006). At follow up, objective cognitive functioning was examined again by taking into account verbal memory, verbal fluency, executive functioning and simple speed. Cognitive complaint was defined as a DECO score of less than 38, so a score below the maximum (Ritchie et al., 2001). The different MCI definitions were thus compared with regards to their predictive value for dementia three years after baseline measurement and six years after follow up measurement. This method of comparing left room for some definitions to show better predictive value for a short time interval and others for a longer time interval.

\section{Analysis of data}

The predictive values of the different MCI definitions for dementia onset in the first three years after baseline were analyzed with sensitivity, specificity, positive predictive value and negative predictive value. The same predictive values were calculated for the MCI definitions at three years follow up for dementia developed within nine years after baseline. Cox regression analysis was performed to analyze the optimal combination of MCI criteria to predict dementia. The effect of aging on the predictive values was measured by calculating age specific sensitivity and specificity. The trade-off between sensitivity and specificity of the different definitions was displayed in different receiver operating characteristic (ROC) curves for dementia developed within three and between three and nine years after baseline. The area under the ROC- curve (AUC) was included as a combined measure of sensitivity and specificity. Effects of cardiovascular disease 
were tested by analyzing the predictive value of MCI for dementia for all dementia cases and also separately for all cases those who were clean of cardiovascular disease. Statistical analyses were performed using SPSS 13 for Mac OS X.

\section{Results}

\section{Sample characteristics}

The MCI definitions described above identified a variable number of cases. At baseline, 11 MCI-1, 20 MCI-2, 173 MCI-3 and 58 MCI-4 cases were identified (see Table 1.). The number of MCI-1 cases was very small, due to the very strict definition used. The opposite was true for the MCI-3 definition. At three years follow up the same pattern of results was found for the number of cases, with a decrease for MCI-3 and 4 due to attrition. MCI-5 (based on 510 participants) identified 89 cases at three years follow up, in the middle between MCI-3 and 4, which was to be expected since the definition is not as strict as for MCI-4 and not as lenient as for MCI-3.

Table 1 Sample characteristics for the MCI groups

\begin{tabular}{|c|c|c|c|c|c|c|c|}
\hline & $\begin{array}{l}\text { Total } \\
\text { sample }\end{array}$ & MCI-1 & MCI-2 & MCI-3 & MCI-4 & MCI-5 & $\begin{array}{l}\text { Dementia } \\
9 \mathrm{yrs}\end{array}$ \\
\hline Baseline & $n=661$ & $n=11$ & $n=20$ & $n=173$ & $n=58$ & & $n=44$ \\
\hline Age & $69.7(6.0)$ & $68.7(5.9)$ & 71 (6.6) & $71.1(6.4)$ & $72.2(6.3)$ & & $73.5(5.7)$ \\
\hline $\begin{array}{l}\text { Sex }(\% \\
\text { male) }\end{array}$ & & & & & & & \\
\hline $\begin{array}{l}\text { male) } \\
\text { Education }\end{array}$ & 50.4 & 36.4 & 35 & 49.1 & 44.8 & & 57.1 \\
\hline level & $2.9(1.8)$ & $3.2(2.4)$ & $3.6(2.2)$ & $2.8(1.8)$ & $3.1(2)$ & & $3.3(2)$ \\
\hline MMSE & $27.5(1.8)$ & $26.8(1.7)$ & $26.7(1.6)$ & $26.9(1.7)$ & $26.3(1.8)$ & & $27.1(1.7)$ \\
\hline $3 y r$ follow up & & & & & & & \\
\hline Dementia & 13 & 1 & 1 & 7 & 3 & & 13 \\
\hline Died & 70 & 0 & 3 & 29 & 11 & & 6 \\
\hline Refused & 26 & 0 & 0 & 8 & 1 & & 7 \\
\hline Untraceable & 3 & 0 & 0 & 1 & 1 & & 0 \\
\hline FU 3 yrs & $n=519$ & $n=11$ & $n=20$ & $n=125$ & $n=45$ & $n=89$ & \\
\hline Age & $72.1(5.8)$ & $75(5.5)$ & $75.9(5.4)$ & $73.9(6.3)$ & $75.4(6.2)$ & $73.7(6.2)$ & \\
\hline $\begin{array}{l}\text { Sex }(\% \\
\text { male) } \\
\text { Education }\end{array}$ & 51.2 & 27.3 & 50 & 53.3 & 57.8 & 55.1 & \\
\hline level & $2.9(1.8)$ & $3.4(2.1)$ & $3.3(1.9)$ & $3(1.8)$ & $3.1(1.8)$ & $2.9(1.8)$ & \\
\hline MMSE & $27.7(1.8)$ & $28.1(1.8)$ & $27.5(1.6)$ & $27.3(1.7)$ & $27.1(1.9)$ & $27.3(1.7)$ & \\
\hline 9yr follow up & & & & & & & \\
\hline Dementia & 31 & 4 & 7 & 20 & 9 & 17 & 44 \\
\hline Died & 104 & 1 & 5 & 30 & 14 & 24 & 1 \\
\hline Refused & 35 & 0 & 0 & 22 & 6 & 15 & 2 \\
\hline Untraceable & 3 & 0 & 0 & 1 & 1 & 1 & 0 \\
\hline
\end{tabular}

No significant differences were found in age, education, gender and mean MMSE score between the four MCI groups at baseline (Table 1). The MCI-1 group differed from the other groups in gender representation at three years follow-up, but the small group size 
could explain this difference. At follow up no other significant group differences were found. Between baseline and the three years follow up, 99 participants were lost to follow up because they had died (70), refused participation (26) or were untraceable (3). Between the three years follow up measurement and the time at which the dementia diagnosis was evaluated, nine years after baseline, 142 participants were lost to follow up because they had died (104), refused participation (35) or were untraceable (3). In the nine years after baseline, 44 participants had developed dementia, 13 in the first three years.

\section{Predictive values for dementia}

In table 2 the sensitivity, specificity, positive predictive value, negative predictive value and AUC are shown of MCI definitions at baseline for dementia after three years and of MCI definitions at three years follow up for dementia within nine years after baseline.

Table 2 Predictive values of different MCI definitions for dementia.

\begin{tabular}{lllllll}
\hline \multirow{3}{*}{ Dementia after 3 yrs } & & Sensitivity & Specificity & PPV & NPV & AUC \\
& MCI-1 & 0.08 & 0.98 & 0.09 & 0.98 & 0.53 \\
& MCI-2 & 0.08 & 0.97 & 0.05 & 0.98 & 0.52 \\
& MCI-3 & 0.54 & 0.74 & 0.04 & 0.99 & 0.64 \\
Dementia after 9 yrs & MCI-4 & 0.23 & 0.92 & 0.05 & 0.98 & 0.57 \\
& MCI-1 & 0.14 & 0.99 & 0.36 & 0.95 & 0.56 \\
& MCI-2 & 0.24 & 0.97 & 0.35 & 0.96 & 0.61 \\
& MCI-3 & 0.66 & 0.78 & 0.15 & 0.97 & 0.72 \\
& MCI-4 & 0.31 & 0.93 & 0.2 & 0.96 & 0.63 \\
& MCI-5 & 0.59 & 0.84 & 0.18 & 0.97 & 0.70 \\
\hline
\end{tabular}

At baseline, the predictive value of MCI for dementia was highest for MCI-3 (sensitivity $=0.54$; specificity=0.74; AUC=0.64). Specificity was highest for MCI-1 (0.98), but sensitivity for dementia was very low (0.08). Sensitivity was highest for MCI-3, indicating that the highest percentage of dementia cases was identified with this definition (Figure 1). 


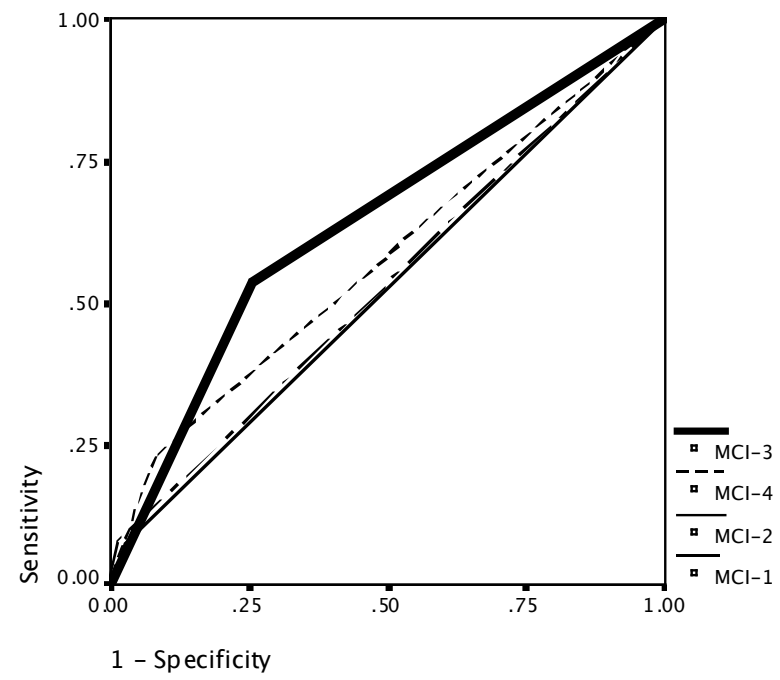

Figure 1 Receiver operating characteristic (ROC) curves showing the predictive value of four MCI definitions for a diagnosis of dementia within 3 years after baseline.

Figure 2 displays the ROC curves of the four MCI definitions, and shows that of the baseline definitions only MCI-3 could predict dementia after 3 years (AUC $=0.64$ ) and that all three years follow up definitions except MCI-1 (AUC $=0.56$ ) could predict dementia within nine years after baseline. As table 2 shows, the combination of positive and negative predictive value was best for MCI-1 ( $\mathrm{ppv}=0.09$; $\mathrm{npv}=0.98)$. At follow-up the two best predicting MCI definitions were again those including multiple cognitive domains, and not including subjective complaints, so MCI-3 and 5 (Table 2 and Figure 2). Sensitivity analysis showed, that MCI-3 again provided the best predictive value for dementia, in terms of specificity and sensitivity (sensitivity: 0.66; specificity: 0.78; AUC: 0.72), even compared MCI-5 (sensitivity: 0.59; specificity: 0.84; AUC: 0.70), when looking at sensitivity. The combination of positive and negative predictive value was best for MCI-1 and 2 (MCI-1: ppv: 0.36; npv: 0.95; MCI-2: ppv: 0.35; npv: 0.96). 


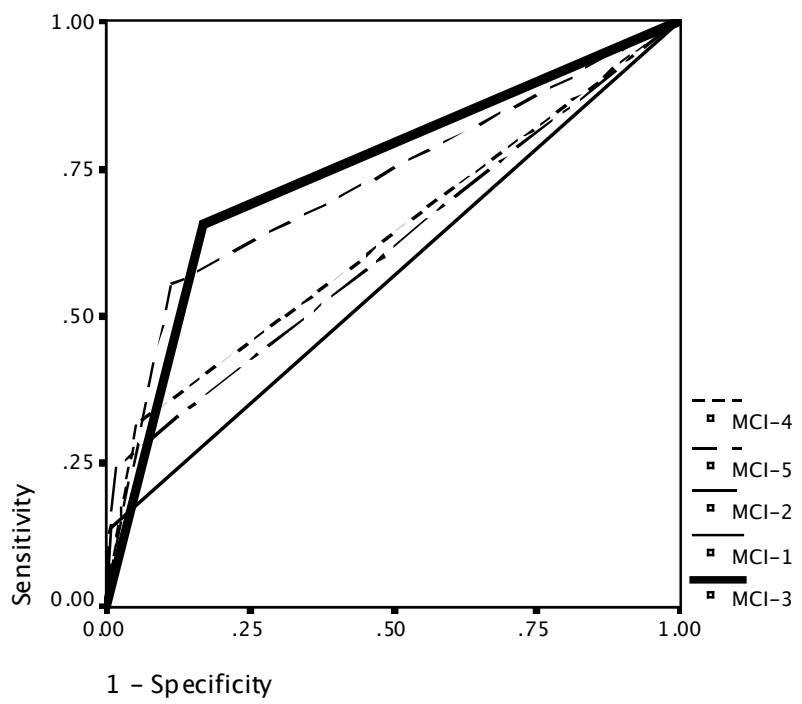

Figure 2 Receiver operating characteristic (ROC) curves showing the predictive value of five MCI definitions defined at three years follow up for a diagnosis of dementia within nine years after baseline.

Cox regression analysis was performed to test which combination of factors resulted in the most predictive definition of MCI. Factors included in the regression model were (only) disturbed memory performance, disturbed performance on any cognitive test, subjective complaints and complaints from the partner, all coded as 0,1 variables. Dementia was the outcome measure. The analysis confirmed that cognitive impairment as measured in the MCI-3 definition, so disturbed performance on any cognitive test, was the only significantly contributing factor in the prediction of dementia $(\mathrm{OR}=2.6,95 \%$ $\mathrm{CI}=1.4$ to $4.8, \mathrm{p}<0.01)$.

\section{Age}

The sample was split up in two groups, based on a median split analysis, to test effects of age on the predictive value of the different MCI definitions for dementia. This resulted in one group aged 60 to $70(n=343)$ and one group aged 70 to $85(n=318)$. The effect of increasing age on the predictive value of MCI for dementia is described in Table 3 and Figure $3 \mathrm{a}$ and $3 \mathrm{~b}$. Table three shows the predictive values of the five MCI definitions for dementia for both age groups. The general effect for all MCI definitions, except MCI-5, is that the sensitivity is higher in the 70-85 group than in the 60-70 group. The sensitivity of MCI for dementia is highest for MCI-3 in the older group (0.70) and for MCI-5 in the younger group (0.57). 
Table 3 The effect of age on the predictive value of different MCI definitions on dementia

\begin{tabular}{|c|c|c|c|c|c|}
\hline & \multicolumn{5}{|c|}{ Dementia after 9 yrs } \\
\hline & AUC & Sensitivity & Specificity & PPV & NPV \\
\hline \multicolumn{6}{|c|}{ Follow up 3 yrs } \\
\hline \multicolumn{6}{|l|}{ MCI-1 } \\
\hline Age 60-70 & 0.5 & 0 & 0.99 & 0 & 0.97 \\
\hline Age $70-85$ & 0.59 & 0.2 & 0.98 & 0.5 & 0.93 \\
\hline \multicolumn{6}{|l|}{ MCI-2 } \\
\hline Age 60-70 & 0.49 & 0 & 0.98 & 0 & 0.97 \\
\hline Age $70-85$ & 0.66 & 0.35 & 0.96 & 0.47 & 0.94 \\
\hline \multicolumn{6}{|l|}{ MCI-3 } \\
\hline Age 60-70 & 0.69 & 0.56 & 0.83 & 0.09 & 0.98 \\
\hline Age $70-85$ & 0.71 & 0.7 & 0.73 & 0.19 & 0.96 \\
\hline \multicolumn{6}{|l|}{ MCI-4 } \\
\hline Age 60-70 & 0.48 & 0 & 0.95 & 0 & 0.91 \\
\hline Age $70-85$ & 0.69 & 0.31 & 0.93 & 0.3 & 0.93 \\
\hline \multicolumn{6}{|l|}{ MCI-5 } \\
\hline Age 60-70 & 0.72 & 0.57 & 0.88 & 0.13 & 0.98 \\
\hline Age $70-85$ & 0.69 & 0.55 & 0.82 & 0.22 & 0.95 \\
\hline
\end{tabular}

The ROC curves show in figure $3 \mathrm{a}$ and $3 \mathrm{~b}$, that the combination of sensitivity and specificity is highest for MCI-3 and MCI-5, with higher sensitivity for MCI-3, for the oldest group.

Figure 3a

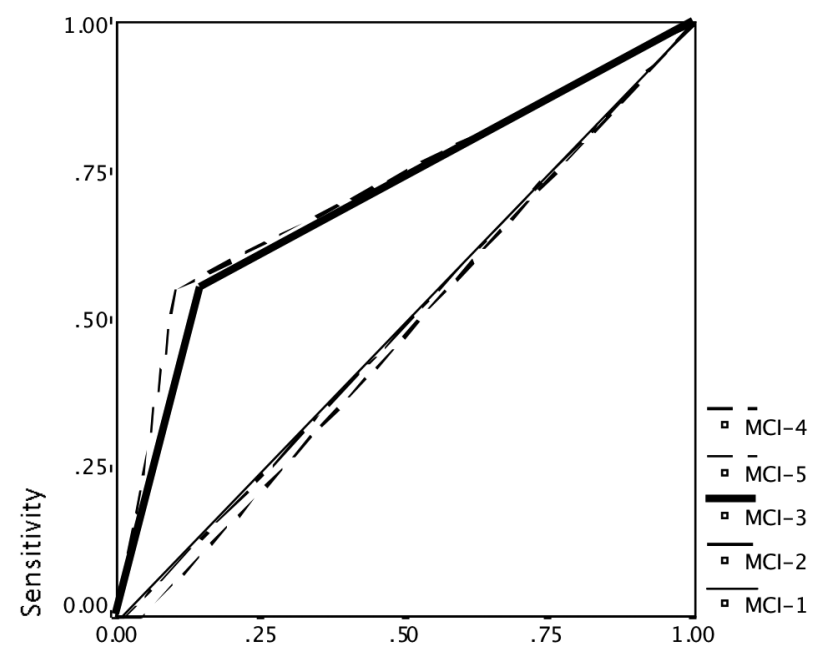

1 - Specificity 
Figure 3b

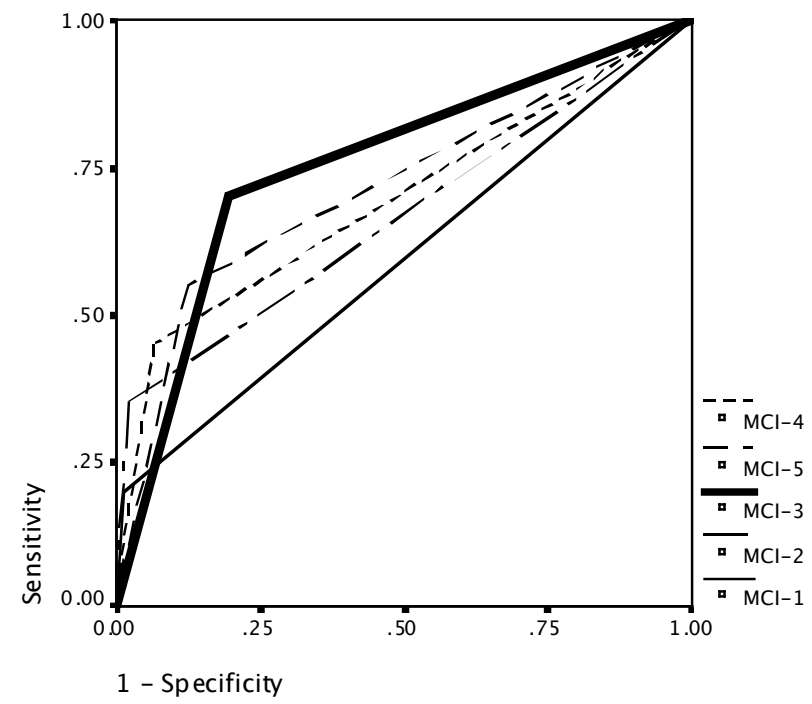

Figure 3a and $\mathbf{b}$ Receiver operating characteristic (ROC) curves showing the predictive value of five MCI definitions defined at 3 years follow up for a diagnosis of dementia within 9 years after baseline for participants ages $60-70(3 a)$ and $70-85(3 b)$.

\section{Dementia type}

Thirteen out of 44 dementia cases were found to have probable vascular dementia (VD) and 31 probable Alzheimer's disease (AD). Analysis showed that excluding the cases with probable VD did not improve the predictive value of MCI-3 for dementia (sensitivity changed from 0.66 to 0.62 , specificity did not change). The same result was found for the other definitions, with unchanged specificity for dementia and slight deterioration of sensitivity. Therefore, in the analyses presented here, no distinction was made between dementia subtypes.

\section{Discussion}

The primary aim of this study was to maximize the predictive value of MCI for dementia in a prospective cognitive aging study. The original criteria for amnestic MCI as developed by Petersen (2001) were compared to MCI definitions that included multiple cognitive domains, definitions that did not include subjective complaints and those that included complaints from the partner. The results of this analysis suggest that the highest sensitivity is obtained when MCI is defined as a disturbed performance in at least one cognitive domain and when complaints are not made part of the definition. MCI-3 was the best definition available for our population sample, with regard to sensitivity for 
dementia. MCI-1 or amnestic MCI showed the best specificity and positive predictive value for dementia in our study, however sensitivity was very low.

With respect to the effect of age on the predictive value of MCI for dementia, the findings confirmed our hypothesis. The sensitivity of MCI for dementia for most definitions was higher in the 70-85 group compared to the 60-70 group. Only the MCI-5 definition showed equal sensitivity in both groups. As was expected based on earlier work (Artero et al., 2006), the inclusion of multiple cognitive domains in the definition of MCI indeed increased its sensitivity for the development of dementia. Including multiple cognitive domains helps differentiate between MCI types (Nelson \& O'Connor, 2008) and between MCI cases and dementia cases (De Jager et al., 2003). The exclusion of subjective complaints from the definition further increased the predictive value of MCI for dementia. The lack of predictive value of subjective complaints for objective cognitive performance was corroborated by results from previous studies. The exclusion of subjective complaints from the MCI criteria improved sensitivity for dementia in other population samples (Busse et al., 2006; Jungwirth et al., 2005). Another MAASrelated study showed, that subjective memory complaints, measured in the same way as in the current study, were not predictive of cognitive decline, over a six year period (Mol et al., 2006).

The MCI-5 definition showed a higher sensitivity for dementia compared to MCI-4. Complaints from the partner (in this study the DECO was in $86 \%$ of the cases filled out by partner, child or close friend) added more to sensitivity than subjective complaints from the study participant. This difference could occur, due to the definition of complaint in both measures. The DECO measures the opinion of the partner on the development of cognitive performance in the past year, while the subjective complaints questions used in this study focus on the experience of complaints at the time of answering the questions. The questions in the DECO are also far more specific and focused on daily life interference than the question used to measure subjective complaints in this study. Lack of insight in their own condition, could also be causing MCI cases that developed dementia within a few years after baseline not to complain. Subjective complaints were found to be related to neuroticism in a previous study on Aging-Associated Cognitive Decline, which is very much related to MCI, as we defined it (Kliegel et al., 2005). Perhaps subjective complaints tell more about the state of mind of the study participants then about their cognitive performance. Negative affect was shown to induce subjective memory complaints, even in the absence of disturbed memory performance (Dux et al., 2008), and this connection between affect and subjective complaints has been found in other studies as well (Jessen et al., 2007; Minett et al., 2008)

In the current study, the sensitivity of the best predicting definition for dementia, MCI-3, was higher in the 70-85 group (0.70) than in the 60-70 (0.56) group. For other definitions this difference was even larger. This finding indicates that age is an important factor to take into account when interpreting predictive values of different MCI definitions for dementia in a population sample. In a clinical sample, MCI was also found to be predictive for $\mathrm{AD}$, but also only in patients over the age of 70 (Visser \& Verhey, 2007). These findings indicate that comparisons between different studies investigating the predictive value of MCI for dementia should be interpreted with caution. A popula- 
tion study with participants older than 65 (Larrieu et al., 2002) will report lower conversion rates to dementia than a population study with participants older than 75 (Palmer et al., 2003), if only due to the effect of age.

The large population sample, its longitudinal design and large age spectrum are all strengths of the current study. The relatively small number of participants in some MCI subgroups (MCI-1, $\mathrm{n}=11$ ) could be considered a limitation of this study, but is not a unique finding in population samples (Larrieu et al., 2002; Lopez et al., 2003; Mosconi et al., 2004). The predictive value for this group, should however be interpreted with caution, since the small number of individuals in this group, makes it difficult to generalize results and to compare the MCI-1 group to, for example, the MCI-3 group. Especially since the group is even split-up in two, to test the effects of age. The number of dementia cases on which this study was based, though comparable to numbers found in other population-based samples, was small. The baseline exclusion criteria used for the MAAS study, which focuses on normal aging, could be of some influence here, possibly excluding the more dementia-prone individuals. However, the follow-up period was nine years in this study and effects will be analyzed again when the study's 12-year follow up is finished. More dementia cases should be identified at that time.

The findings from the current study indicate that the MCI-3 definition, including impairment in at least one cognitive domain, no dementia, and intact ADL functions, currently offers the best predictive value for dementia in the general population. MCI-1, 2 and 4 were low in sensitivity and high in specificity, and for the other two definitions it was the other way around. This trade-off is important to consider when choosing a definition. For population studies, the main goal is to identify as many possible dementia cases as possible, so the focus lies on sensitivity. In a clinical setting focus could well be on specificity, to prevent false positives from being included in clinical trials (Visser \& Verhey, 2007). The same difference influences the choice of including subjective- or partner- complaints in the definition or not. It does not increase sensitivity in a population sample, but effects in clinical samples are different, since complaints are a given in that setting.

An interesting issue for future population studies is to investigate which more advanced individual characteristics could be included in the definition of MCI to increase its sensitivity for dementia. A combination of cognitive performance measures with for example medical indicators of decline, or imaging data could possibly solve this in part (Visser et al., 2002). More future dementia cases could be identified and the number of false positives minimized. Such a combination of factors was tested in a study that combined APOE genotyping and PET data to improve the predictive value of MCI for dementia. This combination was very successful, with maximum sensitivity (1.0) and very high specificity (0.90)(Mosconi et al., 2004). This type of procedure improves the applicability of MCI as a predictor for dementia, and in clinical settings, it could make MCI a more attractive treatment target. 


\section{References}

American Psychiatric Association. (1994). Diagnostic and Statistical Manual of Mental Disorders: DSM IV. (4th ed.). Retrieved. from.

Amieva, H., Jacqmin-Gadda, H., Orgogozo, J. M., Le Carret, N., Helmer, C., Letenneur, L., et al. (2005). The 9 year cognitive decline before dementia of the Alzheimer type: a prospective population-based study. Brain, 128(Pt 5), 1093-1101.

Artero, S., Petersen, R., Touchon, J., \& Ritchie, K. (2006). Revised criteria for mild cognitive impairment: validation within a longitudinal population study. Dement Geriatr Cogn Disord, 22(5-6), 465-470.

Boomsma, L. J., Boukes, F. S., Wind, A. W., \& Assendelft, W. J. (2004). [Summary of the practice guideline 'Dementia' (second revision) from the Dutch College of General Practitioners]. Ned Tijdschr Geneeskd, 148(24), 1191-1197.

Busse, A., Hensel, A., Guhne, U., Angermeyer, M. C., \& Riedel-Heller, S. G. (2006). Mild cognitive impairment: long-term course of four clinical subtypes. Neurology, 67(12), 2176-2185.

De Bie, S. E. (1987). Standaardvragen 1987: Voorstellen voor uniformering van vraagstellingen naar achtergrondkenmerken en interviews [Standard questions 1987: Proposal for uniformization of questions regarding background variables and interviews]. Leiden, The Netherlands: Leiden University Press.

De Jager, C. A., Hogervorst, E., Combrinck, M., \& Budge, M. M. (2003). Sensitivity and specificity of neuropsychological tests for mild cognitive impairment, vascular cognitive impairment and Alzheimer's disease. Psychol Med, 33(6), 1039-1050.

Dubois, B., Feldman, H. H., Jacova, C., Dekosky, S. T., Barberger-Gateau, P., Cummings, J., et al. (2007). Research criteria for the diagnosis of Alzheimer's disease: revising the NINCDS-ADRDA criteria. Lancet Neurol, 6(8), 734-746.

Dux, M. C., Woodard, J. L., Calamari, J. E., Messina, M., Arora, S., Chik, H., et al. (2008). The moderating role of negative affect on objective verbal memory performance and subjective memory complaints in healthy older adults. J Int Neuropsychol Soc, 14(2), 327-336.

Ganguli, M., Dodge, H. H., Shen, C., \& DeKosky, S. T. (2004). Mild cognitive impairment, amnestic type: an epidemiologic study. Neurology, 63(1), 115-121.

Jessen, F., Wiese, B., Cvetanovska, G., Fuchs, A., Kaduszkiewicz, H., Kolsch, H., et al. (2007). Patterns of subjective memory impairment in the elderly: association with memory performance. Psychol Med, 37(12), 1753-1762.

Jolles, J., Houx, P. J., van Boxtel, M. P. J., \& Ponds, R. W. H. M. (1995). Maastricht Aging Study: Determinants of cognitive aging. . Maastricht, The Netherlands: Neuropsych Publishers.

Jungwirth, S., Weissgram, S., Zehetmayer, S., Tragl, K. H., \& Fischer, P. (2005). VITA: subtypes of mild cognitive impairment in a community-based cohort at the age of 75 years. Int J Geriatr Psychiatry, 20(5), 452-458.

Kliegel, M., Zimprich, D., \& Eschen, A. (2005). What do subjective cognitive complaints in persons with aging-associated cognitive decline reflect? Int Psychogeriatr, 17(3), 499-512.

Lamberts, H., \& Wood, M. (1987). ICPC: International Classification of Health Problems in Primary Care. Oxford: Oxford University Press.

Larrieu, S., Letenneur, L., Orgogozo, J. M., Fabrigoule, C., Amieva, H., Le Carret, N., et al. (2002). Incidence and outcome of mild cognitive impairment in a population-based prospective cohort. Neurology, 59(10), 1594-1599.

Lezak, M. D., Howieson, D. B., \& Loring, D. W. (2004). Neuropsychological Assessment. New York: Oxford University Press.

Lopez, O. L., Jagust, W. J., DeKosky, S. T., Becker, J. T., Fitzpatrick, A., Dulberg, C., et al. (2003). Prevalence and classification of mild cognitive impairment in the Cardiovascular Health Study Cognition Study: part 1. Arch Neurol, 60(10), 1385-1389.

Metsemakers, J. F., Hoppener, P., Knottnerus, J. A., Kocken, R. J., \& Limonard, C. B. (1992). Computerized health information in The Netherlands: a registration network of family practices. Br J Gen Pract, 42(356), 102-106.

Minett, T. S., Da Silva, R. V., Ortiz, K. Z., \& Bertolucci, P. H. (2008). Subjective memory complaints in an elderly sample: a cross-sectional study. Int J Geriatr Psychiatry, 23(1), 49-54. 
Mol, M. E., van Boxtel, M. P., Willems, D., \& Jolles, J. (2006). Do subjective memory complaints predict cognitive dysfunction over time? A six-year follow-up of the Maastricht Aging Study. Int J Geriatr Psychiatry, 21(5), 432-441.

Mosconi, L., Perani, D., Sorbi, S., Herholz, K., Nacmias, B., Holthoff, V., et al. (2004). MCI conversion to dementia and the APOE genotype: a prediction study with FDG-PET. Neurology, 63(12), 2332-2340.

Nelson, A. P., \& O’Connor, M. G. (2008). Mild cognitive impairment: a neuropsychological perspective. CNS Spectr, 13(1), 56-64.

Palmer, K., Fratiglioni, L., \& Winblad, B. (2003). What is mild cognitive impairment? Variations in definitions and evolution of nondemented persons with cognitive impairment. Acta Neurol Scand Suppl, 179, 14-20.

Petersen, R. C., Doody, R., Kurz, A., Mohs, R. C., Morris, J. C., Rabins, P. V., et al. (2001). Current concepts in mild cognitive impairment. Arch Neurol, 58(12), 1985-1992.

Petersen, R. C., Smith, G. E., Waring, S. C., Ivnik, R. J., Kokmen, E., \& Tangelos, E. G. (1997). Aging, memory, and mild cognitive impairment. Int Psychogeriatr, 9 Suppl 1, 65-69.

Petersen, R. C., Smith, G. E., Waring, S. C., Ivnik, R. J., Tangalos, E. G., \& Kokmen, E. (1999). Mild cognitive impairment: clinical characterization and outcome. Arch Neurol, 56(3), 303-308.

Ritchie, K., Artero, S., \& Touchon, J. (2001). Classification criteria for mild cognitive impairment: a population-based validation study. Neurology, 56(1), 37-42.

Stroop, J. (1935). Studies of interference in serial verbal reaction. Journal of Experimental Psychology, 18, 643662.

Van Boxtel, M. P., Buntinx, F., Houx, P. J., Metsemakers, J. F., Knottnerus, A., \& Jolles, J. (1998). The relation between morbidity and cognitive performance in a normal aging population. J Gerontol A Biol Sci Med Sci, 53(2), M147-154.

Van der Elst, W., Van Boxtel, M. P., Van Breukelen, G. J., \& Jolles, J. (2005). Rey's verbal learning test: normative data for 1855 healthy participants aged 24-81 years and the influence of age, sex, education, and mode of presentation. J Int Neuropsychol Soc, 11(3), 290-302.

Van der Elst, W., Van Boxtel, M. P., Van Breukelen, G. J., \& Jolles, J. (2006a). The Concept Shifting Test: adult normative data. Psychol Assess, 18(4), 424-432.

Van der Elst, W., Van Boxtel, M. P., Van Breukelen, G. J., \& Jolles, J. (2006b). The Letter Digit Substitution Test: normative data for 1,858 healthy participants aged 24-81 from the Maastricht Aging Study (MAAS): influence of age, education, and sex. J Clin Exp Neuropsychol, 28(6), 998-1009.

Van der Elst, W., Van Boxtel, M. P., Van Breukelen, G. J., \& Jolles, J. (2006c). The Stroop color-word test: influence of age, sex, and education; and normative data for a large sample across the adult age range. Assessment, 13(1), 62-79.

Visser, P. J., Kester, A., Jolles, J., \& Verhey, F. (2006). Ten-year risk of dementia in subjects with mild cognitive impairment. Neurology, 67(7), 1201-1207.

Visser, P. J., \& Verhey, F. R. (2007). Mild cognitive impairment as predictor for Alzheimer's disease in clinical practice: effect of age and diagnostic criteria. Psychol Med, 1-10.

Visser, P. J., Verhey, F. R., Scheltens, P., Cruts, M., Ponds, R. W., van Broeckhoven, C. L., et al. (2002). Diagnostic accuracy of the Preclinical AD Scale (PAS) in cognitively mildly impaired subjects. J Neurol, 249(3), 312-319.

Wechsler, D. (1955). Manual for the Wechsler Adult Intelligence Scale. New York: Psychological Corporation.

Winblad, B., Palmer, K., Kivipelto, M., Jelic, V., Fratiglioni, L., Wahlund, L. O., et al. (2004). Mild cognitive impairment--beyond controversies, towards a consensus: report of the International Working Group on Mild Cognitive Impairment. J Intern Med, 256(3), 240-246. 
3

Long-term stability of Mild Cognitive Impairment: results from a 6-year longitudinal population study 


\begin{abstract}
This study aimed to investigate the stability of MCI over a period of 6 years in a large population-based sample. Statistical and aging effects of longitudinal MCI measurement were separated from true change over time. Data were taken from the Maastricht Aging Study (MAAS), MCI was defined as impaired memory functioning, no dementia and normal Activities of Daily Living. Three methods of stability measurement were compared: a fixed MCI criterion, a follow-up dependent MCI criterion and an MCI criterion adjusted for practice effects. Of the 349 participants over the age of sixty with complete data for three measurements, 30 were MCI at baseline $(9 \%)$. According to all three MCI definitions, a substantial number reverted to normal performance after three years (67$83 \%)$ and six years (43\%).

MCI was found to be an instable condition over time, independent of the stability definition used. Regression-to-the-mean caused the instability and should not be misinterpreted as evidence for instability of prodromal cognitive disorders, but as a consequence of using behavioral measures to define them, which are sensitive to practice effects. Our findings challenge the usefulness of the application of the MCI concept in longitudinal population-based studies.
\end{abstract}




\section{Introduction}

Mild Cognitive Impairment (MCI) usually describes an intermediate state between normal cognitive functioning and dementia and is often used to diagnose Alzheimer's Disease in its pre-dementia stages (Petersen et al., 1999). The predictive value of MCI for dementia varies greatly between studies, due to choice of MCI definition (Ganguli et al., 2004; Larrieu et al., 2002) and the setting and age of the study population in which it is applied (Rockwood et al., 2007; Visser \& Verhey, 2007). Since dementia is obviously not the only possible outcome for MCI cases, the question remains what happens to the non-converting subjects. Stable MCI or reversion to normal cognitive functioning, seem to be the two other possible longitudinal outcomes. To date, the stability of MCI over time has scarcely been systematically investigated, with dissatisfying findings in the few studies that have been conducted. MCI was shown to be a reversible condition over time and to have low predictive value for dementia in large population studies (Fisk et al., 2003; Palmer et al., 2002), and conversion to a state of non-MCI has often been observed, even in clinical samples (Loewenstein et al., 2007; Visser et al., 2006). The instability of MCI over time could be an indication that it's definition should be adjusted (Artero et al., 2006). However, even though MCI is a clinical concept, its merely psychometric definition comes with issues not related to MCI per se, which could be causing the instability. These issues should be resolved first, before the true stability of MCI can be investigated. Regression-to-the mean (Hsu, 1989) and methodological effects of re-using the same test for multiple measurements are known issues in cognitive testing (Hageman \& Arrindell, 1999). In previous studies, the same cognitive cutoff for MCI was often used for multiple measurements in time (De Jager \& Budge, 2005; Loewenstein et al., 2007). However, this may lead to an under-representation of MCI cases at follow-up measurements, since cognitive performance tends to improve over multiple test assessments due to practice effects (Rabbitt et al., 2001). If the same cut-off of 1.5 $\mathrm{SD}$ below the mean at baseline is used at follow-up measurements, then participants drop out of the MCI group due to effects of practice, not because they actually improved their cognitive functioning over the years. Effects of practice are most often observed on memory tests (McCaffrey \& Westervelt, 1995) that are particularly important for the diagnosis of (amnestic) MCI. MCI cases have been found to show increased effects of practice on memory tests compared to matched controls. Regression-to-the mean is one explanation for this finding, as is the heterogeneity of the MCI group, causing some cases to progress to dementia while others revert to normal cognitive functioning (Duff et al., 2008). Several attempts have been made to develop methods for correcting such unwanted effects, like using reliable change scores, which correct for effects of measurement error and practice. These change scores have proven to be accurate in distinguishing cognitively intact and impaired individuals (Frerichs \& Tuokko, 2005). Another way to deal with practice effects in the context of MCI diagnosis is to recalibrate the MCI criterion at each measurement point in time. In this case equality of practice effects for all participants in a study is assumed, and aging effects are not taken into account, with a fixed proportion of the study population in the MCI group at each measurement point in time. Correcting for effects of practice by adjusting performance 
change over time is another method that takes effects of aging into account and leaves room for the total MCI proportion to change over time.

In this study, the stability of amnestic MCI was measured in three ways, by using the same MCI cutoff for each measurement, by re-determining MCI at each follow-up and by correcting for effects of practice over time. The goal of this study was to investigate the true stability of MCI over a 6-year period with data from the Maastricht Aging Study (MAAS), a large longitudinal study into the determinants of cognitive aging (Jolles et al., 1995). This study focuses on amnestic MCI, since the aforementioned methodological issues are expected to have the largest effect on this MCI-subtype. MCI is expected to be a relatively stable condition over time, if defined according to the right criteria for longitudinal research. In that case, the majority of the unstable MCI cases are expected to progress to dementia and not to improve their cognitive performance over time.

\section{Method}

\section{Sample}

The participants included took part in the Maastricht Aging Study (MAAS), a longitudinal study into the determinants of cognitive aging (Jolles et al., 1995; Van Boxtel et al., 1998). 10,396 potential participants were recruited from a patients register of collaborating general practitioners (GP) in the south of the Netherlands (RNH) (Metsemakers et al., 1992) by sending a prepaid postcard. 4,490 agreed to participate (43.2\%), 3,531 refused participation $(34 \%)$ and 2,375 did not return the postcard $(22.8 \%)$.

Participants were excluded from participation when medical records from the RNH reported conditions that may interfere with cognitive functioning, including coma, all tumors of the nervous system, congenital malformations of the nervous system, history of stroke, parkinsonism, multiple sclerosis, dementia, schizophrenia, (affective) psychosis and mental retardation. Health problems in the RNH database were recorded according to the International Classification of Primary Care (Lamberts \& Wood, 1987). The 4,490 potential participants were additionally screened by telephone for medical conditions not reported by the RNH (history of TIA, brain surgery, haemodialysis for renal failure, electroconvulsive therapy, and regular use of psychotropic drugs) and to update information reported by the RNH. 301 potential participants were excluded from participation based on this interview. Of the remaining 4,189 participants, 1,856 were randomly selected in 12 equally sized age categories $(25+/-1$ years, $30+/-1$ years $\ldots 80$ $+/$ - 1 years), stratified for sex and education level (De Bie, 1987). Participants included in the present study were aged 60 years and older at baseline and were tested neuropsychologically at baseline (1992-1994), after three years and after six years. Only participants for whom complete data were available for baseline and both follow up measurements were included in the current study, since it focuses on longitudinal stability of MCI (N=420). 


\section{Classification of MCI}

In this study, baseline amnestic MCI (Petersen et al., 1999) was defined as performance of at least $1.5 \mathrm{SD}$ below the mean on one or both of the memory measures, in combination with normal ADL performance and absence of dementia (MMSE score $>24$ ). The visual Verbal Learning Test (Van der Elst et al., 2005) was used to test memory. The total immediate free recall score of five trials and the delayed free recall score after twenty minutes were used to define MCI. Activities of Daily Living were assessed with the functional subscale of the RAND-36 (VanderZee et al., 1996), and subjects who indicated to need help with any of the activities were excluded. Subjective complaints or partner complaints about memory functioning were not included in this study, since it was focused on the stability of psychometrically defined MCI.

At follow up MCI status was re-determined by using the same cut-off (1.5 SD below mean at baseline) for the memory tests at three- and six- years follow up as was used at baseline (Busse et al., 2006; Loewenstein et al., 2007). Two methods that dealt with effects of practice and increasing age were compared to this procedure. The first method was to re-calibrate the cognitive cut-off for MCI, at three- and six-years follow up (1.5 SD below the mean calculated for measurement separately). The third method corrected performance change over time for effects of practice, and then used the recalibrated MCI cut-off for each follow-up. The average performance change over time was determined for healthy participants. For this purpose, a group was selected, who did not show significant decline on either of the two memory tests, or on any of the other cognitive tests included in the test battery over time. Significant decline was determined as a performance decline on any cognitive test of three percentiles or more between two follow-up measurements or a MMSE performance below or equal to 24 or a performance decline of at least three points. The no-decline group consisted of 355 participants and twenty percent of them were selected randomly as the norm group (71 participants).

The neuropsychological tests in the battery included the Stroop-Color Word Test (SCWT) (Stroop, 1935; Van der Elst et al., 2006c) and the Concept Shifting Task (Van der Elst et al., 2006a), to measure complex speed. The interference score of the SCWT was used in this study, as a measure of cognitive flexibility. This interference score was calculated by taking the time needed for the third card (naming ink colors of incongruent printed color names) and subtracting the mean of the time on the first (reading color names) and second (naming colors of patches) card. The Concept Shifting Test (CST) measures executive functioning, and is comparable to the Trail Making Test (Lezak et al., 2004). The shifting score on this task was calculated by subtracting the average time needed for version A (digits) and B (letters) from the total time needed for version C (letters and digits). This procedure separates time needed for complex shifting from time needed for simple reading and counting (Van der Elst et al., 2006c). As a measure of general information processing speed, the Letter Digit Substitution Test (Van der Elst et al., 2006b) was included, which is based on the Digit Symbol Substitution Test (Wechsler, 1955). The MMSE was included as a test of general cognitive abilities (Folstein et al., 1975). Change between baseline and the first follow-up measurement and between the first and second follow-up measurement was calculated for the selected, cognitively healthy group. The follow-up performance for the baseline MCI group was 
corrected for the average performance change of this cognitively healthy group. The recalibrated MCI criterion was then used at each follow-up to evaluate caseness. The selected norm-group was excluded from further analyses, bringing the group size to 349 participants.

\section{Measurement of stability}

Stability of MCI was measured by calculating the chance for participants to be in the MCI group at baseline and if so, to stay in this group in the follow-up measurements after 3 and 6 years. In addition, the chance of improved cognitive functioning after 3 and 6 years was calculated. The complete number of MCI cases at each follow-up was compared to the number of stable MCI cases, to calculate the proportional stability. These comparisons were only made for the first two MCI stability methods. The third method used longitudinal information to evaluate caseness, and therefore the total number of cases could not be calculated for each follow-up separately. Nine years after baseline all participants who had developed dementia during the study were identified by their GP on the basis of data from the MAAS study that was send to the GP, and using the criteria of DSM-III-R and IV, and the guidelines of the GP practice (Boomsma et al., 2004). The type of dementia was determined by an experienced neuropsychiatrist from the Memory Clinic of the Maastricht University Medical Center (FRJV) on the basis of the neuropsychological data, daily functioning and the participant's medical profile (vascular risk factors, comorbidity, course) and using the established criteria (Dubois et al., 2007).

\section{Results}

\section{Baseline characteristics}

At baseline, 30 of the 349 participants were amnestic MCI case ( $9 \%)$. Characteristics of these individuals are summarized in Table 1. Age, education, sex and mean MMSE score were not different compared with the control sample. Of the 30 baseline MCI cases, three had developed dementia nine years after baseline (10\%), of the 319 participants free of MCI at baseline, ten had developed dementia nine years later $(3 \%)$.

Table 1 Baseline characteristics for the total sample and the MCI group at baseline, 3 and 6 years follow up.

\begin{tabular}{lllllll}
\hline & Total sample & Baseline MCI & FU 3 yrs & & & FU 6 yrs \\
& & & MCI-1 & MCI-2 & MCI-3 & MCI \\
$\mathrm{N}$ & 349 & 30 & 10 & 12 & 4 & 17 \\
Baseline Age (sd) & $67.9(5.4)$ & $68.4(6.0)$ & $68.7(6.4)$ & $67.7(6.3)$ & $70.8(4.2)$ & $67.5(6)$ \\
Education (sd) & $3(1.8)$ & $3.1(1.9)$ & $3.7(2.1)$ & $3.7(2.1)$ & $4.3(3.3)$ & $3.4(2.1)$ \\
Sex (\% male) & $47.00 \%$ & $42.60 \%$ & $50 \%$ & $50 \%$ & $50 \%$ & $47.10 \%$ \\
Baseline MMSE (sd) & $27.9(1.7)$ & $27.3(1.7)$ & $26.4(2.3)$ & $26.5(2.1)$ & $27.3(2.6)$ & $26.6(2)$ \\
Dementia 9 yr FU & 11 & 3 & 1 & 1 & 1 & 3 \\
\hline
\end{tabular}


The results for the three methods of measuring stability are reported separately below.

Method 1: Baseline cut-off at each follow-up.

At the three-year follow-up 33\% of the baseline MCI cases remained stable or declined, and thus $67 \%$ improved to normal cognitive performance. The total number of MCI cases after three years was 38 , so $74 \%$ were new cases. Of the baseline MCI cases $57 \%$ were case at the six-year follow-up. This group included all baseline cases that were also case at the three-year follow-up. At the six-year follow-up, the total number of cases with MCI was 38, with $55 \%$ new cases.

Method 2:Re-calibrated cut-off at each follow-up.

At the three-year follow up, $40 \%$ of the MCI cases were still case and so $60 \%$ had improved to normal functioning. The total number of MCI cases at the three-year follow-up was 32, with $63 \%$ new cases. At the six-year follow up, $57 \%$ of the baseline cases met the criteria for MCI. This group included all individuals who were case at baseline and at the three-year follow-up. The total number of MCI cases at the six-year follow-up was 47 , with $64 \%$ new cases.

Method 3: Change over time adjusted for practice effects.

At the three-year follow-up, 13\% of the baseline MCI cases were still case according to the third stability method. After six years, $57 \%$ of the baseline cases complied with the MCI definition, again including all cases identified at baseline and at the three-year follow-up. Figure 1 depicts the profile of the 30 original MCI cases over time. The three colored bars represent the three methods of stability. Table 2 shows the proportional stability of MCI over six years. The flow of MCI cases and non-MCI participants over time is summarized in Figure 1.

Table 2 Flow of the MCI cases over 3 measurements in 6 years.

\begin{tabular}{lllll}
\hline \multirow{2}{*}{ T0 } & & M1 & M2 & M3 \\
& MCI & 30 & 30 & 30 \\
T1 & No MCI & 319 & 319 & 319 \\
& MCI T0 & 10 & 12 & 4 \\
T2 & MCI T1 & 28 & 20 & \\
& No MCI & 311 & 317 & 17 \\
& MCI T0 & 17 & 17 & \\
& MCI T1 & 16 & 16 & \\
\hline
\end{tabular}

Note $\mathrm{T} 0=$ baseline, $\mathrm{T} 1=3$-years follow-up, $\mathrm{T} 2=6$-years follow-up. Flow over time for M3 could only be calculated for baseline MCI cases. 
Figure 1 MCI stability over time: the baseline MCI cases after 3 and 6 years.

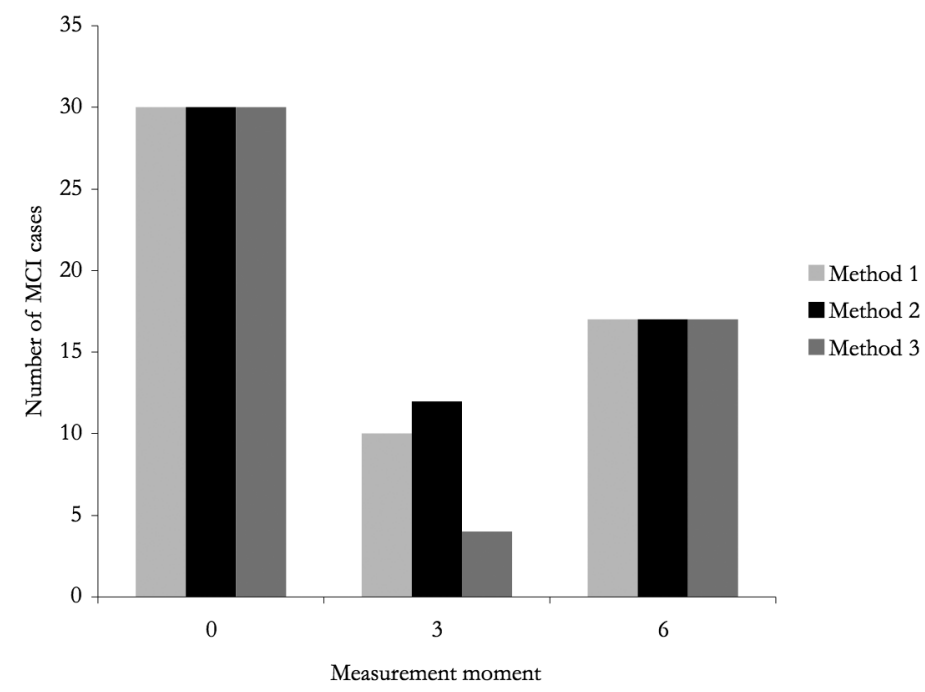

Note

Method 1: A fixed MCI criterion

Method 2: A FU dependent MCI criterion

Method 3: MCI criterion adjusted for practice effects

\section{Discussion}

This study investigated the stability of amnestic Mild Cognitive Impairment over three three- and six-year interval according to three different stability definitions. Results indicated, that MCI was an instable state for all three definitions. The instability was highest for the method that corrected statistically for general effects of practice. Reversion to normal cognitive functioning was a frequent outcome after three years, but a relatively large proportion of the cases that reverted to non-MCI, complied to the MCI definition again at the six-year follow-up. Over six years, MCI was the main outcome for cases identified at baseline (57\%), but still almost half of the baseline MCI group had reverted to normal cognitive functioning. The total number of MCI cases at the threeand six years follow-up consisted mostly of newly identified cases, so participants who performed in the normal range at baseline. The total number of MCI cases increased over time, for the not-corrected baseline cut-off method, but the aging of the sample as a whole could well be causing this, since the prevalence of MCI is expected to increase with age. Conversion to dementia was another possible outcome measured for MCI cases, and a small proportion (10\%) did indeed progress to dementia within nine years. Other population-based studies reported progression rates between 8\% (Larrieu et al., 2002) and 17\% (Ganguli et al., 2004) per year. The exclusion of participants that dropped out in this study causes the percentage of MCI cases that eventually develop 
dementia to be underestimated. MCI cases have a relatively high chance of dropping out at some point during the study, as earlier studies have shown that low neuropsychological performance is a predictor of attrition (Van Beijsterveldt et al., 2002). This could have caused the MCI cases more prone to developing dementia to drop out, and therefore not to be included in the current study sample.

The high reversion rate to normal cognitive functioning is comparable to those found in previous studies. Reversion to normal cognitive functioning is known to be a main outcome of MCI, when measured at two time points. Reversion rates of $40 \%$ are no exception in population samples (Ganguli, 2006; Larrieu et al., 2002). In this study, however, participants were seen and tested three times, and results were quite different for the three- and six-year follow up. At three-year follow up reversion to normal cognitive functioning was the main outcome for the initial 30 MCI cases for all stability definitions (between 60\% and 76\%). However, at six-year follow-up 57\% met MCI criteria (so, $43 \%$ reversion over six years). This finding was the same for the three methods of stability measurement applied. Practice effects were expected to influence the stability of MCI over time greatly. The three methods compared in this study, all dealt with practice effects in different ways, but with the same result: instability of MCI over six years. Even correcting for practice effects entirely did not result in more stability.

This study focused on amnestic MCI, since effects of practice were expected to be largest for this MCI type. However, when repeated for a less-restricted MCI definition, defined as cognitive impairment in any domain, post-hoc analyses showed the same results. In the end, this was to be expected, since effects of regression-to-the-mean exist for neuropsychological measures in general, not just for memory tests. In the MCI definition used in this study, subjective complaints were not included. Post-hoc tests showed, that stability of MCI over time did not increase when subjective complaints were included in the definition. This was expected, since including subjective complaints did also not increase the predictive value of MCI for dementia in a previous study(Baars et al., 2009).

MCI was defined as a transitional state between normal cognitive functioning and dementia (Petersen et al., 1999) and progression to dementia or at least stability of the MCI group was expected to be the main outcome over time. However, the definition of MCI in itself could be causing its instability over time, when based on longitudinal neuropsychological test performance. From previous studies, it is known, that measuring reliable change in cognitive performance over time is limited due to statistical constraints. Regression-to-the-mean causes individuals in the lowest performance range to improve over time, without any reliable change occurring (Frerichs \& Tuokko, 2005; Hsu, 1989). A statistical correction for practice effects does not prevent this finding, as was shown in the instability of MCI for the third method. In that procedure we accounted for effects of practice, but this method showed the most instable pattern of MCI over time. Another factor influencing the stability of MCI is the reliability of the neuropsychological tests that were used. Memory tests are known to show moderate test-retest reliability, which could result in performance increase or decrease, without any 'real' change occurring (Dikmen et al., 1999). Although the test-retest reliabilities of the tests used in the current study were acceptable $(0.63$ for immediate word recall and 
0.67 for delayed word recall (Van der Elst et al., 2008)), effects on stability are still possible.

The fact that the current study was conducted in a sample of healthy participants, and not in a clinical setting, could in part be causing the instability of MCI as well. Progression to dementia is less often the outcome for this group, compared to a clinical sample. However, the stability methods applied in this study would show the same effect on MCI over time in a clinical setting. As long as the MCI diagnosis is at least partly based on neuropsychological test performance, using these tests longitudinally introduces the methodological issues mentioned, in a clinical setting as well as in a population setting.

Our findings question the usefulness of MCI as a longitudinal concept, when defined according to neuropsychological test performance. When interpreting stability of MCI over time, the aforementioned methodological issues should at least be considered. Practice effects, test reliability and regression-to-the-mean are all issues to be taken into account, and the latter two cannot be corrected for. Instability of MCI should not be misinterpreted as a reversible intermediate state of cognitive decline, when in fact statistical issues not reserved for MCI cause the instability. Perhaps, as a case definition in a population sample, MCI should not be used in longitudinal studies. It might be more useful to assess cognitive change in MCI over time using true change in performance, for example using slope analyses, rather then re-determining caseness at each follow up. This maybe especially true in population studies. 


\section{References}

Artero, S., Petersen, R., Touchon, J., \& Ritchie, K. (2006). Revised criteria for mild cognitive impairment: validation within a longitudinal population study. Dement Geriatr Cogn Disord, 22(5-6), 465-470.

Baars, M. A., van Boxtel, M. P., Dijkstra, J. B., Visser, P. J., van den Akker, M., Verhey, F. R., et al. (2009). Predictive Value of Mild Cognitive Impairment for Dementia. The Influence of Case Definition and Age. Dement Geriatr Cogn Disord, 27(2), 173-181.

Boomsma, L. J., Boukes, F. S., Wind, A. W., \& Assendelft, W. J. (2004). [Summary of the practice guideline 'Dementia' (second revision) from the Dutch College of General Practitioners]. Ned Tijdschr Geneeskd, 148(24), 1191-1197.

Busse, A., Hensel, A., Guhne, U., Angermeyer, M. C., \& Riedel-Heller, S. G. (2006). Mild cognitive impairment: long-term course of four clinical subtypes. Neurology, 67(12), 2176-2185.

De Bie, S. E. (1987). Standaardvragen 1987: Voorstellen voor uniformering van vraagstellingen naar achtergrondkenmerkeen en interviews /Standard questions 1987: Proposal for uniformization of questions regarding background variables and interviews]. Leiden, The Netherlands: Leiden University Press.

De Jager, C. A., \& Budge, M. M. (2005). Stability and predictability of the classification of mild cognitive impairment as assessed by episodic memory test performance over time. Neurocase, 11(1), 72-79.

Dikmen, S. S., Heaton, R. K., Grant, I., \& Temkin, N. R. (1999). Test-retest reliability and practice effects of expanded Halstead-Reitan Neuropsychological Test Battery. J Int Neuropsychol Soc, 5(4), 346-356.

Dubois, B., Feldman, H. H., Jacova, C., Dekosky, S. T., Barberger-Gateau, P., Cummings, J., et al. (2007). Research criteria for the diagnosis of Alzheimer's disease: revising the NINCDS-ADRDA criteria. Lancet Neurol, 6(8), 734-746.

Duff, K., Beglinger, L. J., Van Der Heiden, S., Moser, D. J., Arndt, S., Schultz, S. K., et al. (2008). Short-term practice effects in amnestic mild cognitive impairment: implications for diagnosis and treatment. Int Psychogeriatr, 1-14.

Fisk, J. D., Merry, H. R., \& Rockwood, K. (2003). Variations in case definition affect prevalence but not outcomes of mild cognitive impairment. Neurology, 61(9), 1179-1184.

Folstein, M. F., Folstein, S. E., \& McHugh, P. R. (1975). "Mini-mental state”. A practical method for grading the cognitive state of patients for the clinician. J Psychiatr Res, 12(3), 189-198.

Frerichs, R. J., \& Tuokko, H. A. (2005). A comparison of methods for measuring cognitive change in older adults. Arch Clin Neuropsychol, 20(3), 321-333.

Ganguli, M. (2006). Mild cognitive impairment and the 7 uses of epidemiology. Alşheimer Dis Assoc Disord, 20(3 Suppl 2), S52-57.

Ganguli, M., Dodge, H. H., Shen, C., \& DeKosky, S. T. (2004). Mild cognitive impairment, amnestic type: an epidemiologic study. Neurology, 63(1), 115-121.

Hageman, W. J., \& Arrindell, W. A. (1999). Establishing clinically significant change: increment of precision and the distinction between individual and group level of analysis. Behav Res Ther, 37(12), 1169-1193.

Hsu, L. M. (1989). Reliable changes in psychotherapy: Taking into account regression toward the mean. Behavioral Assessment, 11, 459-467.

Jolles, J., Houx, P. J., van Boxtel, M. P. J., \& Ponds, R. W. H. M. (1995). Maastricht Aging Study: Determinants of cognitive aging. . Maastricht, The Netherlands: Neuropsych Publishers.

Lamberts, H., \& Wood, M. (1987). ICPC: International Classification of Health Problems in Primary Care. Oxford: Oxford University Press.

Larrieu, S., Letenneur, L., Orgogozo, J. M., Fabrigoule, C., Amieva, H., Le Carret, N., et al. (2002). Incidence and outcome of mild cognitive impairment in a population-based prospective cohort. Neurology, 59(10), 1594-1599.

Lezak, M. D., Howieson, D. B., \& Loring, D. W. (2004). Neuropsychological Assessment. New York: Oxford University Press.

Loewenstein, D. A., Acevedo, A., Agron, J., \& Duara, R. (2007). Stability of neurocognitive impairment in different subtypes of mild cognitive impairment. Dement Geriatr Cogn Disord, 23(2), 82-86.

McCaffrey, R. J., \& Westervelt, H. J. (1995). Issues associated with repeated neuropsychological assessments. Neuropsychol Rev, 5(3), 203-221.

Metsemakers, J. F., Hoppener, P., Knottnerus, J. A., Kocken, R. J., \& Limonard, C. B. (1992). Computerized health information in The Netherlands: a registration network of family practices. BrJ Gen Pract, 42(356), 102-106. 
Palmer, K., Wang, H. X., Backman, L., Winblad, B., \& Fratiglioni, L. (2002). Differential evolution of cognitive impairment in nondemented older persons: results from the Kungsholmen Project. Am J Psychiatry, 159(3), 436-442.

Petersen, R. C., Smith, G. E., Waring, S. C., Ivnik, R. J., Tangalos, E. G., \& Kokmen, E. (1999). Mild cognitive impairment: clinical characterization and outcome. Arch Neurol, 56(3), 303-308.

Rabbitt, P., Diggle, P., Smith, D., Holland, F., \& Mc Innes, L. (2001). Identifying and separating the effects of practice and of cognitive ageing during a large longitudinal study of elderly community residents. Neuropsychologia, 39(5), 532-543.

Rockwood, K., Chertkow, H., \& Feldman, H. H. (2007). Is mild cognitive impairment a valid target of therapy. Can J Neurol Sci, 34 Suppl 1, S90-96.

Stroop, J. (1935). Studies of interference in serial verbal reaction. Journal of Experimental Psychology, 18, 643-662.

Van Beijsterveldt, C. E., van Boxtel, M. P., Bosma, H., Houx, P. J., Buntinx, F., \& Jolles, J. (2002). Predictors of attrition in a longitudinal cognitive aging study: the Maastricht Aging Study (MAAS). J Clin Epidemiol, 55(3), 216-223.

Van Boxtel, M. P., Buntinx, F., Houx, P. J., Metsemakers, J. F., Knottnerus, A., \& Jolles, J. (1998). The relation between morbidity and cognitive performance in a normal aging population. J Gerontol A Biol Sci Med Sci, 53(2), M147-154.

Van der Elst, W., Van Boxtel, M. P., Van Breukelen, G. J., \& Jolles, J. (2005). Rey’s verbal learning test: normative data for 1855 healthy participants aged 24-81 years and the influence of age, sex, education, and mode of presentation. J Int Neuropsychol Soc, 11(3), 290-302.

Van der Elst, W., Van Boxtel, M. P., Van Breukelen, G. J., \& Jolles, J. (2006a). The Concept Shifting Test: adult normative data. Psychol Assess, 18(4), 424-432.

Van der Elst, W., Van Boxtel, M. P., Van Breukelen, G. J., \& Jolles, J. (2006b). The Letter Digit Substitution Test: normative data for 1,858 healthy participants aged 24-81 from the Maastricht Aging Study (MAAS): influence of age, education, and sex. J Clin Exp Neuropsychol, 28(6), 998-1009.

Van der Elst, W., Van Boxtel, M. P., Van Breukelen, G. J., \& Jolles, J. (2006c). The Stroop color-word test: influence of age, sex, and education; and normative data for a large sample across the adult age range. Assessment, 13(1), 62-79.

Van der Elst, W., Van Boxtel, M. P., Van Breukelen, G. J., \& Jolles, J. (2008). Detecting the significance of changes in performance on the Stroop Color-Word Test, Rey's Verbal Learning Test, and the Letter Digit Substitution Test: the regression-based change approach. J Int Neuropsychol Soc, 14(1), 71-80.

VanderZee, K. I., Sanderman, R., Heyink, J. W., \& de Haes, H. (1996). Psychometric qualities of the RAND 36-Item Health Survey 1.0: a multidimensional measure of general health status. Int J Behav Med, 3(2), 104 122.

Visser, P. J., Kester, A., Jolles, J., \& Verhey, F. (2006). Ten-year risk of dementia in subjects with mild cognitive impairment. Neurology, 67(7), 1201-1207.

Visser, P. J., \& Verhey, F. R. (2007). Mild cognitive impairment as predictor for Alzheimer's disease in clinical practice: effect of age and diagnostic criteria. Psychol Med, 1-10.

Wechsler, D. (1955). Manual for the Wechsler Adult Intelligence Scale. New York: Psychological Corporation. 
4

Neuropsychological trajectories of preclinical dementia: nine-year follow-up results from the Maastricht Aging Study 


\begin{abstract}
Neuropsychological tests are used to make a diagnosis of dementia. Longitudinal studies are needed to investigate changes in neuropsychological performance in the preclinical phase of dementia and to study whether differences between healthy individuals and future dementia cases can be detected in a period of years before dementia diagnosis. This study aimed to investigate changes in neuropsychological test performance of individuals who were healthy at baseline and who received a diagnosis of dementia in the course of a nine-year period. A total of 661 healthy participants in the Maastricht Aging Study (MAAS), aged 60 years and older, completed baseline neuropsychological assessment, which included tests for verbal memory (delayed recall of a verbal learning task), psychomotor speed, verbal fluency and executive functioning (interference score on Stroop Color-Word Test (SCWT)). At nine-year follow-up, 44 persons were diagnosed with dementia. Between baseline and nine-year follow-up neuropsychological assessment took place at three- and six-years follow-up. Baseline neuropsychological test performance and change over time were studied for individuals diagnosed with dementia and healthy controls. At baseline, the individuals who would eventually be diagnosed with dementia performed worse on all outcome measures, compared to controls. None of the performance decrements were within the clinical range. Increased decline over time for future dementia cases differed for cognitive domains. Memory declined mainly in the first three years after baseline. Executive functioning, as assessed by performance on the SCWT, declined mostly between three and six years after baseline.

Neuropsychological test performance differs for individuals with future dementia and healthy controls, already nine years before dementia diagnosis.
\end{abstract}




\section{Introduction}

The study of cognitive performance at an early stage of dementia, or even before a diagnosis is made, provides valuable information about the factors that determine who will develop dementia and on the course of the disease (Portet et al., 2006). Previous studies have indicated that dementia is preceded by a period of cognitive decline that may manifest itself in different domains. Cognitive complaints, physical health and mental health are all factors affected in the years prior to dementia diagnosis (Palmer et al., 2007; Ramakers et al., 2007). Cognitive performance is compromised in cases of preclinical dementia as well and neuropsychological tests may be a useful tool to help distinguish future dementia cases from healthy controls. What is not clear as yet, is which domains of cognitive functioning are affected at an early stage of preclinical dementia. Is the cognitive decline spread over all cognitive domains or is it just memory performance that is affected in such an early stage? This study will investigate cognitive performance changes in individuals who were diagnosed with dementia during a nine-year period. The aim is to study whether cognitive changes that occur in pre-clinical dementia are domain-specific and whether different cognitive domains show distinct patterns of cognitive decline over time.

Tests for verbal memory (Chen et al., 2000; Estevez-Gonzalez et al., 2003) and verbal fluency (Henry et al., 2004) were found to be useful tools to separate dementia patients from healthy controls. Longitudinal studies have to provide insight into the developmental process of dementia and its early stages. Studies to date have differed with regard to findings on the cognitive development of future dementia cases over time. Participants who developed dementia at a later stage of a longitudinal study, already showed lower cognitive performance at the onset of that study in most samples (Daly et al., 2000; Dickerson et al., 2007). Increased multiple domain cognitive decline over time in persons with future dementia compared to healthy controls was found in some studies (Mickes et al., 2007), while other studies reported increased decline to be domain dependent (only increased decline in memory performance) (Albert et al., 2007; Amieva et al., 2005) or even found no increased decline over time at all (Backman et al., 2001). The cognitive domain generally found to deteriorate first was memory performance (Elias et al., 2000; Lovden et al., 2005).

Differences in study design could be the cause of discrepant findings with respect to the increased decline of cognitive performance over time. First, studies varied with respect to the cognitive domains tested. Measures of episodic memory were included in almost all studies, but not all included specific tests of, for example, executive functioning (Tabert et al., 2006). In addition, studies often reported only one follow-up measurement (Palmer et al., 2003; Saxton et al., 2004), consequently not providing information on longitudinal trajectories of neuropsychological performance, or on cognitive development over different time intervals. The total follow-up time also differed between studies; some followed individuals for four years (Albert et al., 2007; Masur et al., 1994) while other studies had follow-up terms of no less than nine years (Amieva et al., 2005; Backman et al., 2001). 
In the present study, neuropsychological test performance was followed for individuals who were diagnosed with dementia during a nine-year observation period and was compared to the performance of healthy controls over the same time span. Data from the Maastricht Aging Study (MAAS) were used, which is a population-based study into the determinants of cognitive aging $(\mathrm{N}=1823,60+: \mathrm{n}=661)$. In the past, data from MAAS have been used to study cognitive changes over time in individuals with certain health-related conditions (Bosma et al., 2000; Tisserand et al., 2004). Cognitive changes that occur in the transition from normal cognitive functioning to dementia and to follow trajectories of change for individuals diagnosed with dementia at a later point in time. Cognitive performance was expected to be affected, even nine years prior to dementia diagnosis. In addition, future dementia patients were expected to show increased cognitive decline over time compared to healthy controls and the pattern of decline was expected to be dependent of the cognitive domain tested.

\section{Method}

\section{Sample}

This study was performed as part of the Maastricht Aging Study (MAAS), a longitudinal study into the determinants of cognitive aging (a detailed description of the MAAS study design is given elsewhere (Baars et al., 2009; Jolles et al., 1995)). The current study included all MAAS participants aged sixty years and older at baseline $(n=661)$, with an educational level ranging from primary school to academic education (levels 1 to 8, (De Bie, 1987)). Three and six years after baseline, all persons still available were invited to take part in follow-up assessments (522 and 437 respectively were included). At nineyear follow-up, dementia diagnosis was evaluated for all MAAS participants according to the following procedure. At baseline, persons with a diagnosis of dementia (based on $\mathrm{RNH}$ database information) or a MMSE score of 24 or less were excluded from participation. Nine years after baseline, all participants who had developed dementia in the course of the study were identified by their GP (in case of loss-to-follow-up) or on the basis of data from the MAAS study, using the criteria of the DSM-IV (DSM-IV: American Psychiatric Association, 1994), and the Dutch guidelines of dementia diagnosis in general practice (Boomsma et al., 2004). Dementia type was determined by an experienced neuropsychiatrist from the Memory Clinic of the Maastricht University Medical Center (FRJV) on the basis of the most recent neuropsychological assessment, daily life functioning (determined with the Katz index, (Katz et al., 1963) and the participant's medical profile (vascular risk factors, comorbidity, course), using the established criteria (Dubois et al., 2007).

\section{Instruments}

Cognitive functioning was assessed using a battery of neuropsychological instruments. The domains included were memory, executive functioning, mental speed and verbal fluency. The visual Verbal Learning Test (Van der Elst et al., 2005) was used to test episodic memory. Fifteen monosyllabic, non-related words were shown on a computer 
screen, after which a free recall phase followed. This procedure was repeated five times. After twenty minutes, delayed free recall was tested. The Stroop-Color Word Test (Stroop, 1935; Van der Elst et al., 2006c) was included to measure complex speed. The interference score of the Stroop was used, as a measure of inhibition. This interference score was calculated by taking the time needed for the third card (naming ink colors of incongruent printed color names) and subtracting the mean of the time on the first (reading color names) and second (naming colors of patches) card (Van der Elst et al., 2006c). This calculation minimizes the effects of less complex executive functions and simple speed on the interference score. To test general information processing speed, the Letter Digit Substitution Test (Van der Elst et al., 2006b) was included, which is based on the Digit Symbol Substitution Test (Wechsler, 1955). To test verbal fluency, participants were asked to name as many animals as possible in 60 seconds (Van der Elst et al., 2006a).

\section{Statistical analysis}

First, sensitivity and specificity analyses were performed to study the predictive value of low cognitive performance at baseline, three-year and six-year for a diagnosis of dementia.

Cross-sectional and longitudinal effects of dementia diagnosis on cognitive performance were tested using Linear Mixed Models (LMM, (Snijders \& Bosker, 1999)). This method was chosen, as LMM accounts for the correlation between repeated measurements, in this case cognitive performance. Moreover, this method allows for missing data to depend on the observed covariates and response (Missing-At-Random), which is the case in our study, since age was found to influence drop-out rate. Using LMM, all available data from each participant are included in the model and attrition is accounted for. The final model included fixed terms for intercept (baseline performance for an individual with a value of zero on all covariates), age, age ${ }^{2}$ (to control for nonlinear trends in the longitudinal data), time 1 (years between baseline and first follow-up), time 2 (years between first and second follow-up), dementia $(0=$ no diagnosis, $1=$ diagnosed in nine years after baseline), sex $(1=$ male, $2=$ female) and educational level (range $1-8)$. Interaction terms between dementia and both time variables were included, to test for effects of dementia diagnosis on cognitive change during the two test intervals. Because serial correlation was likely to be present between the repeated measurements, an unstructured covariance structure for the responses was chosen (Snijders \& Bosker, 1999). P-values of $<0.05$ were considered to be statistically significant.

\section{Results}

Of the 661 participants included in this study at baseline, $522(79 \%)$ completed the three-year follow up and 437 (66\%) completed the six-year follow-up. In the first nine years after baseline, $44(7 \%)$ of those 661 baseline participants were diagnosed with dementia. In total, 11 participants were diagnosed in the first three years after baseline, 20 between three- and six-year follow-up and 13 between six and nine years follow-up 
(the average number of years between baseline assessment and dementia diagnosis was 4.6). Of these 44 dementia cases, 31 were diagnosed with probable Alzheimer's Disease (AD) and 13 with probable vascular dementia (VD).

Table 1 Baseline characteristics for patients diagnosed with dementia during the study and healthy controls. Figures are means (SD) or percentages where indicated.

\begin{tabular}{lll}
\hline & Dementia cases & Healthy controls \\
& $\mathrm{n}=44$ & $\mathrm{n}=617$ \\
Age $(\mathrm{yrs})$ & $73.5(5.7)^{*}$ & $69.4(6)$ \\
Education level & $3.3(2)$ & $2.8(1.8)$ \\
Sex $(\%$ male) & $57.1 \%$ & $50 \%$ \\
\hline
\end{tabular}

${ }^{*} \mathrm{p}<0.05$

Using sensitivity and specificity analyses we tested whether dementia cases could already have been detected at baseline, three-, and six-years follow-up. We used a cut-off of 1.5 SD below the reference group mean, to indicate low cognitive performance. This cutoff is commonly used to define Mild Cognitive Impairment (Artero et al., 2006; Busse et al., 2006), which is a state of cognitive performance in between normal functioning and dementia (Petersen et al., 1999). Using this cut-off, at baseline specificity was high for all cognitive measures $(>=0.94$ ), but sensitivity was low (highest was 0.20 for delayed word recall). At three-year follow-up, sensitivity was higher for all measures (delayed word recall again highest with 0.48 ) and specificity did not change $(>=0.94$ for all measures). At six-year follow-up sensitivity was highest of all three time points, being 0.62 for the delayed recall measure. Specificity was still high $(>=0.91)$. Positive and negative predictive values were relatively low for all performance measures, both at baseline and both follow-ups. We also performed Linear Mixed Models (LMM) analysis to study paths of change over time for individual test scores. LMM has the advantage of including all individuals in the analysis, while in sensitivity analysis only individuals with a complete series of assessments can be included. Age, education level and sex were included as covariates in these analyses.

At baseline, the future dementia cases were older (mean $=73.5$ years, $\mathrm{SD}=5.7$ ) than controls (mean $=69.4$ years, $\mathrm{SD}=6$ ) $($ Table 1$)$, and performed worse on all neuropsychological measures (verbal memory, processing speed, verbal fluency and executive functioning) when compared to controls (adjusted for age, education and sex). Estimates in Table 2 represent the effects of the coefficients (and 95\% CI) on the test scores. Future dementia cases scored an average of 2.54 words below the mean for healthy controls on the delayed recall measure of the VLT, at baseline. For the LDST, this difference was four points (meaning four digits less filled in, on average), on verbal fluency, 2.34 fewer animals were named and the Stroop interference measure showed that 11.2 extra seconds were needed by patients compared to controls. 
Table 2 Cross-sectional effects of dementia diagnosis and demographical covariates on neuropsychological test performance (results of LMM analysis, estimates are given and 95\% CI)

\begin{tabular}{lllll}
\hline \multirow{2}{*}{ Age } & Delayed recall & Psychomotor speed & Inhibition & Fluency \\
& $-0.17^{*}$ & $-0.60^{*}$ & $-1.83^{*}$ & $-0.14^{*}$ \\
Education level & {$[-0.21-0.14]$} & {$[-0.70-0.49]$} & {$[-2.19-1.46]$} & {$[-0.21-0.08$} \\
& $0.26^{*}$ & $2.05^{*}$ & $2.99^{*}$ & $0.76^{*}$ \\
Sex & {$[0.150 .38]$} & {$[1.692 .40]$} & {$[1.774 .22]$} & {$[0.540 .98]$} \\
& $1.23^{*}$ & $0.34^{*}$ & 4.89 & 0.16 \\
Dementia diagnosis & {$[0.881 .68]$} & {$[-0.921 .60]$} & {$[0.569 .23]$} & {$[-0.610 .93]$} \\
& $-2.54^{*}$ & $-4.0^{*}$ & $-11.21^{*}$ & $-2.34^{*}$ \\
& {$[-3.38-1.70]$} & {$[-6.62-1.38]$} & {$[-20.41-2.0]$} & {$[-3.95-0.72]$} \\
\hline
\end{tabular}

Note. Age is expressed as age in years at baseline, centered around the group mean. Sex: $1=$ male, $2=$ female. For all measures higher scores indicate better performance (for inhibition the inversed estimates are given). $*_{\mathrm{p}}<0.05$

The longitudinal analyses are depicted in Table 3 and Figure 1. In the first test interval between baseline and three years follow-up, delayed word recall declined 2.62 words more per year in future dementia cases compared to healthy controls. However, there was no increased decline compared to controls in the second test interval between the three- and six-years follow-up. For LDST performance, decline was larger in future dementia cases for both time intervals, with a 3.71 and 4.12 points per year difference respectively. Increased decline on the Stroop interference score was found for both time intervals, with differences of 14.26 and 34.9 seconds per year. Fluency performance showed steady increased decline for both test intervals: in the first interval 2.84 fewer animals per year were named and in the second interval this number was 2.62.

Figure 1 Effect of dementia diagnosis on neuropsychological test performance over six years. Lines represent standardized z-scores on neuropsychological tests for dementia cases.

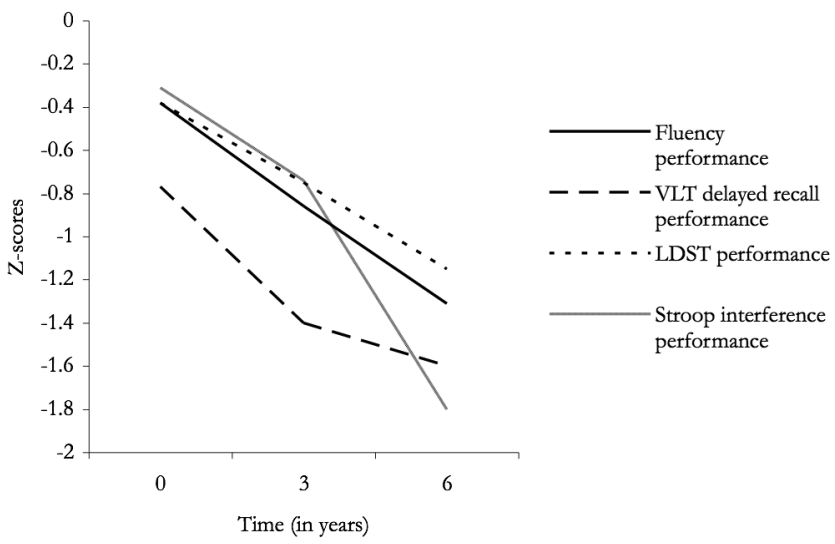

Note. The reference group mean z-score was set to zero for all measures. 
Three-way interaction between age, dementia diagnosis and time was tested post-hoc, to make sure the presented effects were not only present for the very old dementia cases. However, no three-way interaction effect was found.

Table 3 Longitudinal effects of dementia diagnosis and covariates on neuropsychological test performance over time (results of LMM analysis, estimates are given and 95\% CI).

\begin{tabular}{|c|c|c|c|c|}
\hline & Delayed recall & Psychomotor speed & Inhibition & Fluency \\
\hline \multirow[t]{2}{*}{ Intercept } & $6.44^{*}$ & $33.81^{*}$ & $79.53^{*}$ & $19.08^{*}$ \\
\hline & {$\left[\begin{array}{lll}5.67 & 7.22\end{array}\right]$} & {$\left[\begin{array}{lll}31.35 & 36.26\end{array}\right]$} & [70.98 88.09] & [17.57 20.60] \\
\hline \multirow[t]{2}{*}{ Age } & $-0.17^{*}$ & $-0.60 *$ & $-1.95^{*}$ & $-0.16^{*}$ \\
\hline & {$[-0.20-0.14]$} & {$[-0.71-0.50]$} & {$[-2.31-1.58]$} & {$\left[\begin{array}{lll}-0.22 & -0.09\end{array}\right]$} \\
\hline \multirow[t]{2}{*}{$\mathrm{Age}^{2}$} & $-0.006^{*}$ & $-0.016^{*}$ & $-0.11 *$ & $-0.01 *$ \\
\hline & {$[-0.01-0.0]$} & {$\left[\begin{array}{ll}-0.03 & 0.0\end{array}\right]$} & {$\left[\begin{array}{ll}-0.17 & -0.05\end{array}\right]$} & {$\left[\begin{array}{ll}-0.02 & 0.0\end{array}\right]$} \\
\hline \multirow[t]{2}{*}{ Education level } & $0.25^{*}$ & $2.05^{*}$ & $3.08^{*}$ & $0.77^{*}$ \\
\hline & {$\left[\begin{array}{lll}0.14 & 0.37\end{array}\right]$} & {$\left[\begin{array}{ll}1.69 & 2.40\end{array}\right]$} & {$[1.854 .31]$} & {$\left[\begin{array}{lll}0.56 & 0.99\end{array}\right]$} \\
\hline \multirow[t]{2}{*}{ Sex } & $1.29 *$ & 0.37 & $5.15^{*}$ & 0.19 \\
\hline & {$\left[\begin{array}{ll}0.89 & 1.68\end{array}\right]$} & {$\left[\begin{array}{ll}-0.89 & 1.62\end{array}\right]$} & [0.83 9.48$]$ & {$\left[\begin{array}{lll}-0.58 & 0.96\end{array}\right]$} \\
\hline \multirow[t]{2}{*}{ Dementia diagnosis } & -3.72 & -5.27 & -13.74 & -3.44 \\
\hline & {$[-4.74-2.69]$} & {$\left[\begin{array}{ll}-8.21 & -2.33\end{array}\right]$} & {$\left[\begin{array}{lll}-24.92 & -2.55\end{array}\right]$} & {$\left[\begin{array}{lll}-5.42 & -1.45\end{array}\right]$} \\
\hline \multirow[t]{2}{*}{ Time 1} & -0.81 & -0.26 & 5.78 & 0.36 \\
\hline & {$\left[\begin{array}{lll}-1.02 & -0.59\end{array}\right]$} & {$\left[\begin{array}{lll}-0.76 & 0.24\end{array}\right]$} & {$\left[\begin{array}{lll}3.49 & 8.07\end{array}\right]$} & {$\left[\begin{array}{lll}-0.06 & 0.78\end{array}\right]$} \\
\hline \multirow[t]{2}{*}{ Time 2} & -0.23 & -0.47 & -3.14 & -1.32 \\
\hline & {$\left[\begin{array}{lll}-0.47 & 0.01]\end{array}\right]$} & {$\left[\begin{array}{ll}-1.01 & 0.07\end{array}\right]$} & {$[-5.63-0.65]$} & {$\left[\begin{array}{lll}-1.77 & -0.86\end{array}\right]$} \\
\hline \multirow[t]{2}{*}{ Time $1 *$ Dementia } & $-2.62^{*}$ & $-3.71 *$ & $14.26^{*}$ & $-2.84^{*}$ \\
\hline & {$\left[\begin{array}{lll}-3.55 & -1.70\end{array}\right]$} & {$[-5.80-1.62]$} & {$\left[\begin{array}{lll}4.50 & 24.02\end{array}\right]$} & {$[-4.60-1.07]$} \\
\hline \multirow[t]{2}{*}{ Time $2 *$ Dementia } & -0.84 & $-4.12^{*}$ & $-34.89 *$ & $-2.62^{*}$ \\
\hline & {$\left[\begin{array}{lll}-2.06 & 0.38\end{array}\right]$} & {$[-6.88-1.36]$} & {$[-48.18-21.60]$} & {$[-4.95-0.30]$} \\
\hline
\end{tabular}

Note. Age is age in years at baseline, centered around the group mean, sex: $1=$ male, $2=$ female , time $1=$ first three years, time $2=$ last three years. For all measures higher scores indicate better performance (for inhibition the inversed estimates are given). Coefficients represent change per performance unit on each test for each factor ( $95 \%$ CI are given between brackets).

$*_{\mathrm{p}}<0.05$

\section{Discussion}

This study aimed to investigate changes that occurred in neuropsychological test performance in healthy individuals who were diagnosed with dementia in the course of a nine-year period. Participants diagnosed with dementia during the course of the study were expected to show worse cognitive performance at baseline, and also to show increased cognitive decline over time compared to healthy controls. As the results demon- 
strated, at baseline, participants with imminent dementia indeed performed worse than healthy controls on all neuropsychological measures that were included. Furthermore, their performance appeared to decline more and faster than for healthy controls, according to a domain-specific decline pattern.

The difference in baseline performance between future dementia cases, the increased decline over time in all cognitive domains and the distinct decline pattern of different cognitive domains over time were the main findings of this study. Combining these three questions in one study is exceptional as is the approach to follow several cognitive domains over time and to compare the patterns of decline found in those domains.

The difference in baseline performance between future dementia cases and controls is corroborated by other large-scale population studies, (Masur et al., 1994; Saxton et al., 2004; Small et al., 1997) and the same result was found in clinical samples (Powell et al., 2006). The increased rate of decline over time for future dementia cases compared to controls is corroborated by some (Chen et al., 2001; Mickes et al., 2007) but not all studies (Backman et al., 2001), or was not present in all cognitive domains (only in memory performance, but not in executive functioning, speed) (Albert et al., 2007; Amieva et al., 2005). Compared to the cited studies, we were able to use a relatively long observation period of nine years (Albert et al., 2007; Masur et al., 1994), and we included not only memory performance measures but also estimates for executive functioning and speed. In addition, the age range of the MAAS was broad compared to other samples, which may help identify individuals in an earlier pre-dementia stage compared to when only very old individuals are included (Backman et al., 2001).

The pattern of cognitive decline was found to be task-related. Verbal memory performance was already low at baseline, declined between baseline and three-year follow-up but not in the second interval between three- and six-year follow-up, while decline in executive functioning increased over time and was largest during the last interval. Decline in episodic memory functioning is known to be a primary sign of Alzheimer's Disease (AD), and early memory decline in future dementia cases has been corroborated by many other studies (Chen et al., 2000; Grober et al., 2000). The decline pattern for executive functions does not show a uniform pattern in previous studies. Some studies report a similar pattern as in memory performance (Backman \& Small, 2007), while others found that executive functions are relatively spared compared to memory performance (Albert et al., 2007; Amieva et al., 2005). Executive functioning as measured by a neuropsychological test, such as the Stroop, has been suggested as a proxy for daily life functioning (Pereira et al., 2008). In the years before dementia diagnosis, activities of daily living (ADL) are expected to be relatively spared. For example, in Mild Cognitive Impairment (MCI) (Petersen et al., 1999), ADL is by definition not affected and when it does, conversion to a diagnosis of dementia occurs. This is in line with the decline pattern found in this study, which states that executive function declined most strongly in the second test-interval.

The dementia cases were older than the controls in this study, which was to be expected since age is the main risk factor for dementia. Three-way interaction effects between age, dementia diagnosis and time were tested post-hoc, which revealed that the 
observed interaction effects of dementia and time on cognitive performance were not mediated by age.

In summary, this study showed, that future dementia cases already perform worse than healthy controls on cognitive performance measures years before the actual diagnosis is made and that the pattern of cognitive decline over time is domain-specific. Memory decline precedes decline in executive functioning, even though both domains are already affected at baseline. Neuropsychological tests may help to identify individuals at risk for dementia many years before a clinical diagnosis can be made. 


\section{References}

Albert, M., Blacker, D., Moss, M. B., Tanzi, R., \& McArdle, J. J. (2007). Longitudinal change in cognitive performance among individuals with mild cognitive impairment. Neuropsychology, 21(2), 158-169.

Amieva, H., Jacqmin-Gadda, H., Orgogozo, J. M., Le Carret, N., Helmer, C., Letenneur, L., et al. (2005). The 9 year cognitive decline before dementia of the Alzheimer type: a prospective population-based study. Brain, 128(Pt 5), 1093-1101.

Artero, S., Petersen, R., Touchon, J., \& Ritchie, K. (2006). Revised criteria for mild cognitive impairment: validation within a longitudinal population study. Dement Geriatr Cogn Disord, 22(5-6), 465-470.

Baars, M. A., van Boxtel, M. P., Dijkstra, J. B., Visser, P. J., van den Akker, M., Verhey, F. R., et al. (2009). Predictive value of mild cognitive impairment for dementia. The influence of case definition and age. Dement Geriatr Cogn Disord, 27(2), 173-181.

Backman, L., \& Small, B. J. (2007). Cognitive deficits in preclinical Alzheimer's disease and vascular dementia: patterns of findings from the Kungsholmen Project. Physiol Behav, 92(1-2), 80-86.

Backman, L., Small, B. J., \& Fratiglioni, L. (2001). Stability of the preclinical episodic memory deficit in Alzheimer's disease. Brain, 124(Pt 1), 96-102.

Boomsma, L. J., Boukes, F. S., Wind, A. W., \& Assendelft, W. J. (2004). [Summary of the practice guideline 'Dementia' (second revision) from the Dutch College of General Practitioners]. Ned Tijdschr Geneeskd, 148(24), 1191-1197.

Bosma, H., van Boxtel, M. P., Ponds, R. W., Houx, P. J., \& Jolles, J. (2000). Pesticide exposure and risk of mild cognitive dysfunction. Lancet, 356(9233), 912-913.

Busse, A., Hensel, A., Guhne, U., Angermeyer, M. C., \& Riedel-Heller, S. G. (2006). Mild cognitive impairment: long-term course of four clinical subtypes. Neurology, 67(12), 2176-2185.

Chen, P., Ratcliff, G., Belle, S. H., Cauley, J. A., DeKosky, S. T., \& Ganguli, M. (2000). Cognitive tests that best discriminate between presymptomatic $\mathrm{AD}$ and those who remain nondemented. Neurology, 55(12), 1847-1853.

Chen, P., Ratcliff, G., Belle, S. H., Cauley, J. A., DeKosky, S. T., \& Ganguli, M. (2001). Patterns of cognitive decline in presymptomatic Alzheimer disease: a prospective community study. Arch Gen Psychiatry, 58(9), 853-858.

Daly, E., Zaitchik, D., Copeland, M., Schmahmann, J., Gunther, J., \& Albert, M. (2000). Predicting conversion to Alzheimer disease using standardized clinical information. Arch Neurol, 57(5), 675-680.

De Bie, S. E. (1987). Standaardvragen 1987: Voorstellen voor uniformering van vraagstellingen naar achtergrondkenmerken en interviews [Standard questions 1987: Proposal for uniformization of questions regarding background variables and interviews]. Leiden, The Netherlands: Leiden University Press.

Dickerson, B. C., Sperling, R. A., Hyman, B. T., Albert, M. S., \& Blacker, D. (2007). Clinical prediction of Alzheimer disease dementia across the spectrum of mild cognitive impairment. Arch Gen Psychiatry, 64(12), 1443-1450.

DSM-IV: American Psychiatric Association (Ed.). (1994). Diagnostic and Statistical Manual of Mental Disorders: DSM IV. (4th ed.). Washington D.C.

Dubois, B., Feldman, H. H., Jacova, C., Dekosky, S. T., Barberger-Gateau, P., Cummings, J., et al. (2007). Research criteria for the diagnosis of Alzheimer's disease: revising the NINCDS-ADRDA criteria. Lancet Neurol, 6(8), 734-746.

Elias, M. F., Beiser, A., Wolf, P. A., Au, R., White, R. F., \& D’Agostino, R. B. (2000). The preclinical phase of alzheimer disease: A 22-year prospective study of the Framingham Cohort. Arch Neurol, 57(6), 808-813.

Estevez-Gonzalez, A., Kulisevsky, J., Boltes, A., Otermin, P., \& Garcia-Sanchez, C. (2003). Rey verbal learning test is a useful tool for differential diagnosis in the preclinical phase of Alzheimer's disease: comparison with mild cognitive impairment and normal aging. Int J Geriatr Psychiatry, 18(11), 1021-1028.

Grober, E., Lipton, R. B., Hall, C., \& Crystal, H. (2000). Memory impairment on free and cued selective reminding predicts dementia. Neurology, 54(4), 827-832.

Henry, J. D., Crawford, J. R., \& Phillips, L. H. (2004). Verbal fluency performance in dementia of the Alzheimer's type: a meta-analysis. Neuropsychologia, 42(9), 1212-1222.

Jolles, J., Houx, P. J., van Boxtel, M. P. J., \& Ponds, R. W. H. M. (1995). Maastricht Aging Study: Determinants of cognitive aging. . Maastricht, The Netherlands: Neuropsych Publishers.

Katz, S., Ford, A. B., Moskowitz, R. W., Jackson, B. A., \& Jaffe, M. W. (1963). Studies of Illness in the Aged. the Index of Adl: a Standardized Measure of Biological and Psychosocial Function. JAMA, 185, 914-919. 
Lovden, M., Bergman, L., Adolfsson, R., Lindenberger, U., \& Nilsson, L. G. (2005). Studying individual aging in an interindividual context: typical paths of age-related, dementia-related, and mortality-related cognitive development in old age. Psychol Aging, 20(2), 303-316.

Masur, D. M., Sliwinski, M., Lipton, R. B., Blau, A. D., \& Crystal, H. A. (1994). Neuropsychological prediction of dementia and the absence of dementia in healthy elderly persons. Neurology, 44(8), 1427-1432.

Mickes, L., Wixted, J. T., Fennema-Notestine, C., Galasko, D., Bondi, M. W., Thal, L. J., et al. (2007). Progressive impairment on neuropsychological tasks in a longitudinal study of preclinical Alzheimer's disease. Neuropsychology, 21(6), 696-705.

Palmer, K., Backman, L., Winblad, B., \& Fratiglioni, L. (2003). Detection of Alzheimer's disease and dementia in the preclinical phase: population based cohort study. Bmj, 326(7383), 245.

Palmer, K., Berger, A. K., Monastero, R., Winblad, B., Backman, L., \& Fratiglioni, L. (2007). Predictors of progression from mild cognitive impairment to Alzheimer disease. Neurology, 68(19), 1596-1602.

Pereira, F. S., Yassuda, M. S., Oliveira, A. M., \& Forlenza, O. V. (2008). Executive dysfunction correlates with impaired functional status in older adults with varying degrees of cognitive impairment. Int Psychogeriatr, 20(6), 1104-1115.

Petersen, R. C., Smith, G. E., Waring, S. C., Ivnik, R. J., Tangalos, E. G., \& Kokmen, E. (1999). Mild cognitive impairment: clinical characterization and outcome. Arch Neurol, 56(3), 303-308.

Portet, F., Ousset, P. J., Visser, P. J., Frisoni, G. B., Nobili, F., Scheltens, P., et al. (2006). Mild cognitive impairment (MCI) in medical practice: a critical review of the concept and new diagnostic procedure. Report of the MCI Working Group of the European Consortium on Alzheimer's Disease. J Neurol Neurosurg Psychiatry, 77(6), 714-718.

Powell, M. R., Smith, G. E., Knopman, D. S., Parisi, J. E., Boeve, B. F., Petersen, R. C., et al. (2006). Cognitive measures predict pathologic Alzheimer disease. Arch Neurol, 63(6), 865-868.

Ramakers, I. H., Visser, P. J., Aalten, P., Boesten, J. H., Metsemakers, J. F., Jolles, J., et al. (2007). Symptoms of preclinical dementia in general practice up to five years before dementia diagnosis. Dement Geriatr Cogn Disord, 24(4), 300-306.

Saxton, J., Lopez, O. L., Ratcliff, G., Dulberg, C., Fried, L. P., Carlson, M. C., et al. (2004). Preclinical Alzheimer disease: neuropsychological test performance 1.5 to 8 years prior to onset. Neurology, 63(12), 2341 2347.

Small, B. J., Herlitz, A., Fratiglioni, L., Almkvist, O., \& Backman, L. (1997). Cognitive predictors of incident Alzheimer's disease: a prospective longitudinal study. Neuropsychology, 11(3), 413-420.

Snijders, T., \& Bosker, R. (1999). Multilevel analysis. An introduction to basic and advanced multilevel modeling. London: Sage.

Stroop, J. (1935). Studies of interference in serial verbal reaction. Journal of Experimental Psychology, 18, 643-662.

Tabert, M. H., Manly, J. J., Liu, X., Pelton, G. H., Rosenblum, S., Jacobs, M., et al. (2006). Neuropsychological prediction of conversion to Alzheimer disease in patients with mild cognitive impairment. Arch Gen Psychiatry, 63(8), 916-924.

Tisserand, D. J., van Boxtel, M. P., Pruessner, J. C., Hofman, P., Evans, A. C., \& Jolles, J. (2004). A voxelbased morphometric study to determine individual differences in gray matter density associated with age and cognitive change over time. Cereb Cortex, 14(9), 966-973.

Van der Elst, W., Van Boxtel, M. P., Van Breukelen, G. J., \& Jolles, J. (2005). Rey's verbal learning test: normative data for 1855 healthy participants aged 24-81 years and the influence of age, sex, education, and mode of presentation. J Int Neuropsychol Soc, 11(3), 290-302.

Van der Elst, W., Van Boxtel, M. P., Van Breukelen, G. J., \& Jolles, J. (2006a). Normative data for the Animal, Profession and Letter M Naming verbal fluency tests for Dutch speaking participants and the effects of age, education, and sex. J Int Neuropsychol Soc, 12(1), 80-89.

Van der Elst, W., Van Boxtel, M. P., Van Breukelen, G. J., \& Jolles, J. (2006b). The Letter Digit Substitution Test: normative data for 1,858 healthy participants aged 24-81 from the Maastricht Aging Study (MAAS): influence of age, education, and sex. J Clin Exp Neuropsychol, 28(6), 998-1009.

Van der Elst, W., Van Boxtel, M. P., Van Breukelen, G. J., \& Jolles, J. (2006c). The Stroop color-word test: influence of age, sex, and education; and normative data for a large sample across the adult age range. $A s$ sessment, 13(1), 62-79.

Wechsler, D. (1955). Manual for the Wechsler Adult Intelligence Scale. New York: Psychological Corporation. 


\section{5}

Migraine does not affect cognitive decline: results from the Maastricht Aging Study 


\begin{abstract}
The objective of this study was to investigate the effects of migraine and related pharmacotherapy on cognitive performance and cognitive change over time in a longitudinal population-based study. Migraineurs $(n=99)$ and healthy controls $(n=1724)$ participating in the Maastricht Aging Study (MAAS) were cognitively tested at baseline and after six years. Scores on MMSE, immediate and delayed recall tests, and tests for simple and complex speed were compared for both groups. GEE analyses were performed to test the longitudinal effects of migraines on cognition. Effects of migraine medication use were also tested. Migraine headaches were found to have no effect on any of the cognitive measures. Medication use also had no effect on all cognitive measures. No evidence was found that migraine headaches or migraine related medication use are risk- or protective factors for cognitive dysfunction or cognitive deterioration over time.
\end{abstract}




\section{Introduction}

Several studies have investigated the effects of migraine headaches on cognitive function. Results varied from no effect on general cognitive function and verbal memory performance (Jelicic et al., 2000; Pearson et al., 2006) to a negative effect on verbal performance. So, people with migraine are characterized by more cognitive dysfunction, compared to those without (Waldie et al., 2002). A relation between migraine and cognitive dysfunction has also been suggested by MRI studies showing that white matter lesions were more apparent in migraine patients compared to controls (Intiso et al., 2006; Kruit et al., 2004). Pathological thickening of the somatosensory cortex has also been found in migraine patients (DaSilva et al., 2007). Recently, authors from the Baltimore Epidemiologic Catchment Area (ECA) Study reported that migraineurs, especially those who experience aura, showed less cognitive decline over time, than controls (Kalaydjian et al., 2007). This seems a remarkable finding, since white matter lesions have been shown to predict cognitive dysfunction and an accelerated decline in memory performance and psychomotor speed (Vermeer et al., 2003). The Baltimore ECA study was the first large population study that focused on the longitudinal effects of migraine on cognition. Further research should clarify the relationship between migraines and cognition. The current study also set out to investigate longitudinal effects of migraines on a range of cognitive domains. White matter lesions predicted decline in cognitive speed in previous studies, therefore measures for speed were included in this study (de Groot et al., 2000). Apart from a verbal memory- and a general cognitive abilities test, measures of psychomotor speed and executive function were included. Furthermore, associations between migraine related medication use and cognitive function were studied in more detail. In the Baltimore ECA study only non-aspirin NSAIDs were included as covariates in the analysis, but potential effects of specific migraine medication (Silberstein \& Goadsby, 2002) were not tested. The second goal of this study was to analyze separately effects of specific migraine medication and non-specific headache medication on the relation between migraine headache and cognitive abilities.

\section{Methods}

\section{Study population}

The participants included in this study were recruited from the Maastricht Aging Study (MAAS), a longitudinal study into the determinants of cognitive aging (Jolles et al., 1995; Van Boxtel et al., 1998). Participants were tested neuropsychologically at baseline (19921994), after three years (only participants of 50 years and older) and again after six years. 10,396 potential participants were recruited from a patients register of collaborating general practitioners in the south of the Netherlands (RNH) (Metsemakers et al., 1992) by sending a prepaid postcard. 4,490 agreed to participate (43.2\%), 3,531 refused participation (34\%) and 2,375 did not return the postcard (22.8\%).

Participants were excluded from participation when medical records from the general practitioner (GP) reported serious conditions that could interfere with cognitive 
functioning, including coma, all tumors of the nervous system, congenital malformations of the nervous system, history of stroke, parkinsonism, multiple sclerosis, dementia, organic psychosis (other than dementia), schizophrenia, affective psychosis and mental retardation. Health problems in the RNH database were recorded according to the International Classification of Primary Care (Lamberts \& Wood, 1987). Next, all 4,490 potential participants were screened by telephone, for additional medical conditions not registered by the RNH (history of TIA, brain surgery, haemodialysis for renal failure, electroconvulsive therapy, and daily use of psychotropic drugs). 301 Potential participants were excluded from participation based on this interview. Of the remaining 4,189 participants, 1,856 were randomly selected from 12 equally sized age categories $(25+/-$ 1 years, 30+/- 1 years . . 8 80 +/- 1 years), stratified for sex and education level (De Bie, 1987). After baseline measurement, 27 participants were excluded with a Mini Mental State Examination (MMSE) score (Folstein et al., 1975) below 25. Another 6 participants were excluded due to technical problems during baseline assessment $(n=4)$, or because their native language was not Dutch $(n=2)$. After the baseline measurement 1,823 participants, aged 24 to 81 years at baseline, were admitted to the longitudinal part of the study. At 3 years follow up, 849 of the original 956 participants aged 50 or older at baseline, were tested again. Six years after baseline 1,376 of the original 1,823 participants were tested again.

\section{Assessment of migraines}

Participants in the MAAS all filled out a questionnaire at baseline. This included a structured list of medical conditions as diagnosed by a medical doctor, including migraine headaches. Participants were asked to check which conditions had ever been diagnosed, who made the diagnosis, (GP or a specialist, e.g. neurologist), and whether they had ever been admitted to a hospital due to the condition. Finally, they were asked to state whether the medical condition was still an active health problem, or whether they had been diagnosed in the past, but the disease was not currently active anymore. In this study, participants were included in the migraine group if a medical doctor ever made a diagnosis of migraine and if this condition was considered an 'active' medical condition (Jelicic et al., 2000). No further specification was made of the type of migraine. In every follow-up measurement of the MAAS the same list medical conditions list was checked for changes in a face-to-face interview.

\section{Measurement of cognitive function}

The MMSE was included as a screening test of general cognitive abilities (Folstein et al., 1975). Several separate domains of cognitive functioning were probed using a battery of neuropsychological instruments. The domains covered included memory, executive functioning and mental speed. The visual Verbal Learning Test (Van der Elst et al., 2005) was used to test verbal memory. The total immediate recall score of five trials and the delayed recall score after twenty minutes were recorded. The Stroop-Color Word Test (Stroop, 1935; Van der Elst et al., 2006b) was administered to measure complex speed. The interference score of the Stroop as a measure of cognitive flexibility is calculated by taking the time needed for the third card (naming ink colors of incongruent 
printed color names) and subtracting the average of the time needed for the first (reading color names) and second (naming colors of patches) card. This derived value corrected for simple speed, is considered a pure indicator of inhibition. The Stroop interference score is considered a measure of executive functioning. Attention, visual recognition and working memory are important factors in all parts of the task, but the inhibition of reading (Stroop-III) was the measure of executive functioning of interest. Finally, basic information processing speed was measured with the Letter Digit Substitution Test (Van der Elst et al., 2006a), which is based on the Digit Symbol Substitution Test (Wechsler, 1955). In this test, the time needed to copy letters in boxes that are indexed by digits, according to a key of letter/digit combinations on the top of a sheet of paper.

\section{Measurement of medication use and other covariates}

Participants were asked to list all medications used on a regular basis and the medical reason for using a specific drug. Participants were coded as a migraine medication user, when they took at least one known typical anti-migraine drug (e.g. ergotamines, triptans), or were taking atypical medication for their migraine only, such as NSAID's, or paracetamol.

Several other covariates of potential relevance were included, such as age, education level, sex, a history of hypertension, type- 2 diabetes or myocardial infarction, and symptoms of depression and anxiety. The same set of covariates was used in the Baltimore ECA study, and was used in this study to adjust the study outcome for differences in population sample characteristics. A diagnosis of non-insulin dependent (type-2) diabetes was based on the data from the medical questionnaire and interview including reported medication use. Hypertension was either reported in the same interview or based on a threefold measurement of blood pressure in seated position using a Dinamap 8100 automatic blood pressure monitor (Van Boxtel et al., 1996). Hypertension was considered present when a mean diastolic blood pressure of $90 \mathrm{mmHg}$ or higher or a mean systolic blood pressure of $140 \mathrm{mmHg}$ or higher was found (WHO, 1993). History of myocardial infarction was reported in the medical interview. Finally, mood was assessed with subscales of the Symptom Check List (Arrindell \& Ettema, 1986).

\section{Statistical analysis}

Cross-sectional and longitudinal differences between groups of migraineurs and controls were tested by means of Generalized Estimating Equations (GEE) module in the Statistical Package for Social Sciences (SPSS for Windows, version 15). This method of analysis has the advantage over normal Generalized Linear Models (GLM) that attrition and serial correlation of repeatedly measured variables is accounted for in the model as well (Zeger \& Liang, 1986).

The GEE model for all cognitive measures were constructed as follows:

Cognitive score $=\beta_{0}+\beta_{1}$ Age $+\beta_{2}$ Education $+\beta_{3}$ Sex $+\beta_{4}$ Migraine $+\beta_{5}$ time ${ }_{\mathrm{ij}}+$ $\beta_{6}\left(\right.$ Migraine $_{\mathrm{i} 1} *$ time $\left._{\mathrm{ij}}\right)+\varepsilon_{\mathrm{ij}}$

The $\beta_{1}$ parameter represents the cross-sectional effect of migraine on the cognitive parameter of interest, which is the difference in cognitive score between the migraine group and the control group at baseline. The effect of time on cognitive performance is 
measured by $\beta_{2}$. The longitudinal interaction effect is represented by the $\beta_{5}$ parameter, which estimates the interaction effect of time and migraine on a cognitive score, so the rate of change between baseline and 6-years follow up. Effects of medication use were tested in separate GEE models for all outcome measures, constructed as follows:

Cognitive score $=\beta_{0}+\beta_{1}$ Age $+\beta_{2}$ Education $+\beta_{3}$ Sex $+\beta_{4}$ Specific medication $+\beta_{5}$ Non-specific medication $+\beta_{6}$ time $_{\mathrm{ij}}+\varepsilon_{\mathrm{ij}}$

Differences between the two groups could be influenced by selective attrition, so if migraine caused people to drop out of the study, differences between the two groups at follow up could be caused by this selective attrition. In addition, logistic regression analyses were performed to check if attrition was unrelated to migraine status. In all analyses, alpha levels of .01 or lower were considered statistically significant, to correct for effects of multiple comparisons.

\section{Results}

\section{Sample characteristics}

Of the 1,823 MAAS participants included in this study at baseline, 99 were diagnosed as migraineurs, according to the criteria described above. Baseline characteristics (Table 1) of both groups were compared: the migraine group was significantly younger than the control group and a larger proportion was female. Other differences were not significant. With logistic regression analysis, possible effects of migraine on dropout rate were tested, with drop out being the outcome variable and migraine the independent variable. Results showed, that migraineurs were not more prone to dropping out than controls $(\mathrm{OR}=0.91,95 \% \mathrm{CI}=0.56$ to $1.5, \mathrm{p}=0.71)$.

Table 1 Sample characteristics at baseline $(n=1,823)$ by migraine status

\begin{tabular}{lll}
\hline & Migraineurs & Controls \\
Age, mean (SD), years & $47.1(12.9)^{*}$ & $51.8(16.6)$ \\
Male, n (\%) & $36(36.4 \%)$ & $877(50.9 \%)$ \\
Education level, mean (SD) & $3.4(1.8)$ & $3.5(1.9)$ \\
Diabetes, n (\%) & $3(3 \%)$ & $97(5.6 \%)$ \\
Hypertension, n (\%) & $37(37.4 \%)$ & $641(37.2 \%)$ \\
SCL Depression score & $22.3(7.8)$ & $20.7(6.3)$ \\
SCL Anxiety score & $14.1(6)$ & $12.5(4.1)$ \\
Myocardial infarction, n (\%) & $1(1 \%)$ & $66(3.8 \%)$ \\
\hline
\end{tabular}

\section{Effects of migraine on cognitive decline}

Results of the GEE analysis are reported in Table 2, which shows the variable coefficients for the migraine group and the controls. The B-values and the confidence intervals for the factors included in the GEE model are reported, and significant effects cognitive measures are marked. A higher age resulted in a lower performance on all cognitive measures. A higher education resulted in a higher performance on all cognitive measures. Women outperformed men on all cognitive measures. The delayed recall score on the VLT did not differ between the migraineurs and the control group, because 
the factor migraine did not alter the cognitive score significantly. The same result was found for the MMSE and immediate recall score of the VLT. Medication use, both migraine specific and non migraine specific, did not influence performance on the MMSE or the memory tasks In addition to the tests that were used in the ECA study(Kalaydjian et al., 2007), we also tested the associations between migraine diagnosis and performance on tests for speed and executive function, as outlined above. Performance on the LDST and Stroop interference parameter again were not significantly different for migraineurs and controls, and were thus comparable to those for memory performance and MMSE score.

Table 2 B-values and confidence intervals for longitudinal effects of migraine on cognitive performance

\begin{tabular}{|c|c|c|c|c|c|}
\hline \multirow{3}{*}{ Age (yrs) } & Imm. recall & Delayed recall & MMSE & LDST & Stroop \\
\hline & -0.26 & -0.08 & -0.05 & -0.43 & 0.71 \\
\hline & {$\left[\begin{array}{ll}-0.29 & -0.24\end{array}\right]$} & {$\left[\begin{array}{ll}-0.08 & -0.07\end{array}\right]$} & {$\left[\begin{array}{ll}-0.06 & -0.04\end{array}\right]$} & {$\left[\begin{array}{ll}-0.46 & .0 .40\end{array}\right]$} & {$\left[\begin{array}{ll}0.65 & 0.78\end{array}\right]$} \\
\hline \multirow[t]{2}{*}{ Sex (m vs $f$ ) } & 3.77 & 1.17 & 0.17 & 1.02 & -3.31 \\
\hline & {$\left[\begin{array}{ll}3.07 & 4.47\end{array}\right]$} & {$\left[\begin{array}{ll}1.01 & 1.40\end{array}\right]$} & {$\left[\begin{array}{ll}0.01 & 0.33\end{array}\right]$} & {$[0.22 \quad 1.83]$} & {$\left[\begin{array}{ll}-5.18 & -1.49\end{array}\right]$} \\
\hline \multirow[t]{2}{*}{ Education level } & 1.25 & 0.30 & 0.25 & 1.75 & -2.10 \\
\hline & {$\left[\begin{array}{ll}1.05 & 1.45\end{array}\right]$} & {$\left[\begin{array}{ll}0.25 & 0.36\end{array}\right]$} & {$\left[\begin{array}{ll}0.21 & 0.30\end{array}\right]$} & {$\left[\begin{array}{ll}1.51 & 1.98\end{array}\right]$} & {$\left[\begin{array}{ll}-2.61 & -1.60\end{array}\right]$} \\
\hline \multirow[t]{2}{*}{ Migraine } & 0.36 & -0.29 & 0.52 & 1.07 & 0.86 \\
\hline & {$\left[\begin{array}{ll}-2.62 & 3.35\end{array}\right]$} & {$\left[\begin{array}{ll}-1.25 & 0.69\end{array}\right]$} & {$\left[\begin{array}{ll}-0.32 & 1.37\end{array}\right]$} & {$\left[\begin{array}{ll}-1.72 & 3.86\end{array}\right]$} & {$\left[\begin{array}{ll}-4.84 & 6.55\end{array}\right]$} \\
\hline \multirow[t]{2}{*}{ Time } & 4.49 & 0.89 & 0.28 & 2.32 & 2.15 \\
\hline & {$\left[\begin{array}{ll}4.04 & 4.93\end{array}\right]$} & {$[0.75 \quad 1.04]$} & {$\left[\begin{array}{ll}0.14 & 0.42\end{array}\right]$} & {$\left[\begin{array}{ll}1.95 & 2.68\end{array}\right]$} & {$[0.89$ 3.41] } \\
\hline \multirow[t]{2}{*}{ Migraine*Time } & 0.54 & 0.38 & -0.35 & -0.90 & -2.72 \\
\hline & {$\left[\begin{array}{ll}1.31 & 2.43\end{array}\right]$} & {$\left[\begin{array}{ll}-0.23 & 0.98\end{array}\right]$} & {$\left[\begin{array}{ll}-0.86 & 0.16\end{array}\right]$} & $\left.\begin{array}{ll}--2.52 & 0.70\end{array}\right]$ & {$\left[\begin{array}{ll}-5.96 & 0.53\end{array}\right]$} \\
\hline
\end{tabular}

\section{Effects of medication use}

Medication use, both specific and non-specific did not alter the relation between migraines and cognitive function. Decline over time was neither increased nor decreased for migraineurs who used either specific or non-specific medication.

\section{Discussion}

This study investigated the effects of migraine diagnosis on cognitive performance and on performance change over time. Multiple domains of cognitive functioning were included, in contrast to previous studies (Jelicic et al., 2000; Kalaydjian et al., 2007) that only included tests on memory performance and on general cognitive performance. The cross-sectional and longitudinal effects of migraine on cognitive function were tested in one single model, for each cognitive variable separately, by means of GEE. Results showed, that baseline performance on all cognitive variables did not differ for migraineurs and controls. Furthermore, after six years, migraineurs also showed no different change pattern compared to controls, on any of the cognitive outcome variables. Thus, no apparent protective or negative effect of migraine diagnosis on cognitive functions over time was identified.

Selective attrition can be a source of bias in longitudinal studies (Van Beijsterveldt et al., 2002). However, the absence of differences between the two groups was not due to 
selective attrition, as was shown in the logistic regression analysis, that compared dropout patterns in both groups.

Medication use was included in this study, to investigate whether effects of migraines on cognition were possibly mediated by migraine medication use. No such effects were found on any of the cognitive measures. The migraineurs taking medication were expected to experience more severe migraines compared not migraineurs who do not take medication. However, even participants taking specific migraine medication, which is only prescribed for heavy migraine cases (ergotamines, triptans), did not show increased decline over time, compared to controls. In this study, we did not distinguish between preventative and acute interventional migraine medication use. It is theoretically possible that migraineurs were using migraine medication during the neuropsychological test sessions. However, all participants were volunteers who were screened by telephone for current health condition before each test session. Participants were re-scheduled for a new test session in case they reported health problems during this screening phone-call or when they cancelled on the day of the test session due to illness. No specific information on migraine severity and frequency was available. However, individuals suffering severe migraine headaches or those with more frequent migraine attacks were expected to use the specific migraine medication more often, than migraineurs with less severe and less frequent headaches. Since no effects were found for specific migraine medication use, migraine frequency and severity is not expected to influence cognitive performance over time.

Although this study focuses on effects of current migraine on cognitive decline over time, we did have information on past migraine diagnosis as well, and post-hoc analyses showed, that participants with a history of migraines did not show a different decline pattern than healthy controls.

The most straightforward explanation for the results of the present study is that migraine headaches simply do not have a substantial negative or positive effect on cognitive performance or change therein. Since previous studies also did not find a protective or negative effect of migraine on cognitive performance (Jelicic et al., 2000; Pearson et al., 2006), this seems in our view, at this point, the most plausible explanation.

However, our findings do not confirm those found in the Baltimore ECA study (Kalaydjian et al., 2007), in which migraineurs were found to be performing better than controls and declining less over time. This difference in outcome with the present study could be due to the type of diagnosis that was used in both studies. In the Baltimore ECA study, migraine was diagnosed using a screening method developed by the International Headache Society, focusing on severity of headaches and type of migraine. In our study, migraineurs were identified if diagnosed by a medical doctor and if the migraines were a current problem, so a combination of self report and diagnosis by a medical doctor. Different patient groups could therefore have been identified by the two methods, as migraineurs may not always report their condition to a physician. It is unlikely, however, that the present method for identification of migraine patients has resulted in an underestimation of the effects of migraines on cognition, as we expect that only persons with limited disease burden may have failed to report their complaints to their physician. If this tendency indeed was present in our data, the contrast in outcome 
measures between both groups (and with that the odds of finding a significant difference) would have been increased, not reduced.

The frequency of medication use could help explain the findings as well. Only half of the migraineurs in MAAS reported using migraine medication (44 out of 99). This could be an indication that the migraine severity was relatively low. However, in the Baltimore ECA study migraineurs reported medication use in only $25 \%$ of the cases (Kalaydjian et al., 2007), so migraine severity does not explain the discrepant findings. The lack of effects of migraines on cognitive function could be explained by this finding. However, when the GEE analysis was repeated for only the migraineurs on medication, results did not change.

The results found in the Baltimore ECA study were most apparent for migraineurs with aura. In our study, we did not have information on aura, so the lack of effect of migraines on cognition could be explained by this difference. However, recent imaging studies have shown, that migraineurs with aura show increased chance of stroke (Bigal et al., 2009). Therefore the lack of aura information in our study is not likely to explain the difference in results compared to the Baltimore ECA study, since in that study migraineurs were found to show less cognitive decline over time than controls. It may be possible that the migraineurs in our study were very successful in changing some behavioral patterns, such as hours of sleep or diet, in order to reduce the frequency of their migraine attacks and the effects of these attacks on their cognitive performance. This is also mentioned in the ECA study report to explain their positive effects of migraine on cognition (Kalaydjian et al., 2007).

This study adds valuable new insights to the discussion on the effects of migraine headaches on cognitive function, because cognitive performance change over time was not affected by migraine headaches. Compared to previous studies, this study is unique because it investigated the longitudinal effects of migraine on cognition in a populationbased sample and on several cognitive domains. The effects of migraines on cognition have been studied before, but mainly in clinical samples (Bell et al., 1999; Le Pira et al., 2004), or in a small selection of cognitive domains in population samples (Jelicic et al., 2000; Kalaydjian et al., 2007). These studies investigated effects on memory and general cognitive abilities, but did not include measures for speed or executive functioning. Studies have shown though, that periventricular white matter lesions mainly have effects on speed and executive functions (de Groot et al., 2000)and that migiraines are a possible cause for such lesions.

Concluding, in this study, a migraine diagnosis did not influence cognitive performance or decline over time. Neither positive effects nor negative effects were found. Considering that these findings came from a large, longitudinal population study, focusing on a wide range of cognitive domains, these results are an indication that effects of migraine on cognition simply do not exist, or that these effects are mediated by one or more of the factors described above. In future studies, the specificity of migraine as a predictor of cognitive decline could possibly be increased by focusing on those migraine patients that show white matter lesions, since possible effects on cognitive performance could be reserved for this group of migraineurs. 


\section{References}

Arrindell, W. A., \& Ettema, J. H. M. (1986). Scl-90. Manual for a Multidimensional Indicator of Psychopathology [handleiding bij een multidimensionele psychopathologie-indicator]. Lisse: Swets \& Zeitlinger B.V.

Bell, B. D., Primeau, M., Sweet, J. J., \& Lofland, K. R. (1999). Neuropsychological functioning in migraine headache, nonheadache chronic pain, and mild traumatic brain injury patients. Arch Clin Neuropsychol, 14(4), 389-399.

Bigal, M. E., Kurth, T., Hu, H., Santanello, N., \& Lipton, R. B. (2009). Migraine and cardiovascular disease: possible mechanisms of interaction. Neurology, 72(21), 1864-1871.

DaSilva, A. F., Granziera, C., Snyder, J., \& Hadjikhani, N. (2007). Thickening in the somatosensory cortex of patients with migraine. Neurology, 69(21), 1990-1995.

De Bie, S. E. (1987). Standaardvragen 1987: Voorstellen voor uniformering van vraagstellingen naar achtergrondkenmerken en interviews [Standard questions 1987: Proposal for uniformization of questions regarding background variables and interviews]. Leiden, The Netherlands: Leiden University Press.

de Groot, J. C., de Leeuw, F. E., Oudkerk, M., van Gijn, J., Hofman, A., Jolles, J., et al. (2000). Cerebral white matter lesions and cognitive function: the Rotterdam Scan Study. Ann Neurol, 47(2), 145-151.

Folstein, M. F., Folstein, S. E., \& McHugh, P. R. (1975). "Mini-mental state”. A practical method for grading the cognitive state of patients for the clinician. J Psychiatr Res, 12(3), 189-198.

Intiso, D., Di Rienzo, F., Rinaldi, G., Zarrelli, M. M., Giannatempo, G. M., Crociani, P., et al. (2006). Brain MRI white matter lesions in migraine patients: is there a relationship with antiphospholipid antibodies and coagulation parameters? Eur J Neurol, 13(12), 1364-1369.

Jelicic, M., van Boxtel, M. P., Houx, P. J., \& Jolles, J. (2000). Does migraine headache affect cognitive function in the elderly? Report from the Maastricht Aging Study (MAAS). Headache, 40(9), 715-719.

Jolles, J., Houx, P. J., van Boxtel, M. P. J., \& Ponds, R. W. H. M. (1995). Maastricht Aging Study: Determinants of cognitive aging. . Maastricht, The Netherlands: Neuropsych Publishers.

Kalaydjian, A., Zandi, P. P., Swartz, K. L., Eaton, W. W., \& Lyketsos, C. (2007). How migraines impact cognitive function: findings from the Baltimore ECA. Neurology, 68(17), 1417-1424.

Kruit, M. C., van Buchem, M. A., Hofman, P. A., Bakkers, J. T., Terwindt, G. M., Ferrari, M. D., et al. (2004). Migraine as a risk factor for subclinical brain lesions. Jama, 291(4), 427-434.

Lamberts, H., \& Wood, M. (1987). ICPC: International Classification of Health Problems in Primary Care. Oxford: Oxford University Press.

Le Pira, F., Lanaia, F., Zappala, G., Morana, R., Panetta, M. R., Reggio, E., et al. (2004). Relationship between clinical variables and cognitive performances in migraineurs with and without aura. Funct Neurol, 19(2), 101-105.

Metsemakers, J. F., Hoppener, P., Knottnerus, J. A., Kocken, R. J., \& Limonard, C. B. (1992). Computerized health information in The Netherlands: a registration network of family practices. Br J Gen Pract, 42(356), 102-106.

Pearson, A. J., Chronicle, E. P., Maylor, E. A., \& Bruce, L. A. (2006). Cognitive function is not impaired in people with a long history of migraine: a blinded study. Cephalalgia, 26(1), 74-80.

Silberstein, S. D., \& Goadsby, P. J. (2002). Migraine: preventive treatment. Cephalalgia, 22(7), 491-512.

Stroop, J. (1935). Studies of interference in serial verbal reaction. Journal of Experimental Psychology, 18, 643662.

Van Beijsterveldt, C. E., van Boxtel, M. P., Bosma, H., Houx, P. J., Buntinx, F., \& Jolles, J. (2002). Predictors of attrition in a longitudinal cognitive aging study: the Maastricht Aging Study (MAAS). J Clin Epidemiol, 55(3), 216-223.

Van Boxtel, M. P., Buntinx, F., Houx, P. J., Metsemakers, J. F., Knottnerus, A., \& Jolles, J. (1998). The relation between morbidity and cognitive performance in a normal aging population. J Gerontol A Biol Sci Med Sci, 53(2), M147-154.

Van Boxtel, M. P., Gaillard, C., Van Es, P. N., Jolles, J., \& De Leeuw, P. W. (1996). Repeated automatic versus ambulatory blood pressure measurement: the effects of age and sex in a normal ageing population. J Hypertens, 14(1), 31-40.

Van der Elst, W., Van Boxtel, M. P., Van Breukelen, G. J., \& Jolles, J. (2005). Rey's verbal learning test: normative data for 1855 healthy participants aged 24-81 years and the influence of age, sex, education, and mode of presentation. J Int Neuropsychol Soc, 11(3), 290-302. 
Van der Elst, W., Van Boxtel, M. P., Van Breukelen, G. J., \& Jolles, J. (2006a). The Letter Digit Substitution Test: normative data for 1,858 healthy participants aged 24-81 from the Maastricht Aging Study (MAAS): influence of age, education, and sex. J Clin Exp Neuropsychol, 28(6), 998-1009.

Van der Elst, W., Van Boxtel, M. P., Van Breukelen, G. J., \& Jolles, J. (2006b). The Stroop color-word test: influence of age, sex, and education; and normative data for a large sample across the adult age range. Assessment, 13(1), 62-79.

Vermeer, S. E., Prins, N. D., den Heijer, T., Hofman, A., Koudstaal, P. J., \& Breteler, M. M. (2003). Silent brain infarcts and the risk of dementia and cognitive decline. N Engl J Med, 348(13), 1215-1222.

Waldie, K. E., Hausmann, M., Milne, B. J., \& Poulton, R. (2002). Migraine and cognitive function: a life-course study. Neurology, 59(6), 904-908.

WHO. (1993). 1993 guidelines for the management of mild hypertension: memorandum from a World Health Organization/International Society of Hypertension meeting. Guidelines Sub-Committee. J Hypertens, 11(9), 905-918.

Zeger, S. L., \& Liang, K. Y. (1986). Longitudinal data analysis for discrete and continuous outcomes. Biometrics, 42(1), 121-130. 



\section{6}

Obesity, blood pressure and cognitive function: a reply to Waldstein and Katzel 
With great interest we read the paper of Waldstein and Katzel in this journal (Waldstein \& Katzel, 2006). In a comprehensive cross-sectional study in 90 healthy older persons these authors investigated potential relationships between vascular risk factors and cognitive performance. Higher waist circumference and blood pressure (BP) showed both main and multiplicative effects on several performance tests, including manual dexterity (Grooved Pegboard) and response inhibition (Stroop Colour-Word test). As pointed out by the authors, these results add to those of several earlier studies that gave support to the role of a vascular mechanism in age-related cognitive deficits. While the bulk of this literature is based on studies in persons with overt vascular conditions, the authors carefully removed individuals with vascular disease, such as diabetes, which make their findings particularly noteworthy, due to their potential clinical implications.

Based on our own data, we found in an earlier age-stratified study in 936 healthy persons aged between 24 and 81 years no main effects of BP on several domains of neuropsychological performance, including verbal memory and cognitive flexibility (Van Boxtel et al., 1997). Furthermore, a measure of central obesity, expressed as waist-to-hip ratio (Despres et al., 1990) also showed no main effect after appropriate correction for demographic influences. Thus, the strength of the associations reported by Waldstein et al., notwithstanding the relatively small number of participants in their study, called for a reappraisal of our own data from the Maastricht Aging Study (MAAS) on this topic.

MAAS is a longitudinal study into the determinants of usual and successful cognitive ageing in an age-stratified population based sample of 1,823 individuals (for a review of the design and methods, see (Jolles et al., 1995; Van Boxtel et al., 1998)). At baseline participants were free of clinically overt pathology related to the central nervous system. Data for this analysis were collected at the 3-year follow-up assessment in 838 persons aged 50 years or older. This group was restricted further with the exclusion criteria used by Waldstein et al., i.e. age range between 54 and 81 years $(n=729)$, history of cardiovascular disease $(n=95)$, diabetes mellitus $(n=74)$, stroke, dementia diagnosis or an MMSEscore (Folstein et al., 1975) of $<24(n=26)$, heavy alcohol use $(n=91)$, evidence of previous head injury $(n=17)$, or psychotropic drug use $(n=30)$, based on self-report data available from the MAAS questionnaire. Overall, 488 participants provided data for the analysis. All were of Caucasian origin. Table 1 presents the characteristics of this group. Core variables in MAAS are highly comparable, or even identical, to the Waldstein et al. study. Blood pressure was measured three times in seated position using a Dinamap 8100 automatic monitor (Critikon, Tampa FL, USA) (Van Boxtel et al., 1996). Waist circumference (WC) was measured at the minimal abdominal circumference and body mass index (BMI) was derived by dividing body weight $(\mathrm{kg})$ by length squared $\left(\mathrm{m}^{2}\right)$. Actual smoking status was assessed at baseline only. A neuropsychological evaluation was performed in the same session. In part based on the significance of findings made by Waldstein et al., we selected three representative tests from the extensive test battery, particularly to restrict type I error due to multiple testing. Verbal memory was tested with the Word Learning Task (WLT) in which 15 monosyllabic words are visually presented five times in a fixed order. The sum of recalled words over five trials was recorded as a measure of immediate recall (Van der Elst et al., 2005). Perceptuomotor speed and mental flexibility were measured with the Concept Shifting Test, which is 
conceptually identical to the Trail Making Test parts A and B from the WAIS used by Waldstein et al., but with a different stimulus layout. Finally, the Stroop test measures response inhibition, which is part of the executive function domain (Van der Elst et al., 2006). The interference score was calculated by taking the difference between the time needed for colour word naming (III) minus the colour patch naming time (II) (Lezak, 2004). The resulting score provides an index that is conceptually identical to the Stroop interference score computed by Waldstein et al. (Van der Elst et al 2006), who measured performance in number of items named rather than time, and who used Golden's criteria for calculating interference. Mood was measured by using the anxiety and depression subscales of the Hopkins Symptom Check List, or SCL (Arrindell \& Ettema, 2003). Education was measured according to a Dutch scoring system, ranging from 1 (primary education) to 8 (academic degree). No blood chemistry analysis or physical performance tests were done in this group and participants were not taken of their antihypertensive medication when a diagnosis of hypertension had been made in the past.

Thus, we tried to replicate the findings of the Waldstein study in a substantially larger population of comparable demographical and medical makeup. Mean values of obesity indicators BMI and WC were comparable in both studies (BMI 27.5 vs. 27.4 $\mathrm{kg} / \mathrm{m}^{2}$ and WC 91.4 vs. $91.8 \mathrm{~cm}$, in the Waldstein sample and MAAS, respectively; see Table 1). However, we found no evidence for main effects of BP, WC or BMI on the cognitive variables studied (Table 2). In addition, no interactions between BP and obesity indicator on test performance could be identified. Although the dataset was more restricted due to additional exclusion criteria and the data were taken from the follow-up measurement these results confirm what we found earlier in a study on MAAS data with a wider age range (24-81 years) (Van Boxtel et al., 1997).

Table 1 Characteristics of the study group $(\mathrm{N}=488)$

\begin{tabular}{lll}
\hline Characteristics & M (SD) or \% & Range \\
Age & $65.8(7.9)$ & $54-80$ \\
Education & $3.1(1.7)$ & $1-8$ \\
Gender (\% male) & 46.7 & \\
Alcohol consumption & $2.6(3.4)$ & $0-14$ \\
Smokers actual (\%) a & 21.3 & \\
SCL 90 depression score & $21.8(6.8)$ & $16-56$ \\
SCL 90 anxiety score & $13.0(4.5)$ & $10-39$ \\
Systolic blood pressure & $141.4(16.6)$ & $103-224$ \\
Diastolic blood pressure & $77.8(10.1)$ & $46-109$ \\
Diagnosed hypertension & 27.3 & \\
Waist Circumference (WC) & $91.8(11.1)$ & $58-124$ \\
Body Mass Index (BMI) & $27.4(4.2)$ & $14.9-46.3$ \\
\hline${ }^{a}$ Based on baseline assessment three years earlier & \\
${ }^{\mathrm{b}} n=104$ of $n=133$ diagnosed with hypertension were on antihypertensive medication
\end{tabular}

Although a comparable approach was used in terms of participant selection and neuropsychological and statistical methodology there are some differences between Waldstein's study and our own data. First, the proportion of males was balanced and therefore smaller in the current study (47 vs. 63\%). Earlier findings in the Framingham cohort indicated that obesity was a risk factor for lower cognitive performance in men, 
but not in women (Elias et al., 2003, 2005). Vascular risk factors may act less strongly on target organs in women, most likely due to hormonal causes (Rossouw, 2002). However, a sex-stratified re-analysis of our data did not point towards different results in men and women. Second, no test of manual dexterity was available in MAAS comparable to the Grooved Pegboard test in the Waldstein study, so we could not replicate their (positive) findings on this particular task. Third, at least thirteen cognitive outcome measures were tested by Waldstein et al., while we deliberately kept the number of variables down to four. Indeed, the choice of our cognitive measures was in part driven by the significance of results of Waldstein et al. who made no specific predictions regarding the kind of cognitive effects that were to be expected. We considered the identification of spurious relationships between $\mathrm{BP}$, obesity parameters and other cognitive variables contained in the MAAS database of no true relevance for the purpose of the current study. Fourth, due to the observational nature of MAAS and for ethical reasons, antihypertensive medication was not stopped prior to the test session, as was done in 17 out of 90 participants $(18.8 \%)$ in the Waldstein et al. study. This may have reduced the BP variability in our sample and potentially obscured the relationships between BP and the outcome measures under study. However, mean BP values in MAAS were even higher (141.4 vs. $132.1 \mathrm{mmHg}$ and 77.8 vs. $74.9 \mathrm{mmHg}$, for systolic and diastolic BP in the MAAS and the Waldstein et al. study, respectively). Statistical control for antihypertensive medication use did not change the pattern of observed effects (results not shown). We therefore do not expect that this study difference significantly affected our results. Fifth, all participants in MAAS were of the Caucasian race, while 7 percent in the other study was not. It may be of interest to verify if these persons were 'influential cases' in the Waldstein study, as ethnicity may affect the vascular risk profile (Brown, 2006). Finally, the proportion 'current smokers' was much larger in MAAS than in the other sample (21.3 vs. $2 \%$ ), which may be due to cultural factors or measurement inaccuracy (MAAS smoking status was taken from baseline assessment).

In conclusion, the associations found by Waldstein et al. between vascular variables BP and obesity on the one hand and cognitive function on the other were not convincingly replicated in the much larger dataset of MAAS. The result of the current study therefore attenuates the clinical implication of the Waldstein et al. findings, as the vascular mechanism of cognitive dysfunction appears to be less robust in healthy older persons than was suggested in their concluding remarks. 


\section{References}

Arrindell, W. A., \& Ettema, J. H. M. (2003). SCL-90. Handleiding bij een multidimensionele psychopathologie indicator [SCL-90. Manual of a multidimensional indicator of psychopathology]. Lisse, The Netherlands: Swets Test Publishers.

Brown, M. J. (2006). Hypertension and ethnic group. Bmj, 332(7545), 833-836.

Despres, J. P., Moorjani, S., Lupien, P. J., Tremblay, A., Nadeau, A., \& Bouchard, C. (1990). Regional distribution of body fat, plasma lipoproteins, and cardiovascular disease. Arteriosclerosis, 10(4), 497-511.

Elias, M. F., Elias, P. K., Sullivan, L. M., Wolf, P. A., \& D'Agostino, R. B. (2003). Lower cognitive function in the presence of obesity and hypertension: the Framingham heart study. Int J Obes Relat Metab Disord, $27(2), 260-268$.

Elias, M. F., Elias, P. K., Sullivan, L. M., Wolf, P. A., \& D’Agostino, R. B. (2005). Obesity, diabetes and cognitive deficit: The Framingham Heart Study. Neurobiol Aging, 26 Suppl 1, 11-16.

Folstein, M. F., Folstein, S. E., \& McHugh, P. R. (1975). "Mini Mental State”. Journal of Psychiatric Research, 12, 189-198.

Jolles, J., Houx, P. J., van Boxtel, M. P. J., \& Ponds, R. W. H. M. (Eds.). (1995). Maastricht Aging Study: Determinants of cognitive aging. Maastricht: Neuropsych Publishers.

Lezak, M. D. (2004). Neuropsychological Assessment (4th ed.). New York: Oxford University Press.

Rossouw, J. E. (2002). Hormones, genetic factors, and gender differences in cardiovascular disease. Cardiovasc Res, 53(3), 550-557.

Van Boxtel, M. P. J., Buntinx, F., Houx, P. J., Metsemakers, J. F. M., Knottnerus, J. A., \& Jolles, J. (1998). The relation between morbidity and cognitive performance in a normal aging population. Journal of Gerontology, 53A(2), M146-M154.

Van Boxtel, M. P. J., Gaillard, C., Houx, P. J., Buntinx, F., de Leeuw, P. W., \& Jolles, J. (1997). Can the blood pressure predict cognitive task performance in a healthy population sample? Journal of Hypertension, 15(10), 1069-1079.

Van Boxtel, M. P. J., Gaillard, C., van Es, P. N., Jolles, J., \& de Leeuw, P. W. (1996). Repeated automatic versus ambulatory blood pressure measurement: The effects of age and sex in a normal ageing population. Journal of Hypertension, 14(1), 31-40.

Van der Elst, W., van Boxtel, M. P., van Breukelen, G. J., \& Jolles, J. (2005). Rey's verbal learning test: normative data for 1855 healthy participants aged 24-81 years and the influence of age, sex, education, and mode of presentation. J Int Neuropsychol Soc, 11(3), 290-302.

Van der Elst, W., Van Boxtel, M. P., Van Breukelen, G. J., \& Jolles, J. (2006). The stroop color-word test: influence of age, sex, and education; and normative data for a large sample across the adult age range. Assessment, 13(1), 62-79.

Van der Elst, W., van Boxtel, M. P. J., van Breukelen, G., \& Jolles, J. (2006). The Concept Shifting Test: Adult normative data. Psychological Assessment.

Waldstein, S. R., \& Katzel, L. I. (2006). Interactive relations of central versus total obesity and blood pressure to cognitive function. Int J Obes (Lond), 30(1), 201-207. 


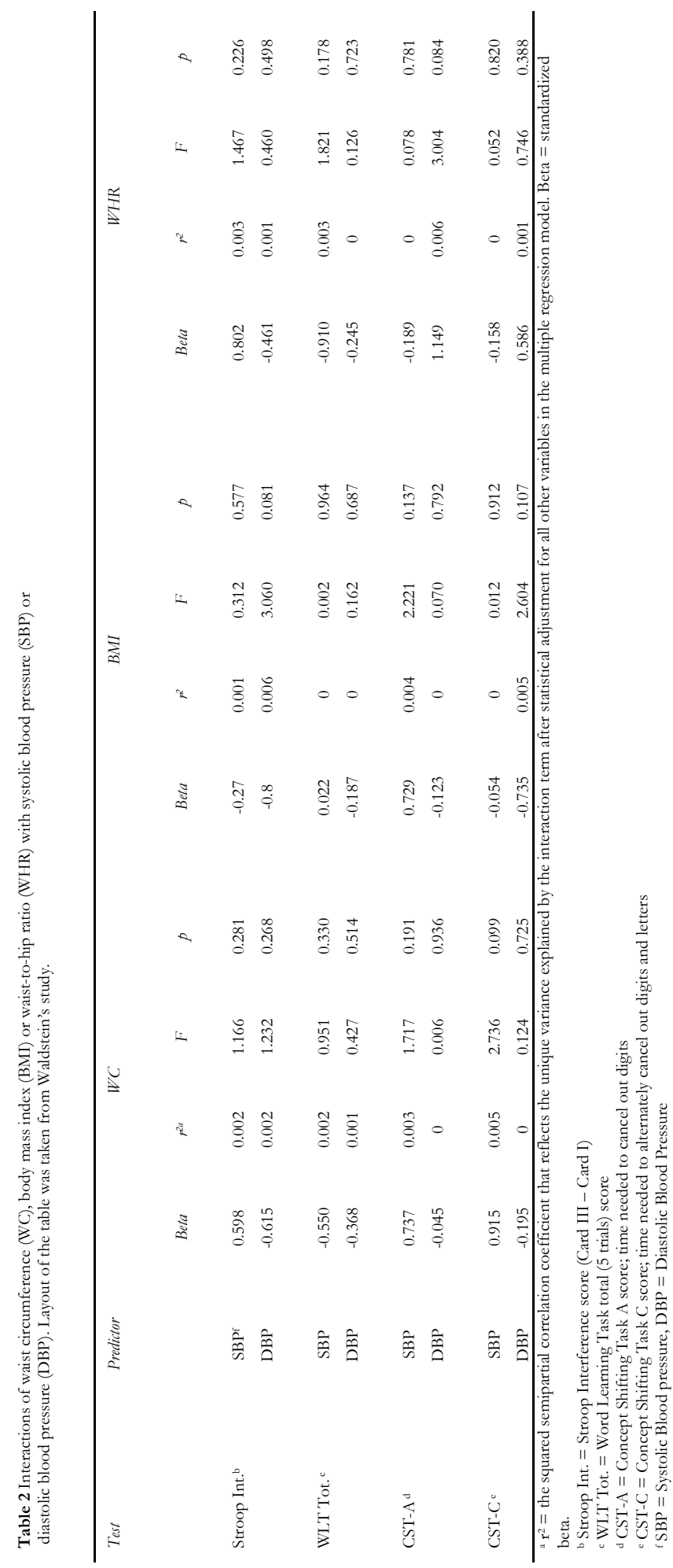


Effects of hypertension on cognitive decline: mediation by exposure duration, antihypertensive treatment and APOE-e4 genotype, but not by diabetes 


\begin{abstract}
The aim of this study was to investigate the effects of hypertension and diabetes on cognitive decline over a 12-year episode, in a normal aging population. A total of 1,823 healthy participants in the Maastricht Aging Study completed baseline assessment between 1993 and 1995. Twelve-year follow-up results at three different time points with a six-year interval were available for three out of four panels of the baseline group $(n=903)$. Neuropsychological assessment was performed in three cognitive domains: verbal memory (delayed recall), psychomotor speed (letter-digit copying) and executive functioning (set shifting). Participants with evidence of exposure to high blood pressure for at least six years showed a larger cognitive decline on all three cognitive measures, compared to participants without hypertension or who had high blood pressure on only one occasion. Diabetes was negatively associated with cognitive performance at baseline; however, effects of diabetes on cognitive decline were not mediated by exposure time. Presence of at least one Apolipoprotein E-e4 (APOE-e4) allele increased the effect of hypertension on the three cognitive measures for individuals with hypertension and at least six exposure years. Effects of APOE-e4 genotype and exposure were only present in individuals with untreated hypertension.

Effects of hypertension on cognitive decline are mediated by exposure duration, anti-hypertensive treatment, and APOE-e4 genotype. Effects of type-2 diabetes on cognitive decline are not mediated by exposure-time.
\end{abstract}




\section{Introduction}

Presence of vascular risk factors and the emergence of cognitive decline are both common in older people. A deterioration of cognitive functions may be the first sign of dementia. It is therefore important to identify vascular risk factors for cognitive decline and to treat vascular symptoms in order to minimize effects on cognition. Atherosclerosis, which is associated with long-standing elevated blood pressure, has been proposed as one of the central mechanisms behind the cognitive decline in old age (Arnett et al., 2000; Birkenhager et al., 2001). Imaging studies have shown that vascular risk factors cause structural and functional changes in the brain. For example, type- 2 diabetes has been associated with cortical atrophy and vascular lesions in Magnetic Resonance Imaging (MRI) studies (Manschot et al., 2007; Schmidt et al., 2004) and hypertension was associated with increased presence and severity of white matter lesions in a large population based study (X. Guo et al., 2009).

Cross-sectional studies investigating the association between hypertension and cognitive decline or dementia have reported inconsistent findings. Negative associations between hypertension and cognitive functioning have been reported, especially in middle-aged individuals (Cerhan et al., 1998; M. F. Elias et al., 2003). However, some studies report no association between hypertension and cognitive performance (Di Carlo et al., 2000; Z. Guo et al., 1999; Van Boxtel et al., 1997). In very old individuals (aged 75 years or older) low blood-pressure even seems to be a risk factor for low cognitive performance, which may indicate that a certain level of blood-pressure is necessary, especially at old age, to maintain cognitive performance (Moretti et al., 2008; Qiu et al., 2005). Ushaped relations between hypertension and cognition have been reported as well, indicating that both high and low blood pressure may be associated with reduced cognitive performance (Morris et al., 2002; Waldstein et al., 2005).

Longitudinal studies into the effects of midlife hypertension on cognition in later life, generally reported an increased risk for cognitive decline and dementia for persons with hypertension (P. K. Elias et al., 2004; Kivipelto et al., 2001; Launer et al., 1995). Exposure duration differs greatly between longitudinal studies, with some reporting four years of follow-up (M. F. Elias et al., 2003) while others report follow-up periods of over twenty years (P. K. Elias et al., 2004; D. S. Knopman et al., 2009). Effects of hypertension appear to increase with longer exposure-time, and therefore, differences in results are to be expected when follow-up periods vary (Qiu et al., 2005). In addition, influential covariates may cause differences in results, since not all studies control for these factors. Stroke was often included as a covariate (M. F. Elias et al., 1993; Launer et al., 2000), but in some studies other possibly influential covariates such as Body Mass Index (BMI), smoking, alcohol use and Apolipoprotein E4 (APOE-e4) genotype were not included (Kilander et al., 2000; Swan et al., 1998). A higher BMI, smoking and excessive alcohol use, have been associated with an increased risk of hypertension (Beilin, 1999; Morris et al., 2002). The diverse findings in the reported studies may in part be explained by the covariates that were or were not included. The interaction between APOE genotype and hypertension in their effect on cognition is not clear yet. Some studies report no interaction (Kivipelto et al., 2002), while others have reported addi- 
tional negative effects of hypertension on cognitive function for APOE-e4 carriers (Anstey \& Christensen, 2000; Peila et al., 2001). Antihypertensive treatment in patients with hypertension was shown to reduce dementia risk (Birkenhager et al., 2001; Forette et al., 2002). It is therefore important to take antihypertensive use into account as a potentially important covariate.

The negative association between type- 2 diabetes (or non-insulin-dependent diabetes mellitus, NIDDM) and cognitive functioning is less equivocal, with consistent findings in both cross-sectional (Van Boxtel et al., 1998; Van Harten et al., 2007) and longitudinal studies (D. Knopman et al., 2001; W. Xu et al., 2008). NIDDM causes persons to show worse cognitive performance and increased cognitive decline over time, especially on measures of speed and executive functioning (Van den Berg et al., 2006) and has been found to increase the risk for dementia (Luchsinger et al., 2005; Peila et al., 2002). Oxidative stress, protein glycosilation and ischemia are consequences of NIDDM that may explain the association with cognitive decline and dementia (Biessels, 1999).

Vascular symptoms often coexist and associations between hypertension and NIDDM have been reported in previous studies (Feskens et al., 1995; Luchsinger et al., 2005). The combination of both symptoms has been found to result in an additive effect on the risk for dementia (Whitmer et al., 2005) or in a synergistic effect (Peila et al., 2002; W. L. Xu et al., 2004). These studies all included the combination of both symptoms without investigating their modulating effect on cognitive performance over time. Identifying this modulating effect is the focus of the current study.

The combination of multiple blood pressure measurements with multiple cognitive assessments over time in a large age cohort is crucial to study the cumulative effects of exposure to hypertension on cognitive development over time. The present study used 12-year follow-up data to investigate effects of blood pressure, measured under highly standardized conditions, on cognitive change over time, and the interaction between hypertension and the aforementioned covariates, in a large sample of healthy adult persons. Both blood pressure measures and cognitive tests were taken at six-year intervals. The inclusion of young as well as middle-aged and old individuals could possibly clarify the contradicting results found in previous studies. We may identify a U-shaped distribution, or a linear relation between hypertension, age and cognition, all in one sample. Effects of exposure to NIDDM on cognitive change were tested as well, and so was the interaction between hypertension and NIDDM. Interaction between hypertension exposure and the APOE-e4 genotype were also studied. Previous studies did not agree in their findings on interaction between hypertension and APOE genotype. Effects may depend on hypertension exposure duration. We hypothesized that long-term exposure to hypertension leads to an increased cognitive decline over time. This effect was expected to be enhanced by the presence of a diagnosis of NIDDM or the APOE-e4 genotype. 


\section{Method}

\section{Sample}

This study was performed as part of the Maastricht Aging Study (MAAS), a longitudinal study into the determinants of cognitive aging (Jolles et al., 1995). A total of 10,396 potential participants, drawn from a patients register of collaborating general practitioners (GPs) in the south of the Netherlands (RNH) (Metsemakers et al., 1992) were approached for participating with a prepaid postcard. Of this group, 4,490 agreed to participate $(43.2 \%), 3,531$ refused participation (34\%) and 2,375 did not return the postcard $(22.8 \%)$.

Health problems in the RNH database were recorded according to the International Classification of Primary Care (Lamberts \& Wood, 1987). Participants were excluded from baseline participation when medical conditions were present, that could interfere with cognitive functioning, including coma, all tumors of the nervous system, congenital malformation of the nervous system, history of stroke, parkinsonism, multiple sclerosis, dementia, schizophrenia, (affective) psychosis or mental retardation. All 4,490 eligible participants were additionally screened by telephone for relevant medical conditions that were not documented in the RNH database (history of TIA, brain surgery, haemodialysis for renal failure, electroconvulsive therapy, or daily use of psychotropic drugs). In total, 301 potential participants were excluded from participation based on this interview. Of the remaining 4,189 participants, 1,823 were randomly selected in 12 equally sized age categories $(25+/-1$ years, $30+/-1$ years . . $80+/-1$ years), stratified for sex and level of general ability (high/low). The participants were equally distributed over four demographically identical test panels. After the baseline measurement, 1,823 participants, aged 24 to 81 years at baseline, were admitted to the longitudinal part of the study. Participants were invited for follow-up assessments at six and twelve years after the baseline measurement. For the current study, the first three panel studies of MAAS $(n=1,455)$ were included who completed the full 12-year follow-up period when this study was conducted. A total of 1,030 (71\%) and 903 (62\%) participants of the original sample available at baseline were tested at these respective time points.

\section{Assessment of cognitive function}

In the current study we used a selection of the available cognitive measures in the MAAS, including measures for memory performance, speed and executive functioning. The visual Verbal Learning Test (Van der Elst et al., 2005) was used to test episodic memory. Fifteen monosyllabic, non-related words were presented on a computer screen, followed by a free recall phase. This procedure was repeated five times. After twenty minutes delayed free recall was tested. The Concept Shifting Test (CST) measures executive functioning, and is comparable to the Trail Making Test (Lezak et al., 2004). The shifting score on this task was calculated by subtracting the average time needed for version A (digits) and B (letters) from the total time needed for version C (letters and digits). This procedure separates time needed for complex shifting from time needed for simple reading and counting (Van der Elst et al., 2006b). To make the screening of cognitive domains as complete as possible, a measure of general information processing 
speed, the Letter Digit Substitution Test (Van der Elst et al., 2006a) was included, which is based on the Digit Symbol Substitution Test (Wechsler, 1955).

\section{High blood pressure and diabetes}

Automated blood-pressure measurements using an oscillometric procedure were performed on each test occasion three times at fixed 5-minute intervals on the left upper arm, using a Crikiton Dinamap ${ }^{\circledR} 8100$ automatic blood pressure monitor (Critikon, Tampa, Florida, USA). The mean systolic blood pressure (SBP) and diastolic blood pressure (DBP) were calculated per session. Hypertension was defined as either a mean SBP of $140 \mathrm{mmHg}$ or higher, a mean DBP of $90 \mathrm{mmHg}$ or higher (WHO, 1999), or the actual use of antihypertensive medication, as reported in a questionnaire that was administered as part of each assessment. Classification of blood pressure status was based on the number of occasions a participant was found to have high blood pressure. This resulted in three groups: no hypertension, hypertension once, or on at least two occasions. A classification of non-insulin dependent diabetes mellitus (NIDDM) was made based on self-report (participants who reported a diagnosis of NIDDM made by a physician) and current medication use for NIDDM, again reported in the MAAS questionnaire.

\section{Covariates}

To test effects of high blood pressure and NIDDM on cognitive function, potentially relevant health-related covariates were taken into account. Body mass index (BMI) (weight in $\mathrm{kg} /(\text { length in } \mathrm{m})^{2}$ ), a history of cardiovascular disease, current smoking, alcohol intake (in standard units per week) and Apolipoprotein E4 (APOE-e4) status were controlled for. APOE genotyping was determined on genomic DNA extracted from EDTA-anticoagulated blood using the polymerase chain reaction (PCR) technique (Bekers et al., 2002). Age, education level (ranging from primary education (1) to university degree (8)) (De Bie, 1987) and sex were included as demographic covariates.

\section{Statistical analysis}

Cross-sectional and longitudinal effects of high BP and NIDDM on cognitive performance were tested using Linear Mixed Models (Snijders \& Bosker, 1999). This procedure accounts for correlation between repeated measurements. Moreover, missing data may depend on the observed covariates and response (Missing At Random). The model is robust against selective attrition related to the covariates (e.g. NIDDM diagnosis). The final model included fixed terms for intercept (baseline performance for an individual with a value of zero on all covariates), age, age ${ }^{2}$ (in order to control for nonlinear trends in the longitudinal data), time (in years since baseline), sex $(0=$ male, $1=$ female), education (level 1-8 as described above), hypertension on one occasion, hypertension on at least 2 occasions, NIDDM at baseline, and BMI. Interaction terms between hypertension and time, between NIDDM and time and between hypertension and NIDDM were included, since negative effects of hypertension or NIDDM on cognition were expected to depend on exposure duration and effects of hypertension were expected to be larger for NIDDM cases. Because serial correlation was likely to be present between the re- 
peated measurements, an unstructured covariance structure for the responses was used. P-values of 0.05 or smaller were considered statistically significant.

\section{Results}

Baseline characteristics are shown in Table 1 and indicate that participants with hypertension were older, more often male and had higher average BMI than participants without high blood pressure. Individuals with hypertension were also more often diagnosed with NIDDM or cardiovascular disease, and being normotensive was associated with smoking and higher alcohol consumption. The characteristics were comparable for participants with high blood pressure at one or at more occasions. The presence of at least on APOE-e4 allele was more often found in participants with consistent hypertension compared to both other BP groups.

Table 1 Baseline characteristics of all participants, according to hypertension status. Figures indicate means (SD), or percentages where appropriate.

\begin{tabular}{llll}
\hline & No hypertension & Hypertension 1x & Hypertension 2x or 3x \\
$\mathrm{N}$ & 646 & 392 & 374 \\
Age (years) & $42.7(14.3)$ & $60.9(15.1)$ & $59.3(12.3)$ \\
Education level & $3.9(1.8)$ & $3.2(1.9)$ & $3.13(1.7)$ \\
Sex (\% Male) & 46.7 & 54.6 & 53.7 \\
BMI & $25.4(4.2)$ & $27.8(4.1)$ & $27.8(4.1)$ \\
Smoking (\%) & 36.1 & 21.9 & 23.5 \\
$\begin{array}{l}\text { Alcohol intake (units / } \\
\text { week) }\end{array}$ & $13.6(5)$ & $12.6(5.9)$ & $12.9(5.8)$ \\
$\begin{array}{l}\text { Cardiovascular disease } \\
(\%)\end{array}$ & 3.8 & 21.7 & 17.1 \\
$\begin{array}{l}\text { APOE-e4 allele present } \\
(\%)\end{array}$ & 27 & 31 & 32 \\
Type-2 diabetes (\%) & 2.1 & 6.6 & 5.3 \\
\hline Note. The APOE genotype was available for 307, 160 and 245 participants in the three groups, respectively.
\end{tabular}

The Linear Mixed Models (LMM) analysis showed that hypertension had no crosssectional association with any of the cognitive measures included. Persons with NIDDM showed lower cognitive performance on all measures, at baseline.

In the final longitudinal model, summarized in Table 2 and Figures 1-3, only BMI and APOE-e4 were included as covariates (in addition to age, age ${ }^{2}$, education and sex) since other covariates (cardiovascular disease, smoking, alcohol consumption) did not explain unique variance in either the cross-sectional or the longitudinal analysis with LMM. In the final model, participants with hypertension showed more decline over time on delayed recall performance, psychomotor speed and set shifting, compared to controls. 
Table 2 Longitudinal effects of hypertension, diabetes and covariates on cognitive performance

\begin{tabular}{lccc}
\hline & Delayed word recall & Psychomotor speed & Set shifting \\
Intercept & $7.33^{* *}$ & & $16.7^{* *}$ \\
Time & $0.10^{* *}$ & $41.9^{* *}$ & $0.24^{* *}$ \\
Age & $-0.08^{* *}$ & 0.01 & $-0.27^{* *}$ \\
Age & $-0.001^{* *}$ & $-0.44^{* *}$ & $-0.01^{* *}$ \\
Education $^{* *}$ & $-0.01^{* *}$ & $1.5^{* *}$ \\
Sex & $0.31^{* *}$ & $1.83^{* *}$ & $-1.16^{*}$ \\
BMI & $1.27^{* *}$ & $1.47^{* *}$ & 0.07 \\
APOE-e4 & -0.007 & 0.02 & -0.25 \\
BP high 1 & -0.08 & $-0.74^{*}$ & $1.8^{*}$ \\
BP high 2/3 & 0.09 & 0.87 & $2.0^{*}$ \\
NIDDM & 0.24 & 0.96 & -2.5 \\
BP high 1 x Time & -0.50 & $-3.14^{* *}$ & $-0.27^{*}$ \\
BP high 2/3 x Time & $-0.05^{*}$ & $-0.17^{*}$ & $-0.37^{* *}$ \\
NIDDM x Time & $-0.07^{* *}$ & $-0.32^{* *}$ & -0.46 \\
\hline Note. Intercept value & -0.02 & -0.25 & . \\
\hline
\end{tabular}

Note. Intercept value is baseline score for an individual with score zero on all predictors, time is years since baseline, age is age at baseline, centered around the group mean. For all measures higher scores indicate better performance (for set shifting the inversed B-estimates are given). BMI=Body Mass Index, BP=blood pressure, NIDDM=Non-insulin-dependent Diabetes Mellitus.

${ }^{*} \mathrm{p}<0.05,{ }^{*} \mathrm{p}<0.01$.

Hypertension on one occasion caused performance on memory to decline three times as much over 12 years, compared to performance in individuals without hypertension. For processing speed and set shifting similar results were found. Participants with hypertension on at least two test occasions showed more cognitive decline over time compared to participants with hypertension on only one test occasion (estimates of respectively 0.07 and -0.05 for the delayed recall measure). For memory performance the extra decline over twelve years for participants with hypertension on at least two test occasions was forty percent. This percentage was about the same for set shifting, but for psychomotor speed the extra decline was 92 percent (Table 2 and Figures 1-3). The negative effect of NIDDM on cognitive performance did not vary over time (Table 2). A separate LMM analysis showed, that no interaction effects between NIDDM, hypertension and time were found, indicating that NIDDM did not increase the accelerated decline found in participants with continuous hypertension. BMI did not influence the effect of hypertension on cognitive change over time either, when interaction as tested in an LMM model. The presence of at least one APOE-e4 allele increased the 12-year cognitive decline found in participants with continuous hypertension. For memory performance the decline increased by ten percent compared to individuals who were APOE-e4 negative. For set shifting the extra decline was nine percent and for psychomotor speed eleven. 
Figure 1 Effect of hypertension exposure on delayed word recall over twelve years (standardized z-scores)

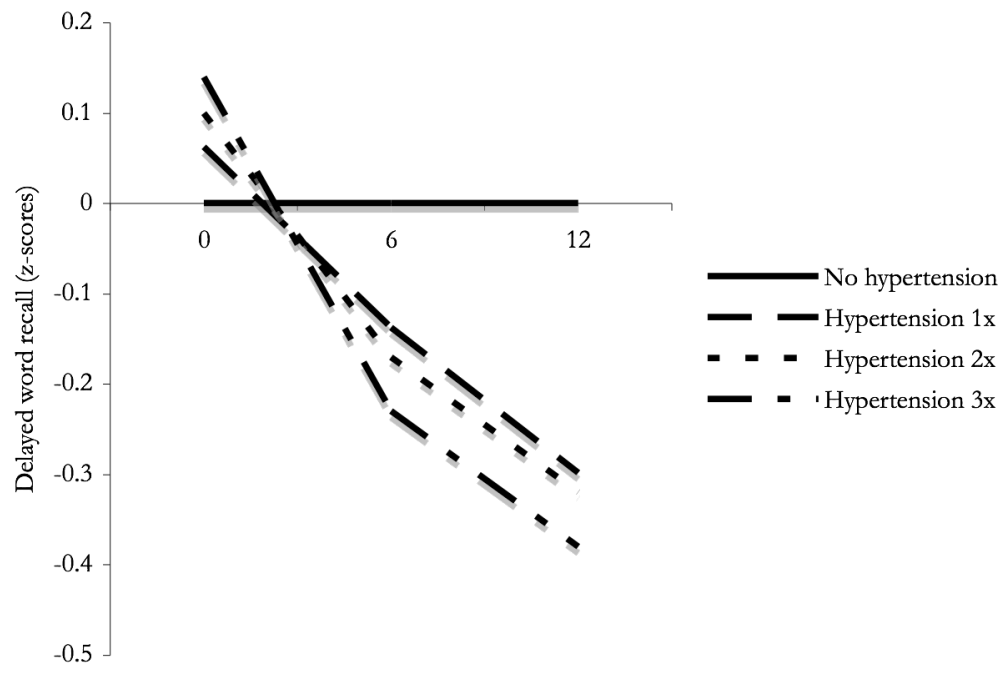

Time (years)

Note. The reference group mean z-score was set to zero.

Figure 2 Effect of hypertension exposure on psychomotor speed over twelve years (standardized z-scores)

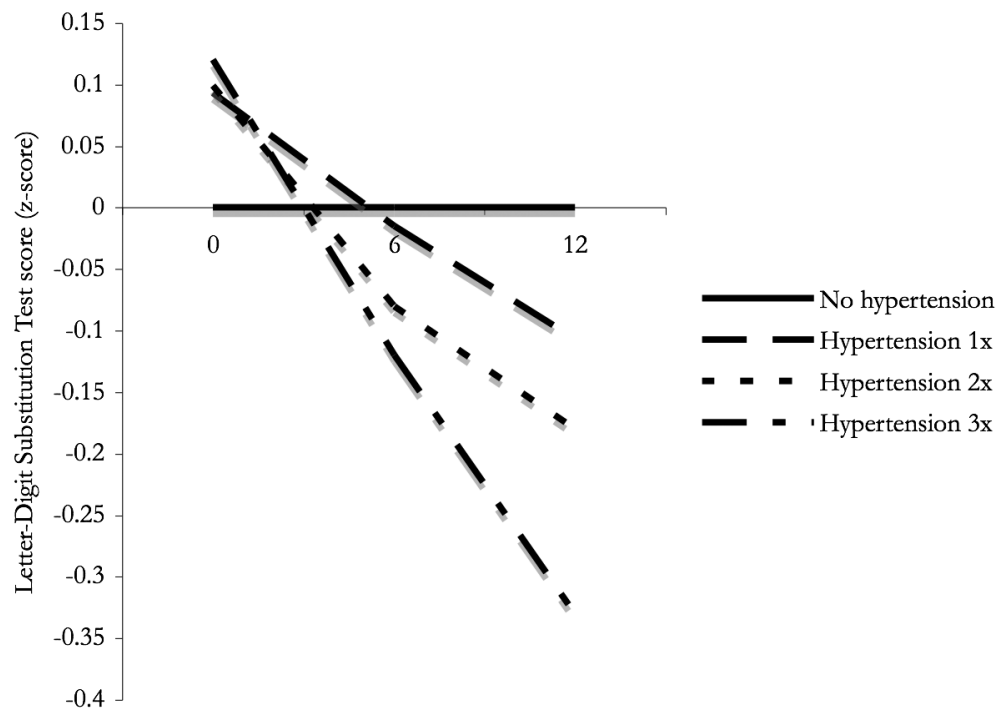

Time (years)

Note. The reference group mean z-score was set to zero. 
Figure 3 Effect of hypertension exposure on set shifting over twelve years (standardized z-scores)

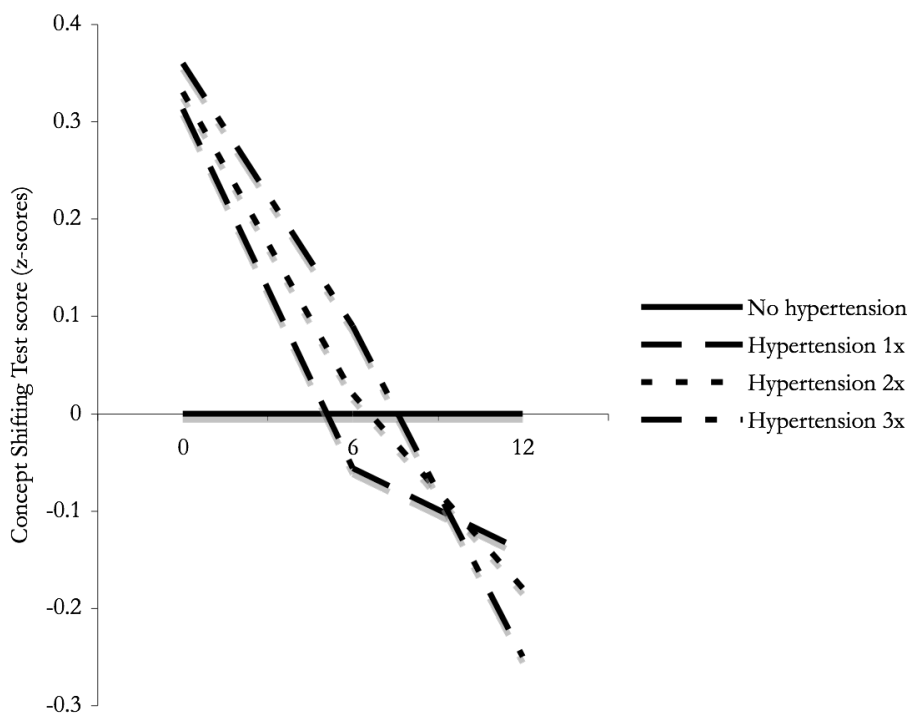

Time (years)

Note. The reference group mean z-score was set to zero. The estimates for the calculation of the z-scores for set shifting were inverted.

When the hypertension group was split up in those receiving hypertension treatment and those not receiving anti hypertensive medication, additional LMM analyses showed that the effects of exposure to hypertension on cognitive decline were only present in participants who were not on antihypertensive treatment. Remarkably, interaction effects between APOE-e4 genotype and hypertension were only found when all hypertension cases were included, so those with and those without anti-hypertensive treatment. All LMM analyses were repeated for the middle-aged and old participants separately (aged 40-65 years and 65-84 years, at baseline), to check for mediating effects of agecohort. The effects of hypertension on performance declined with increasing age, so the effects were smaller in older individuals (results not shown).

\section{Discussion}

We examined the effects of exposure to hypertension and NIDDM on cognitive performance. Prolonged exposure to hypertension resulted in more cognitive decline over time on all cognitive measures. Participants with hypertension on at least two occasions showed more decline in memory, speed and executive functioning over a 12-year episode than healthy controls or participants with hypertension at only one occasion. 
NIDDM diagnosis resulted in lower cognitive performance at baseline, but not in an increased decline over time. Presence of at least one APOE-e4 allele added to the negative effect of long-term hypertension exposure on cognition. The exposure effects were only present in participants who did not receive treatment for their hypertension.

Our finding that hypertension had a negative effect on cognitive performance over time is in line with findings from other longitudinal studies (P. K. Elias et al., 2004; Kivipelto et al., 2001). The effect on cognitive decline was strongest for participants who had been exposed to hypertension for at least six years. Effects of hypertension were more outspoken in middle-aged (40-65 years) participants and were smaller in the older age group (65-84 years), as was expected from previous studies, indicating negative associations most strongly in middle-aged individuals (Kivipelto et al., 2001) and reduced or even inverse associations in the oldest old (Tervo et al., 2004). This inverse relationship has been suggested to be caused by the fact that a certain level of bloodpressure is necessary to maintain cognitive performance in the oldest old ( $Z$. Guo et al., 1997).

The effects of hypertension were robust for participants who had not been treated with anti-hypertensive medication during the test period. Other studies have shown that treatment of hypertension may reduce cognitive decline and the risk for dementia. In these studies, participants who received treatment for their hypertension less often showed conversion to dementia, compared to hypertensives not on treatment (Hajjar et al., 2005; in't Veld et al., 2001). The relation between the APOE-e4 genotype and hypertension and cognition has been investigated in previous studies with inconclusive results. The APOE-e4 genotype was unfavorable for cognitive functioning in individuals with untreated hypertension in one earlier study (Kang et al., 2005), but another study reported no mediation of APOE genotype on effects of hypertension on the incidence of Mild Cognitive Impairment (MCI) (Reitz et al., 2007). The lack of exposure effect found for NIDDM, was also found in another study that was focused on accelerated cognitive decline over time (Van den Berg et al., 2006). However, other studies did find an association between NIDDM and increased cognitive decline over time (Gregg et al., 2000; Kumari \& Marmot, 2005). The relatively small number of participants with NIDDM, even in the continuous high blood pressure group $(n=20,5.3 \%)$ could in part explain the lack of exposure effect, due to lack of statistical power.

The strengths of our study are the long follow-up period, the large sample size and the inclusion of participants sampled from the full adult age range. Another advantage is, that we could include accurate and standardized measurements of both blood pressure and cognitive performance. Blood pressure measurements were performed automatically and three times at each time point of the study, to maximize reliability.

Some limitations need to be addressed as well. APOE genotyping was not available for all participants and availability depended on BP status. For the robust hypertension cases APOE genotype was more often known (66\%) than for normotensives and persons with high BP only once ( $48 \%$ and $41 \%$ respectively). The higher percentage of APOE-e4 genotypes in the hypertension group did not depend on the percentage of individuals for whom the APOE genotype was known. NIDDM diagnosis was based on self-report and actual medication use and not on a standardized medical diagnosis made 
as part of the study. Still, this diagnostic approach has been used in other studies investigating longitudinal effects of NIDDM on cognition that did find such an association (Gregg et al., 2000; W. Xu et al., 2008). .

Smoking and alcohol consumption were more prevalent in the non-hypertensive group. Both hypertensive groups (one occasion and continuous high $\mathrm{BP}$ ) showed the same prevalence of smoking and the same mean in alcohol consumption per week. A possible explanation for this finding may be that those individuals with hypertension are more aware of the risks smoking and drinking alcohol pose to their health, since these risks will have been pointed out to them by their doctors.

Since NIDDM was considered as a fixed diagnosis in the analysis, we included only baseline NIDDM diagnoses in the final model $(n=59)$ in order to maximize the possible effect of exposure. We did check effects for new NIDDM diagnoses at six or twelveyear follow-up. The total number of NIDDM cases increased to 78 when these cases were included. Results did not change from including these 19 extra cases in the model (as part of the fixed factor NIDDM diagnosis). Non-stable diabetes (being diagnosed with diabetes at baseline and not fitting this diagnosis anymore at follow-up) did occur in three percent of the baseline NIDDM cases, however, excluding these cases did not change the results either. The lack of exposure effect of NIDDM could therefore well be caused by a power limitation, which also goes for the lack of interaction effect between NIDDM and hypertension.

In conclusion, we found that long-term exposure to high blood pressure was associated with an increased cognitive decline (verbal memory, information-processing speed and executive functioning) in individuals who did not receive antihypertensive treatment. Cognitive decline is an important predisposing factor for dementia, and as hypertension can promote cognitive decline it may be considered a risk factor for dementia as well. Adequate prevention, and for those people already diagnosed with hypertension, timely treatment of hypertension, will reduce the effects of high blood pressure on agerelated cognitive decline. 


\section{References}

Anstey, K., \& Christensen, H. (2000). Education, activity, health, blood pressure and apolipoprotein E as predictors of cognitive change in old age: a review. Gerontology, 46(3), 163-177.

Arnett, D. K., Boland, L. L., Evans, G. W., Riley, W., Barnes, R., Tyroler, H. A., et al. (2000). Hypertension and arterial stiffness: the Atherosclerosis Risk in Communities Study. ARIC Investigators. Am J Hypertens, 13(4 Pt 1), 317-323.

Beilin, L. J. (1999). Lifestyle and hypertension--an overview. Clin Exp Hypertens, 21(5-6), 749-762.

Bekers, O., op den Buijsch, R. A., de Vries, J. E., Wijnen, P. A., \& van Dieijen-Visser, M. P. (2002). Capillary electrophoretic detection in apolipoprotein E genotyping. Electrophoresis, 23(12), 1878-1881.

Biessels, G. J. (1999). Cerebral complications of diabetes: clinical findings and pathogenetic mechanisms. Neth J Med, 54(2), 35-45.

Birkenhager, W. H., Forette, F., Seux, M. L., Wang, J. G., \& Staessen, J. A. (2001). Blood pressure, cognitive functions, and prevention of dementias in older patients with hypertension. Arch Intern Med, 161(2), 152156.

Cerhan, J. R., Folsom, A. R., Mortimer, J. A., Shahar, E., Knopman, D. S., McGovern, P. G., et al. (1998). Correlates of cognitive function in middle-aged adults. Atherosclerosis Risk in Communities (ARIC) Study Investigators. Gerontology, 44(2), 95-105.

De Bie, S. E. (1987). Standaardvragen 1987: Voorstellen voor uniformering van vraagstellingen naar acbtergrondkenmerken en interviews [Standard questions 1987: Proposal for uniformization of questions regarding background variables and interviews]. Leiden, The Netherlands: Leiden University Press.

Di Carlo, A., Baldereschi, M., Amaducci, L., Maggi, S., Grigoletto, F., Scarlato, G., et al. (2000). Cognitive impairment without dementia in older people: prevalence, vascular risk factors, impact on disability. The Italian Longitudinal Study on Aging. J Am Geriatr Soc, 48(7), 775-782.

Elias, M. F., Elias, P. K., Sullivan, L. M., Wolf, P. A., \& D’Agostino, R. B. (2003). Lower cognitive function in the presence of obesity and hypertension: the Framingham heart study. Int J Obes Relat Metab Disord, 27(2), 260-268.

Elias, M. F., Wolf, P. A., D’Agostino, R. B., Cobb, J., \& White, L. R. (1993). Untreated blood pressure level is inversely related to cognitive functioning: the Framingham Study. Am J Epidemiol, 138(6), 353-364.

Elias, P. K., Elias, M. F., Robbins, M. A., \& Budge, M. M. (2004). Blood pressure-related cognitive decline: does age make a difference? Hypertension, 44(5), 631-636.

Feskens, E. J., Tuomilehto, J., Stengard, J. H., Pekkanen, J., Nissinen, A., \& Kromhout, D. (1995). Hypertension and overweight associated with hyperinsulinaemia and glucose tolerance: a longitudinal study of the Finnish and Dutch cohorts of the Seven Countries Study. Diabetologia, 38(7), 839-847.

Forette, F., Seux, M. L., Staessen, J. A., Thijs, L., Babarskiene, M. R., Babeanu, S., et al. (2002). The prevention of dementia with antihypertensive treatment: new evidence from the Systolic Hypertension in Europe (Syst-Eur) study. Arch Intern Med, 162(18), 2046-2052.

Gregg, E. W., Yaffe, K., Cauley, J. A., Rolka, D. B., Blackwell, T. L., Narayan, K. M., et al. (2000). Is diabetes associated with cognitive impairment and cognitive decline among older women? Study of Osteoporotic Fractures Research Group. Arch Intern Med, 160(2), 174-180.

Guo, X., Pantoni, L., Simoni, M., Bengtsson, C., Bjorkelund, C., Lissner, L., et al. (2009). Blood Pressure Components and Changes in Relation to White Matter Lesions. A 32-Year Prospective Population Study. Hypertension.

Guo, Z., Fratiglioni, L., Winblad, B., \& Viitanen, M. (1997). Blood pressure and performance on the MiniMental State Examination in the very old. Cross-sectional and longitudinal data from the Kungsholmen Project. Am J Epidemiol, 145(12), 1106-1113.

Guo, Z., Fratiglioni, L., Zhu, L., Fastbom, J., Winblad, B., \& Viitanen, M. (1999). Occurrence and progression of dementia in a community population aged 75 years and older: relationship of antihypertensive medication use. Arch Neurol, 56(8), 991-996.

Hajjar, I., Catoe, H., Sixta, S., Boland, R., Johnson, D., Hirth, V., et al. (2005). Cross-sectional and longitudinal association between antihypertensive medications and cognitive impairment in an elderly population. $J$ Gerontol A Biol Sci Med Sci, 60(1), 67-73.

in't Veld, B. A., Ruitenberg, A., Hofman, A., Stricker, B. H., \& Breteler, M. M. (2001). Antihypertensive drugs and incidence of dementia: the Rotterdam Study. Neurobiol Aging, 22(3), 407-412. 
Jolles, J., Houx, P. J., van Boxtel, M. P. J., \& Ponds, R. W. H. M. (1995). Maastricht Aging Study: Determinants of cognitive aging. . Maastricht, The Netherlands: Neuropsych Publishers.

Kang, J. H., Logroscino, G., De Vivo, I., Hunter, D., \& Grodstein, F. (2005). Apolipoprotein E, cardiovascular disease and cognitive function in aging women. Neurobiol Aging, 26(4), 475-484.

Kilander, L., Nyman, H., Boberg, M., \& Lithell, H. (2000). The association between low diastolic blood pressure in middle age and cognitive function in old age. A population-based study. Age Ageing, 29(3), 243 248.

Kivipelto, M., Helkala, E. L., Hanninen, T., Laakso, M. P., Hallikainen, M., Alhainen, K., et al. (2001). Midlife vascular risk factors and late-life mild cognitive impairment: A population-based study. Neurology, 56(12), 1683-1689.

Kivipelto, M., Helkala, E. L., Laakso, M. P., Hanninen, T., Hallikainen, M., Alhainen, K., et al. (2002). Apolipoprotein E epsilon4 allele, elevated midlife total cholesterol level, and high midlife systolic blood pressure are independent risk factors for late-life Alzheimer disease. Ann Intern Med, 137(3), 149-155.

Knopman, D., Boland, L. L., Mosley, T., Howard, G., Liao, D., Szklo, M., et al. (2001). Cardiovascular risk factors and cognitive decline in middle-aged adults. Neurology, 56(1), 42-48.

Knopman, D. S., Mosley, T. H., Catellier, D. J., \& Coker, L. H. (2009). Fourteen-year longitudinal study of vascular risk factors, APOE genotype, and cognition: the ARIC MRI Study. Alzheimers Dement, 5(3), $207-$ 214.

Kumari, M., \& Marmot, M. (2005). Diabetes and cognitive function in a middle-aged cohort: findings from the Whitehall II study. Neurology, 65(10), 1597-1603.

Lamberts, H., \& Wood, M. (1987). ICPC: International Classification of Health Problems in Primary Care. Oxford: Oxford University Press.

Launer, L. J., Masaki, K., Petrovitch, H., Foley, D., \& Havlik, R. J. (1995). The association between midlife blood pressure levels and late-life cognitive function. The Honolulu-Asia Aging Study. Jama, 274(23), 1846-1851.

Launer, L. J., Ross, G. W., Petrovitch, H., Masaki, K., Foley, D., White, L. R., et al. (2000). Midlife blood pressure and dementia: the Honolulu-Asia aging study. Neurobiol Aging, 21(1), 49-55.

Lezak, M. D., Howieson, D. B., \& Loring, D. W. (2004). Neuropsychological Assessment. New York: Oxford University Press.

Luchsinger, J. A., Reitz, C., Honig, L. S., Tang, M. X., Shea, S., \& Mayeux, R. (2005). Aggregation of vascular risk factors and risk of incident Alzheimer disease. Neurology, 65(4), 545-551.

Manschot, S. M., Biessels, G. J., de Valk, H., Algra, A., Rutten, G. E., van der Grond, J., et al. (2007). Metabolic and vascular determinants of impaired cognitive performance and abnormalities on brain magnetic resonance imaging in patients with type 2 diabetes. Diabetologia, 50(11), 2388-2397.

Metsemakers, J. F., Hoppener, P., Knottnerus, J. A., Kocken, R. J., \& Limonard, C. B. (1992). Computerized health information in The Netherlands: a registration network of family practices. Br J Gen Pract, 42(356), 102-106.

Moretti, R., Torre, P., Antonello, R. M., Manganaro, D., Vilotti, C., \& Pizzolato, G. (2008). Risk factors for vascular dementia: hypotension as a key point. Vasc Health Risk Manag, 4(2), 395-402.

Morris, M. C., Scherr, P. A., Hebert, L. E., Bennett, D. A., Wilson, R. S., Glynn, R. J., et al. (2002). Association between blood pressure and cognitive function in a biracial community population of older persons. Neuroepidemiology, 21(3), 123-130.

Peila, R., Rodriguez, B. L., \& Launer, L. J. (2002). Type 2 diabetes, APOE gene, and the risk for dementia and related pathologies: The Honolulu-Asia Aging Study. Diabetes, 51(4), 1256-1262.

Peila, R., White, L. R., Petrovich, H., Masaki, K., Ross, G. W., Havlik, R. J., et al. (2001). Joint effect of the APOE gene and midlife systolic blood pressure on late-life cognitive impairment: the Honolulu-Asia aging study. Stroke, 32(12), 2882-2889.

Qiu, C., Winblad, B., \& Fratiglioni, L. (2005). The age-dependent relation of blood pressure to cognitive function and dementia. Lancet Neurol, 4(8), 487-499.

Reitz, C., Tang, M. X., Manly, J., Mayeux, R., \& Luchsinger, J. A. (2007). Hypertension and the risk of mild cognitive impairment. Arch Neurol, 64(12), 1734-1740.

Schmidt, R., Launer, L. J., Nilsson, L. G., Pajak, A., Sans, S., Berger, K., et al. (2004). Magnetic resonance imaging of the brain in diabetes: the Cardiovascular Determinants of Dementia (CASCADE) Study. Diabetes, 53(3), 687-692.

Snijders, T., \& Bosker, R. (1999). Multilevel analysis. An introduction to basic and advanced multilevel modeling. London: Sage. 
Swan, G. E., DeCarli, C., Miller, B. L., Reed, T., Wolf, P. A., Jack, L. M., et al. (1998). Association of midlife blood pressure to late-life cognitive decline and brain morphology. Neurology, 51(4), 986-993.

Tervo, S., Kivipelto, M., Hanninen, T., Vanhanen, M., Hallikainen, M., Mannermaa, A., et al. (2004). Incidence and risk factors for mild cognitive impairment: a population-based three-year follow-up study of cognitively healthy elderly subjects. Dement Geriatr Cogn Disord, 17(3), 196-203.

Van Boxtel, M. P., Buntinx, F., Houx, P. J., Metsemakers, J. F., Knottnerus, A., \& Jolles, J. (1998). The relation between morbidity and cognitive performance in a normal aging population. J Gerontol A Biol Sci Med Sci, 53(2), M147-154.

Van Boxtel, M. P., Gaillard, C., Houx, P. J., Buntinx, F., de Leeuw, P. W., \& Jolles, J. (1997). Can the blood pressure predict cognitive task performance in a healthy population sample? J Hypertens, 15(10), 10691076.

Van den Berg, E., de Craen, A. J., Biessels, G. J., Gussekloo, J., \& Westendorp, R. G. (2006). The impact of diabetes mellitus on cognitive decline in the oldest of the old: a prospective population-based study. Diabetologia, 49(9), 2015-2023.

Van der Elst, W., Van Boxtel, M. P., Van Breukelen, G. J., \& Jolles, J. (2005). Rey's verbal learning test: normative data for 1855 healthy participants aged 24-81 years and the influence of age, sex, education, and mode of presentation. J Int Neuropsychol Soc, 11(3), 290-302.

Van der Elst, W., Van Boxtel, M. P., Van Breukelen, G. J., \& Jolles, J. (2006a). The Letter Digit Substitution Test: normative data for 1,858 healthy participants aged 24-81 from the Maastricht Aging Study (MAAS): influence of age, education, and sex. J Clin Exp Neuropsychol, 28(6), 998-1009.

Van der Elst, W., Van Boxtel, M. P., Van Breukelen, G. J., \& Jolles, J. (2006b). The Stroop color-word test: influence of age, sex, and education; and normative data for a large sample across the adult age range. $A s$ sessment, 13(1), 62-79.

Van Harten, B., Oosterman, J., Muslimovic, D., Van Loon, B. J., Scheltens, P., \& Weinstein, H. C. (2007). Cognitive impairment and MRI correlates in the elderly patients with type 2 diabetes mellitus. Age Ageing, 36(2), 164-170.

Waldstein, S. R., Giggey, P. P., Thayer, J. F., \& Zonderman, A. B. (2005). Nonlinear relations of blood pressure to cognitive function: the Baltimore Longitudinal Study of Aging. Hypertension, 45(3), 374-379.

Wechsler, D. (1955). Manual for the Wechsler Adult Intelligence Scale. New York: Psychological Corporation.

Whitmer, R. A., Sidney, S., Selby, J., Johnston, S. C., \& Yaffe, K. (2005). Midlife cardiovascular risk factors and risk of dementia in late life. Neurology, 64(2), 277-281.

WHO. (1999). World Health Organization, Guidelines Subcommittee, -International Society of Hypertension guidelines for the management of hypertension. J Hypertens, 17, 151-183.

Xu, W., Qiu, C., Gatz, M., Pedersen, N. L., Johansson, B., \& Fratiglioni, L. (2008). Mid- and Late-life Diabetes in Relation to the Risk of Dementia: A Population-based Twin Study. Diabetes.

Xu, W. L., Qiu, C. X., Wahlin, A., Winblad, B., \& Fratiglioni, L. (2004). Diabetes mellitus and risk of dementia in the Kungsholmen project: a 6-year follow-up study. Neurology, 63(7), 1181-1186. 



\section{8}

Effects of multimorbidity on the progression to dementia over nine years in older individuals with cognitive impairment, no dementia 


\begin{abstract}
The aims of this study were to investigate the effects of multimorbidity on progression to dementia in subjects with cognitive impairment, no dementia (CIND). In addition, we aimed to determine which cluster of diseases predicts dementia progression best and to test whether the number of diseases present influences the effects of multimorbidity. A total of 1,435 participants in the Kungsholmen Project were evaluated for baseline CIND and a diagnosis of dementia over a period of nine years. CIND was diagnosed in 206 participants at baseline, 88 of whom developed dementia in nine years. Multimorbidity was defined as the co-occurrence of two or more diseases. Persons with CIND and multimorbidity at first follow-up had a higher chance of progression to dementia, compared to CIND cases without multimorbidity (OR=2.89, 95\% CI: 1.65 to 5.06 , adjusted for age, gender and education). This effect was not mediated by the number of diseases present. The only disease cluster that separately increased progression to dementia was the cardiovascular cluster (OR=2.70, 95\% CI: 1.2 to 6.3).

In conclusion, multimorbidity affects progression of cognitive impairment no dementia (CIND) to dementia, independent of the number of diseases diagnosed.
\end{abstract}




\section{Introduction}

Cognitive impairment no dementia (CIND) (Ebly et al., 1995) or Mild Cognitive Impairment (Petersen et al., 1999) define stages of cognitive dysfunction, that could progress to dementia eventually. In the past years, modifications to the definition of MCI have been suggested, mainly because predictive value in terms of sensitivity for dementia was low for MCI defined according to original criteria (memory impairment, unimpaired general cognition, subjective complaints) (Artero et al., 2006; Van den Akker et al., 1998; Winblad et al., 2004). CIND (defined as a score of 1 SD below reference mean on MMSE in absence of dementia) is a more broad cognitive impairment definition that does not focus only on memory performance decline (Caracciolo et al., 2008; De Ronchi et al., 2005; Graham et al., 1997; Palmer et al., 2002) but refers to persons with global cognitive impairment that still do not fulfill criteria for dementia. The predictive values of these concepts for dementia development have been studied extensively, with variable results, depending mostly on study setting, study population demographical variables (such as age) and the exact definition used (Artero et al., 2006; Baars et al., 2009; Visser \& Verhey, 2007). Broadly defined cognitive impairment showed a better predictive value for dementia compared to a cognitive impairment definition that only took memory performance into account. About two-thirds of the cases progressed to dementia when such a broad definition was applied (Palmer et al., 2008).

Several risk factors for progression to dementia have been investigated, including vascular disease (Solfrizzi et al., 2004), ApoE-e4 genotype (Van de Pol et al., 2007) and low performance on memory tests (Albert et al., 2007). It is important to define clinically relevant prognostic factors that are associated with the progression of pre-dementia syndromes to dementia, in order to improve the predictive value of current cognitive impairment concepts (Ganguli, 2006).

Multimorbidity is defined as the co-occurrence of two or more chronic illnesses in the same individual (Van den Akker et al., 1998). It has been investigated as an aging related condition, and was found to be influencing survival and functional decline in older individuals (Marengoni et al., 2009). Little is known about the role of multimorbidity in the development of dementia, and in the progression of pre-dementia syndromes to dementia. Since functional decline is an important factor to consider in dementia, multimorbidity could be a prognostic factor to take into account.

In this study, we will investigate the role of multimorbidity in the progression of CIND to dementia. We expect that CIND cases with multimorbidity show increased progression to dementia compared to CIND cases without multimorbidity.

\section{Method}

Data for this study were taken from the Kungsholmen Project (Fratiglioni, Grut et al., 1992; Fratiglioni, Viitanen et al., 1992), a prospective population-based study on aging and dementia, involving all inhabitants over the age of 75 living in the Kungsholmen area in Stockholm, Sweden, in 1987. All participants were clinically evaluated in a per- 
sonal and family interview, took part in lab tests, and all were medically examined by physicians. The examination consisted of medical history, somatic and neurological examination, psychiatric evaluation and neuropsychological tests (including tests on memory, praxis, reasoning, language and visuospatial orientation). The Ethical Committee of Karolinska Institutet approved of the Kungsholmen Project and all participants gave their consent.

\section{Sample}

Out of the 1,475 dementia-free cases, 31 were excluded due to low global cognitive performance (MMSE < 20) without dementia diagnosis and nine because of unknown educational background, bringing the baseline sample to 1.435. Participants were examined approximately every three years (mean duration: first follow-up: $3.4 \pm 0.5$ years, second follow-up: $2.9 \pm 0.9$ years, third follow-up: $2.8 \pm 0.5$ years) for nine years, with dropout rates of twelve, six and six percent between the respective follow-up measurements, and with a total of 762 deaths in nine years $(53.1 \%)$. Those who died or dropped-out during these nine years were on average older than the individuals still taking part in the study $(\mathrm{p}<0.001)$.

\section{Data collection}

An interview and examination by a trained nurse yielded information on formal education, dichotomized in low and high level, functional status, body mass index (BMI), smoking, alcohol consumption, blood pressure, engagement in leisure activities, social network and depressive symptoms.

Information on diseases was derived from the Stockholm Computerized Inpatient Register System (SIRS) in which all diagnoses are made according to the criteria of the International Classification of Disease $10^{\text {th }}$ edition (ICD-10) (WHO, 1992). Information on prescribed drugs is coded and classified according to the guidelines of the Anatomic Therapeutical Classification system (ATC).(Nordic Council on Medicines, 1987)

\section{CIND and dementia diagnosis}

CIND was defined as having no dementia and a score of at least one SD below age- and education-specific means on the Mini-Mental State Examination (MMSE) (Caracciolo et al., 2008). The MMSE means were based on 14 age- and education-specific cutoffs calculated on the dementia-free baseline population (seven age groups and two education levels) (Palmer et al., 2002). CIND was based on the MMSE and identified cases with global cognitive impairment, so not only cases with memory impairment.

Dementia was diagnosed according to the guidelines in the Diagnostic and Statistical Manual of Mental Disorders, fourth edition (DSM-IV) (American Psychiatric Association, 1994), using a three-step procedure (Fratiglioni, Grut et al., 1992; Fratiglioni, Viitanen et al., 1992). Two physicians independently made the dementia diagnosis first. In case of agreement, the diagnosis was accepted. In case of disagreement, a definite diagnosis was made by a third, senior clinician. Clinical records of deceased participants were reviewed by a physician for a dementia diagnosis, which was confirmed by a senior 
clinician in a subsequent step. In case no clinical data were available, the diagnosis reported in the hospital discharge information was taken.

\section{Multimorbidity definition}

Multimorbidity was defined as any co-occurrence of two or more chronic conditions, in the same individual, whether coincidental or not (Van den Akker et al., 1998). Chronic disease was classified according to the following characteristics: 1. Being a permanent medical condition; 2. Being caused by a non-reversible pathological alteration; 3. Requiring treatment; 4. Requiring a long period of care.(Marengoni et al., 2008; Timmreck et al., 1987)

Two sources of information on prevalent diseases were available: the examination of the KP physician and the SIRS. Physicians made the medical diagnoses, based on the medical history, clinical exam, lab data and current drug use, and diseases were classified according to the ICD-10. A total of 30 chronic diseases were identified in the sample that could be divided into 10 clusters (Marengoni et al., 2008) (see Table 1).

Table 1 Prevalent disease clusters according to ICD-10 (WHO, 1992)

\begin{tabular}{ll} 
Disease clusters & Diseases in the clusters \\
$\begin{array}{l}\text { Malignancy } \\
\text { Circulatory system }\end{array}$ & $\begin{array}{l}\text { All types of cancer } \\
\text { Hypertension, cerebrovascular disease, atrial fibrilla- } \\
\text { tion, heart failure, coronary heart disease } \\
\text { Hypothyroidism, diabetes }\end{array}$ \\
$\begin{array}{l}\text { Endocrine, nutritional, metabolic system } \\
\text { Anemia }\end{array}$ & $\begin{array}{l}\text { Arthritis, osteoporosis, rheumatoid diseases } \\
\text { Musculoskeletal system } \\
\text { Mental or behavioral disorders } \\
\text { Digestive disorders }\end{array}$ \\
& $\begin{array}{l}\text { Intestinal diverticula, Crohn disease, colitis ulcerosa, } \\
\text { liver cirrhosis, cholelithiasis }\end{array}$ \\
Respiratory system & Chronic obstructive pulmonary disease (COPD) \\
Nervous system & Parkinson disease \\
Sensory system & Visual and hearing impairments \\
\hline
\end{tabular}

\section{Data analysis}

Multimorbidity prevalence was compared for CIND cases and controls using logistic regression analysis. To analyze the effects of multimorbidity on the predictive value of baseline CIND for dementia nine years after baseline, Cox regression analyses were employed. Covariates included age, education level, gender, multimorbidity at baseline and at three years follow-up. Effects of increasing number of diseases on risk of dementia diagnosis were tested with logistic regression analysis. Separate effects of the different disease clusters on dementia diagnosis were tested in logistic regression analyses, again with age, education level and gender as covariates. The statistical analyses were performed using the SPSS software package, version 16. 


\section{Results}

Sample characteristics are presented in Table 2. At baseline, 1,435 dementia-free participants were tested, with a mean age of $81(\mathrm{SD}=4.8)$, even distribution of level of education (high $>=12$ years of education and low $<12$ years of education) and a female majority (75\% women). According to the previously described diagnostic procedure 206 persons with CIND were identified. Characteristics were comparable to those of the total sample. In the nine years after baseline, 88 persons with CIND were diagnosed with dementia. These individuals were older, less educated and more often female than those CIND who did not progress to dementia in these nine years. Of the 206 persons with CIND at baseline, 58 (28\%) had died before first follow-up, 55 (27\%) between first and second follow-up and $19(9 \%)$ between second and third follow-up. Baseline multimorbidity was found in 77 of the individuals with CIND.

Table 2 Socio-demographic and multimorbidity characteristics for CIND cases and controls. Figures are means (SD) or percentages, where indicated.

\begin{tabular}{lll}
\hline & Controls & Baseline CIND \\
& $\mathrm{N}=1,229$ & $\mathrm{~N}=206$ \\
Age & $81.2(4.8)$ & $81.6(4.9)$ \\
Education level (\% low) & $50 \%$ & $53 \%$ \\
Sex (\% female) & $75 \%$ & $79 \%$ \\
Multimorbidity baseline (\%) & $22 \%$ & $36 \%$ \\
Multimorbidity follow-up (\%) & $23 \%$ & $34 \%$ \\
Dementia within 9 years (\%) & $24 \%$ & $43 \%$ \\
\hline
\end{tabular}

Over time, the absolute number of multimorbidity cases decreased due to attrition, but in percentages, the number of participants with multimorbidity stayed relatively stable over time (36 and 34 percent of the CIND cases at baseline and three-years follow-up respectively). Cardiovascular disease was the most prevalent disease cluster (Table 3).

Table 3 Baseline prevalence of the different disease clusters and of multimorbidity in CIND cases $(n=206)$.

\begin{tabular}{ll}
\hline Disease clusters & Prevalence in CIND cases \\
Digestive & $3.4 \%$ \\
Anemia & $5.3 \%$ \\
Endocrine & $5.3 \%$ \\
Mental & $7.3 \%$ \\
Rheumatic & $15 \%$ \\
Malignancy & $15.5 \%$ \\
Cardiovascular & $38.3 \%$ \\
Multimorbidity & $36.2 \%$ \\
\hline
\end{tabular}

Logistic regression analysis showed, that CIND cases showed a higher prevalence of multimorbidity than controls, at baseline ( $\mathrm{OR}=2.1,95 \% \mathrm{CI}: 1.6$ to 2.9$)$.

The first model tested effects of multimorbidity on progression from baseline CIND to dementia. Baseline CIND cases who had multimorbidity at first follow-up, were approximately three times more at risk to develop dementia within nine years, 
compared to multimorbidity-free CIND cases (OR=2.89, 95\% CI: 1.7 to 5.1) (Table 4 and Figure 1).

Table 4 Relationship between multimorbidity and 9-year progression of cognitive impairment no dementia (CIND; $\mathrm{n}=206$ ) to dementia $(\mathrm{n}=88)$.

\begin{tabular}{lll}
\hline & Risk of dementia after nine years & \\
& Odd's Ratio & 95\% Confidence Interval \\
Multimorbidity at baseline & 1.59 & $0.949-2.66$ \\
Multimorbidity at 3-year follow-up & $2.89 *$ & $1.65-5.06$ \\
\hline
\end{tabular}

Note. Analyses were adjusted for age, education and gender. ${ }^{*} \mathrm{p}<0.05$

Figure 1 Kaplan-Meier curves indicating effect of multimorbidity on progression to dementia for individuals with cognitive impairment, no dementia (CIND).

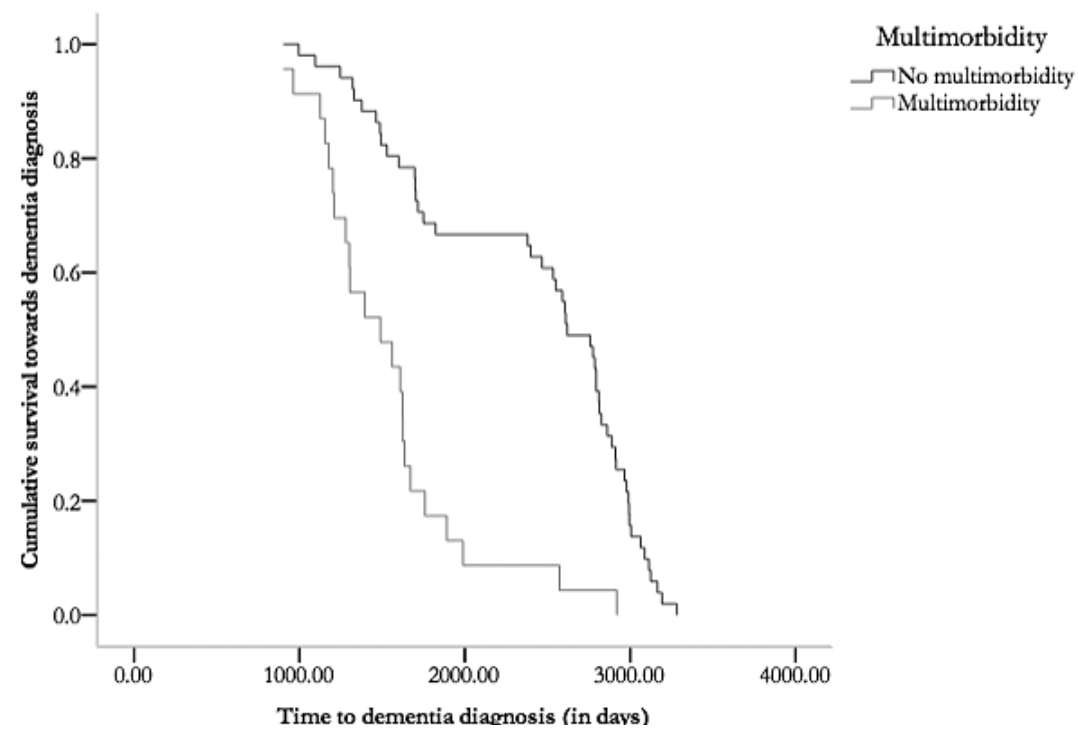

The number of prevalent diseases a participant was diagnosed with did not influence this effect of multimorbidity on progression. The effect on progression was not larger for those with more diseases. Baseline multimorbidity did not affect progression to dementia.

When investigating the separate clusters of diseases that had been defined beforehand, the cardiovascular disease cluster (prevalence 38\%) was the only separate cluster which independently raised the risk of dementia (OR=2.70, 95\% CI: 1.2 to 6.3). 


\section{Discussion}

The main aim of this study was to investigate the effects of multimorbidity on progression from cognitive impairment no dementia (CIND) to dementia. Individuals with CIND and multimorbidity were expected to show increased progression to dementia compared to healthy CIND controls.

Results showed that increased progression to dementia was indeed found for CIND cases with multimorbidity. The cardiovascular disease cluster was the only separate disease cluster to increase the chance of dementia diagnosis. The progression to dementia did not depend on the number of diseases persons with multimorbidity were diagnosed with.

A previous study showed that multimorbidity was a risk factor for disability and was negatively associated with survival (Marengoni et al., 2009). Since all multimorbidity cases in our study were functionally disabled to some extent, no interaction effects were expected between activities of daily living (ADL), as measured with the Katz index (Katz et al., 1963), and multimorbidity. Post-hoc tests showed no interaction effects for ADL functioning and multimorbidity were present. In the sample that was used for this study all participants were over the age of 75 , which gives them a high chance of being ADL dependent, at least to some extent.

Multimorbidity predicted dementia diagnosis for persons with CIND, but with a time lag of three years between CIND and multimorbidity diagnosis. Reason for this lag could be the attrition of very sick persons who did not have a dementia diagnosis. The individuals with CIND who died in the first three years after baseline and who were never diagnosed with dementia were probably diagnosed with CIND due to their health condition and not due to dementia pathology. For the persons with CIND who did develop dementia over time, and who did not die before being diagnosed, multimorbidity affected conversion. Persons with CIND who did not drop out within the first three years were relatively healthy at baseline, compared to controls that dropped out in the first three years (multimorbidity prevalence respectively $27 \%$ and $64 \%$ ). This is not a unique finding, previous studies have indicated that bad health condition is a risk factor for study attrition due to death (Chatfield et al., 2005). So, those still in the study at first follow-up, who had developed multimorbidity in the first three years after baseline, were declining in health. It is know from literature, that health problems increase not only the risk for death but also for dementia (Fratiglioni et al., 2007). Therefore, for those who were still healthy enough at baseline to stay in the study until first follow-up, and whose CIND was therefore expected to be caused by dementia pathology and not by general illness, the multimorbidity they had developed in those three years, made them more at risk for a dementia diagnosis, compared to the healthy CIND cases.

The number of diseases for multimorbidity cases did not influence the predictive value of CIND for dementia. Previous studies have shown that effects of multimorbidity on functional decline and survival were not dependent on the number of diseases (Marengoni et al., 2009). The interaction between the various diseases in multimorbidity may be more predictive than the exact number of diseases present. 
The cardiovascular cluster was the only independent disease cluster with predictive value for dementia. It was also the most prevalent cluster and the diseases in this cluster were therefore expected to have the largest effect on progression, compared to other clusters, because of larger statistical power. In addition, cardiovascular disease has been related to cognitive decline and dementia diagnosis in many previous studies (Elias et al., 2003; Knopman et al., 2001).

Some limitations need to be discussed with respect to the design of the study. The Kungsholmen Project took place in an urbanized area, which may affect the external validity of this study for rural areas. Secondly, since the baseline study population was 75 years of age and older, many participants died during the course of this nine-year followup study (53\%). Refusal to participate at follow-up was not very common $(17 \%$ over nine years). Strengths of this study include the long follow-up period, the populationbased nature of the sample and the large number of participants included.

Our findings showed that multimorbidity increases the progression rate of CIND to dementia. Multimorbidity therefore does not only pose a threat to the survival of older individuals, but also to their cognitive development over time. Dementia cannot be prevented at this time and no successful treatment to stop the disease is available. Treatment of diseases adding up to multimorbidity is possible, and therefore the chance of dementia diagnosis could be reduced. 


\section{References}

Albert, M., Blacker, D., Moss, M. B., Tanzi, R., \& McArdle, J. J. (2007). Longitudinal change in cognitive performance among individuals with mild cognitive impairment. Neuropsychology, 21(2), 158-169.

American Psychiatric Association. (1994). Diagnostic and Statistical Manual of Mental Disorders: DSM IV. (4th ed.). Retrieved. from.

Artero, S., Petersen, R., Touchon, J., \& Ritchie, K. (2006). Revised criteria for mild cognitive impairment: validation within a longitudinal population study. Dement Geriatr Cogn Disord, 22(5-6), 465-470.

Baars, M. A., van Boxtel, M. P., Dijkstra, J. B., Visser, P. J., van den Akker, M., Verhey, F. R., et al. (2009). Predictive value of mild cognitive impairment for dementia. The influence of case definition and age. Dement Geriatr Cogn Disord, 27(2), 173-181.

Caracciolo, B., Palmer, K., Monastero, R., Winblad, B., Backman, L., \& Fratiglioni, L. (2008). Occurrence of cognitive impairment and dementia in the community: a 9-year-long prospective study. Neurology, $70(19 \mathrm{Pt}$ 2), 1778-1785.

Chatfield, M. D., Brayne, C. E., \& Matthews, F. E. (2005). A systematic literature review of attrition between waves in longitudinal studies in the elderly shows a consistent pattern of dropout between differing studies. J Clin Epidemiol, 58(1), 13-19.

De Ronchi, D., Berardi, D., Menchetti, M., Ferrari, G., Serretti, A., Dalmonte, E., et al. (2005). Occurrence of cognitive impairment and dementia after the age of 60: a population-based study from Northern Italy. Dement Geriatr Cogn Disord, 19(2-3), 97-105.

Ebly, E. M., Hogan, D. B., \& Parhad, I. M. (1995). Cognitive impairment in the nondemented elderly. Results from the Canadian Study of Health and Aging. Arch Neurol, 52(6), 612-619.

Elias, M. F., Elias, P. K., Sullivan, L. M., Wolf, P. A., \& D’Agostino, R. B. (2003). Lower cognitive function in the presence of obesity and hypertension: the Framingham heart study. Int J Obes Relat Metab Disord, 27(2), 260-268.

Fratiglioni, L., Grut, M., Forsell, Y., Viitanen, M., \& Winblad, B. (1992). Clinical diagnosis of Alzheimer's disease and other dementias in a population survey. Agreement and causes of disagreement in applying Diagnostic and Statistical Manual of Mental Disorders, Revised Third Edition, Criteria. Arch Neurol, 49(9), 927-932.

Fratiglioni, L., Viitanen, M., Backman, L., Sandman, P. O., \& Winblad, B. (1992). Occurrence of dementia in advanced age: the study design of the Kungsholmen Project. Neuroepidemiology, 11 Suppl 1, 29-36.

Fratiglioni, L., Winblad, B., \& von Strauss, E. (2007). Prevention of Alzheimer's disease and dementia. Major findings from the Kungsholmen Project. Physiol Behav, 92(1-2), 98-104.

Ganguli, M. (2006). Mild cognitive impairment and the 7 uses of epidemiology. Alsheimer Dis Assoc Disord, 20(3 Suppl 2), S52-57.

Graham, J. E., Rockwood, K., Beattie, B. L., Eastwood, R., Gauthier, S., Tuokko, H., et al. (1997). Prevalence and severity of cognitive impairment with and without dementia in an elderly population. Lancet, 349(9068), 1793-1796.

Katz, S., Ford, A. B., Moskowitz, R. W., Jackson, B. A., \& Jaffe, M. W. (1963). Studies of Illness in the Aged. the Index of Adl: a Standardized Measure of Biological and Psychosocial Function. JAMA, 185, 914-919.

Knopman, D., Boland, L. L., Mosley, T., Howard, G., Liao, D., Szklo, M., et al. (2001). Cardiovascular risk factors and cognitive decline in middle-aged adults. Neurology, 56(1), 42-48.

Marengoni, A., von Strauss, E., Rizzuto, D., Winblad, B., \& Fratiglioni, L. (2009). The impact of chronic multimorbidity and disability on functional decline and survival in elderly persons. A community-based, longitudinal study. J Intern Med, 265(2), 288-295.

Marengoni, A., Winblad, B., Karp, A., \& Fratiglioni, L. (2008). Prevalence of chronic diseases and multimorbidity among the elderly population in Sweden. Am J Public Health, 98(7), 1198-1200.

Nordic Council on Medicines, N. (1987). Guidelines for ATC classification. Uppsala: Nordic Council on Medicines.

Palmer, K., Backman, L., Winblad, B., \& Fratiglioni, L. (2008). Mild cognitive impairment in the general population: occurrence and progression to Alzheimer disease. Am J Geriatr Psychiatry, 16(7), 603-611.

Palmer, K., Wang, H. X., Backman, L., Winblad, B., \& Fratiglioni, L. (2002). Differential evolution of cognitive impairment in nondemented older persons: results from the Kungsholmen Project. Am J Psychiatry, 159(3), 436-442. 
Petersen, R. C., Smith, G. E., Waring, S. C., Ivnik, R. J., Tangalos, E. G., \& Kokmen, E. (1999). Mild cognitive impairment: clinical characterization and outcome. Arch Neurol, 56(3), 303-308.

Solfrizzi, V., Panza, F., Colacicco, A. M., D’Introno, A., Capurso, C., Torres, F., et al. (2004). Vascular risk factors, incidence of MCI, and rates of progression to dementia. Neurology, 63(10), 1882-1891.

Timmreck, T. C., Cole, G. E., James, G., \& Butterworth, D. D. (1987). Health education and health promotion: a look at the jungle of supportive fields, philosophies and theoretical foundations. Health Educ, 18(6), 23-28.

Van de Pol, L. A., Van der Flier, W. M., Korf, E. S., Fox, N. C., Barkhof, F., \& Scheltens, P. (2007). Baseline predictors of rates of hippocampal atrophy in mild cognitive impairment. Neurology, 69(15), 1491-1497.

Van den Akker, M., Buntinx, F., Metsemakers, J. F., Roos, S., \& Knottnerus, J. A. (1998). Multimorbidity in general practice: prevalence, incidence, and determinants of co-occurring chronic and recurrent diseases. $J$ Clin Epidemiol, 51(5), 367-375.

Visser, P. J., \& Verhey, F. R. (2007). Mild cognitive impairment as predictor for Alzheimer's disease in clinical practice: effect of age and diagnostic criteria. Psychol Med, 1-10.

WHO. (1992). The ICD-10 Classification of Mental and Behavioral Disorders. Geneva: World Health Organization.

Winblad, B., Palmer, K., Kivipelto, M., Jelic, V., Fratiglioni, L., Wahlund, L. O., et al. (2004). Mild cognitive impairment--beyond controversies, towards a consensus: report of the International Working Group on Mild Cognitive Impairment. J Intern Med, 256(3), 240-246. 

9

Concluding remarks 
The main aims of this thesis were to study the prodromal phase of cognitive decline and dementia, to explore cognitive domains with respect to their predictive value for conversion from normal cognitive functioning to dementia, and finally, to study the association between selected health-related factors on the one hand and cognitive decline and dementia on the other. In this final chapter the results of the studies presented in this thesis are summarized and methodological considerations and implications of the findings are discussed.

\subsection{Cognitive prodromal phase of dementia}

\subsubsection{Defining Mild Cognitive Impairment}

In Chapter 2 we studied conversion to dementia for several commonly used MCI definitions. Previous studies have pointed out that the conversion rate to dementia increases when more cognitive domains than memory alone are included in the MCI definition (Artero et al., 2006; Busse et al., 2006). The conversion rate is not only affected by the definition that is applied. Two studies using the exact same definition might still well end up with strikingly different conversion rates. For example, using the same amnestic MCI definition in two different samples resulted in annual conversion rates of respectively eight percent (Larrieu et al., 2002) and twelve percent (Riedel-Heller et al., 2001). The main difference between the two studies which may explain the discrepant findings is the age range of the samples, which was respectively 65 years and older for the first, and 75 years and older for the second study

We compared the most commonly used definitions of MCI and their predictive values for conversion to dementia. In addition, we tested the predictive values for different age groups. Our findings demonstrated that only a small change in definition or the choice of age group could result in a vast change in the predictive value of MCI for dementia. The study also showed that in our sample the maximum attained sensitivity of MCI for dementia was still rather low: 0.66 in the oldest group, when the broadest MCI definition was used. Therefore, irrespective of the definition used, a large proportion of MCI cases in our study (at least 60 percent) did not convert to dementia within a period of nine years. This finding has implications for the usefulness of MCI as a prodromal state of dementia, at least within the context of a population study like ours. Since the main goal of defining MCI is to identify individuals at risk for dementia, an acceptable sensitivity and specificity are necessary to make MCI a useful research construct. The definition of MCI should be adjusted to improve its predictive value for dementia. Focusing the definition on a more select group of individuals, and therefore including less false positive cases in the MCI group may be a good starting point for improvement. Including biomarkers in the MCI definition could help exclude these false positive cases. Vascular symptoms (Helzner et al., 2009; Launer et al., 2000; Staekenborg et al., 2009; Xu et al., 2008), medial temporal lobe atrophy (Jack et al., 2002), genetic factors, such as Apolipoprotein E (APOE) status (Farlow et al., 2004; Peila et al., 2001) and abnormal levels of $A \beta$ peptides and hyperphosphorylated tau in cerebrospinal fluid (Hansson et 
al., 2006; Hulstaert et al., 1999) have been under investigation as risk factors for dementia and might therefore be useful additions to the definition of MCI. The proposed revised criteria for a diagnosis of Alzheimer's Disease (AD) (Dubois et al., 2007) have suggested to include such factors as supportive evidence for preclinical dementia. Therefore inclusion of these factors in the definition of MCI might improve the sensitivity and specificity for conversion of MCI to dementia. The Preclinical AD Scale (or PASscale) combines six markers of preclinical AD, namely age, MMSE score, functional impairment, cognitive test performance, medial temporal lobe atrophy and APOE genotype. The scale has proved to be useful to detect preclinical AD in individuals who will develop dementia within two or five years (Visser et al., 2002). Application of this clinical scale may also be considered in population studies, as the definition of MCI could be improved by including the PAS factors.

\subsubsection{Stability of Mild Cognitive Impairment}

The concept of MCI is often used under the implicit assumption that this label pertains to a stable clinical concept. In chapter 3 the outcomes for persons with MCI who did not convert to dementia were studied. It was hypothesized that if MCI (as defined according to current criteria) indeed is a stable concept, the majority of MCI cases at baseline would stay mild cognitively impaired and would not revert to normal cognitive functioning at follow-up. However, our study clearly showed that even when different methods to decrease inaccuracy in the measurement of cognitive functions over time were used, the proportion of individuals with persistent MCI within a period of six years never exceeded 60 percent. This means that within six years, no less than 40 percent of the MCI cases identified at baseline did revert to normal cognitive functioning on at least one of two possible measurement occasions. Thus, the use of MCI in a longitudinal study is compromised by its instability over time. This instability is inherent to the neuropsychological measures that are used to define MCI. Effects of practice and regression-to-the-mean pose a threat to the interpretation of neuropsychological test scores over time, when used to identify cases using a cut-off score, which is typically done when making an MCI classification (e.g. score below mean - 1.5 SD on a specific cognitive measure) (Duff et al., 2008; Frerichs \& Tuokko, 2006). Therefore, it would be far more effective to follow the actual performance of MCI cases over time, regardless of whether they are still 'case' at follow-up. Combined, the results from chapters 2 and 3 indicate, that MCI is a heterogenic concept and that its current definition does not coincide with a high predictive value for dementia. Expanding the MCI definition with other potential risk indicators, such as health-related factors, might not only result in higher conversion rates of MCI to dementia, but also in higher stability for individuals with MCI, who do not convert to dementia. To study the predictive value of MCI for dementia, we therefore propose to include vascular symptoms and genetic risk into the MCI definition, on top of the inclusion of multiple cognitive domains. 


\subsubsection{Neuropsychological indicators of preclinical dementia}

In chapter 4, the cognitive profiles of healthy participants, who would later be diagnosed with dementia, were followed over time. This study was performed to increase our understanding of the cognitive changes that occur in the transition from normal functioning to dementia. Participants were not characterized according to a fixed definition, such as MCI. Instead, neuropsychological test performance was measured at baseline, after three and six years, and changes in performance over time were measured. Dementia diagnosis was evaluated for all individuals after nine years, which resulted in $31 \mathrm{AD}$ diagnoses and 13 participants diagnosed with vascular dementia (VD).

First, we retrospectively determined which neuropsychological tests could predict dementia diagnosis best. Memory performance was affected at baseline and increased decline in memory performance compared to controls was found in the first test interval, so between baseline and three-year follow-up. Executive functioning was lower at baseline as well, however, increased decline over time was mainly found in the interval between three- and six-years follow-up. The late increased decline over time found for executive functioning might be due to failing compensation mechanisms that were still effective in the first interval (Amieva et al., 2005). Most dementia cases in our study were diagnosed with $\mathrm{AD}$, and were therefore expected to show memory decline first and decline in executive functioning at a later stage.

The results of this study indicate, that dementia can be predicted in healthy persons, already nine years before diagnosis, based on neuropsychological tests and that decline patterns differ for separate cognitive domains.

\subsubsection{Summary part I}

The study of the prodromal phase of dementia is important to improve the identification in an early stage of those individuals who will eventually be diagnosed with dementia. In our studies MCI was investigated in a population-based context and we conclude that the currently used definition of MCI is associated with a low sensitivity for detecting dementia at a later stage. In addition, the neuropsychological base of the MCI definition compromises its stability over time. Including biomarkers in the MCI definition may improve the predictive value of MCI for later conversion to dementia. We found that to investigate stability over time, following actual changes in neuropsychological test performance is a more efficient method compared to evaluating MCI caseness at different points in time. We also showed that neuropsychological test performance could predict future dementia even until nine years prior to diagnosis. The results of our studies can help identify individuals that may benefit from early interventions, focused on prevention of cognitive deficits. 


\subsection{Risk factors for cognitive decline and effects of prolonged exposure to risk factors}

\subsubsection{Migraine and cognitive function}

Migraine is a condition characterized by episodes of severe headache and has been suggested to be a form of vascular disease (Kruit et al., 2004). Previous studies into cognitive effects of migraines have yielded inconsistent results. Migraineurs have been found to show better cognitive performance than controls (Kalaydjian et al., 2007) but cognitive performance has also been found to be negatively affected by migraine diagnosis (Le Pira et al., 2004) while other studies reported no associations between migraine and cognition (Jelicic et al., 2000; Pearson et al., 2006). Our study investigated effects of migraine diagnosis and migraine associated medication use on cognitive change over time. Migraine diagnosis was found to have no effect on cognitive performance, neither for medication users nor for migraineurs who did not report the use of typical migraine medication (Jelicic et al., 2000; Kalaydjian et al., 2007). Imaging studies have related migraines to white matter hyperintensities (WMH) (Kruit et al., 2005; Swartz \& Kern, 2004), and have hinted at their potential negative effect on cognitive functioning (de Groot et al., 2000; Stenset et al., 2008). However, the connection between WMH and cognition is still unclear. Future studies might increase the specificity of migraine as a predictor of cognitive decline, by focusing on those migraine cases that are particularly prone to WMH (Intiso et al., 2006), since such lesions may affect cognitive performance.

\subsubsection{Obesity, hypertension and cognitive decline}

Chapter 5 describes a cross-sectional study into effects of obesity and hypertension on cognitive performance. It was performed as the test of a hypothesis coined in a previous study by Waldstein et al (Waldstein \& Katzel, 2006). These authors found that obesity and high blood pressure interacted in their effect on cognitive performance. Both high blood pressure (Cerhan et al., 1998; Elias et al., 2003) and obesity (Gustafson et al., 2003) have been found to be negatively associated with cognitive performance. The plausible interaction of both conditions might identify a group of individuals who are at an increased risk for cognitive problems. Waldstein et al (Waldstein \& Katzel, 2006) conducted a study in 90 healthy participants (aged 54 to 81 years old) and indeed found that in individuals with both central obesity and hypertension cognition was impaired compared to controls. Still, in our own, much larger data set we were not able to replicate their findings: using essentially the same methodology, no main effects on comparable cognitive indicators (e.g. memory performance and executive functioning) were found for either high blood pressure or obesity, or their interaction. There were some differences between both studies that deserve attention. The proportion of males in MAAS was balanced and therefore smaller (47, vs. 63\%). Still, additional analyses showed the effects were no different for men and women in our sample. Another potential confounder in the Waldstein et al. study was the racial build up of their sample. 
In the MAAS only Caucasian participants were included, while the other study included seven percent non-Caucasian persons. Influential cases in this latter group could have affected the results, since vascular risk is known to be affected by race (Kurian \& Cardarelli, 2007). The results of these two studies indicate that conclusions on interactions between different vascular symptoms and their effect on cognitive performance can differ greatly between samples. Implications associated with these findings should be interpreted with caution, since results may be biased by the sample they are found in.

\subsubsection{Effects of hypertension, APOE-e4 and diabetes on cognitive change}

Hypertension is a vascular risk factor that has been related to dementia and cognitive decline in previous studies (Kivipelto et al., 2001; Qiu et al., 2005). Hypertension causes atherosclerosis of large arteries, which is associated with an increased risk of cerebrovascular lesions and dementia in late life (Arnett et al., 2000; Birkenhager et al., 2001). In our study we defined hypertension according to the World Health Organization (WHO, 1999) criteria and actual medication use. Previous cross-sectional studies have been inconclusive regarding the effects of hypertension on cognition. Some studies found that hypertension causes cognitive functioning to be negatively affected (Birkenhager et al., 2001; Elias et al., 2003) while other studies did not find such association (Di Carlo et al., 2000; Van Boxtel et al., 1997). In chapter 5 we already described that hypertension was not associated with lower cognitive performance on one single measurement occasion, in our sample. In chapter 7 however, we did find an effect of long-term exposure to hypertension on cognitive change. This effect was robust for untreated hypertension and effects found were largest in APOE-e4 carriers.

Diabetes patients did not show increased performance change over time compared to controls, even though their overall performance was lower. Although the number of patients with diabetes was relatively small, this number was representative for the prevalence in the population.

The observation that only untreated hypertension led to increased cognitive decline over time suggests that adequate treatment of elevated blood pressure may result in less cognitive decline and could therefore protect against a cognitive disorder.

\subsubsection{Multimorbidity and progression from cognitive impairment, no dementia (CIND) to dementia}

Multimorbidity (defined as having two or more chronic disease at the same time) has been reported to affect survival and daily life functioning (Marengoni et al., 2009), but has to date not been investigated within the context of dementia. We expected an effect of multimorbidity on progression from cognitive impairment, no dementia (CIND) to dementia, since this transition is characterized by the emergence of interference with daily life activities (ADL). In CIND, ADL may be mildly affected, but still not to the extent that a diagnosis of dementia is warranted (Caracciolo et al., 2008). The population used for this study (the Kungsholmen Project, or KP), has been used to study both MCI and CIND (Caracciolo et al., 2008). Our findings indicated that the incidence per 1000- 
person-years of pure amnestic MCI was low (11\%) in this sample, which is partly due to the exclusion of ADL impairment in the MCI definition. The prevalence of CIND was much higher (33\%), since some ADL restriction is common in individuals aged 75 years and older.

Since multimorbidity has been shown to predict a decline in ADL (Marengoni et al., 2009), it was expected to influence the progression of CIND to dementia as well. CIND was defined at baseline and participants were followed for nine years. Presence of multimorbidity was found to increase the chance of dementia diagnosis by almost three times in persons with CIND. The effect of multimorbidity on conversion was independent of the total number of diseases present. Our study showed, that multimorbidity is an important health problem to take into account, since it is prevalent among elderly persons and it is not just a physical health issue, since mental fitness is affected as well.

\subsubsection{Summary part II}

Defining risk factors for cognitive decline and dementia is an important first step in strategies towards the prevention of such conditions. The studies into vascular risk factors showed that particularly the prolonged exposure to the effect of a risk profile mediates cognitive decline. The effects of long-term exposure to a hypertensive state on cognition were particularly robust when hypertension was not treated. Hence, successful treatment of hypertension may help to prevent cognitive decline or to postpone a diagnosis of dementia. Furthermore, multimorbidity was found to be a risk factor for dementia. Our results may imply that the effects of multimorbidity on cognition might be attenuated when vascular conditions are adequately treated. Since vascular symptoms were the most prevalent of all disease clusters investigated in this chapter, proper medical treatment of such risk factors could have a considerable effect on cognitive health and delay the conversion to dementia. This is however a hypothesis that needs to be tested in future research.

\subsection{Methodological considerations}

\subsubsection{Study design}

Some methodological considerations need to be discussed with regard to the design of the samples used throughout this thesis. Both MAAS and the KP were subject to attrition due to death or withdrawal, especially the KP, where the number of participants dropped from 1,700 to 265 over a period of 15 years. This is inevitable, as participants were at least 90 years old at 15-years follow-up. However, selective attrition may pose some threats to the interpretation of the results. Previous studies have shown that older, less-educated persons with more prevalent diseases and lower cognitive performance have a higher chance of dropping out of a study (e.g. Van Beijsterveldt et al., 2002), when compared to controls. In the studies using longitudinal cognitive data in this thesis, attrition was accounted for in the statistical methods applied. In case of random 
dropout, the employed statistical procedures such as linear mixed models (chapters 6 and 7) and generalized estimating equations (chapter 5) both used the maximum set of data points available for each participant. In addition, these methods fit longitudinal profiles for those who drop out, based on their test scores at earlier measurements and current test scores of participants with the same profile. However, given that attrition was not completely at random, the effects of the health-related risk factors on cognition reported in this thesis might be somewhat attenuated by the fact that the older, more fragile and therefore more cognitively impaired individuals have a higher chance of dropping out of the study after initial inclusion.

Another important factor to take into account in longitudinal studies of cognitive performance is procedural learning. When using neuropsychological tests longitudinally, practice effects are unavoidable, as test procedures become more familiar to participants. For example, in the verbal memory test used in the studies in this thesis, the delayed recall phase is unannounced, but after the first test session participants may remember this procedure at later test occasions. In chapter 3, test-retest effects actually were part of the study and were accounted for in two of the three methods used. In all other studies that used longitudinal data described in this thesis, these effects were taken into account differently. In these studies changes in neuropsychological test performance were compared for participants who did or did not have a certain risk factor, e.g. hypertension. Under the assumption that practice effects are not dependent of the factors of interest in these studies, such effects have most likely not affected the results to a large extent.

\subsubsection{External validity of the findings}

Both study samples used in this thesis were drawn from the general population and the results may therefore not be directly applicable in a clinical setting, in which a more selected population sample is represented. The MAAS was performed in participants drawn from general practitioners' practices in a widespread region of the south of the Netherlands, whilst the KP was conducted in a well-defined urban area in Stockholm, Sweden. The MAAS was stratified for age, education and gender, in the KP such stratification was not performed. For research purposes the stratification method results in a perfectly balanced sample in which effects can be measured equally in men and women and in high and low educated individuals. The advantage of the inclusion as performed in the KP is that it matches the actual population distribution with respect to gender and education level. For scientific purposes, a balanced design with respect to gender may be preferable over inclusion based on population distribution, since effects of gender can be estimated equally reliably for both sexes.

\subsubsection{Confounders}

Age, education level and sex were treated as covariates in all studies described in this thesis. Advanced age is the most important risk factor for vascular disease, cognitive decline and dementia. Since low education level is another known risk factor for cogni- 
tive disorder, these covariates were closely related to prodromal dementia as studied in this thesis. Effects of procedural learning (as discussed in \$9.3.1.) are also agedependent, with older people showing less benefit from practice than younger individuals. Therefore in all studies in this thesis age and education level were included as covariates.

\subsection{Recommendations}

\subsubsection{Scientific implications}

The results described in this thesis have several implications for future studies into the prodromes or risk factors for cognitive decline and dementia. We showed that the inclusion of multiple cognitive domains in the definition of MCI and taking into account the age group are important factors influencing the conversion from MCI to preclinical AD. However, we believe that the predictive value of MCI for dementia may benefit from including other person characteristics. Factors such as vascular morbidity, information about functional decline, genetic predisposition (e.g. APOE-e4 allele), markers in cerebrospinal fluid, or structural abnormalities on MRI (e.g. hippocampal atrophy) could improve the predictive value of MCI for dementia when included in the definition of MCI (Visser et al., 2002).

With regard to the risk factors for cognitive decline and dementia identified in this thesis, the most important recommendation is to study exposure to health-related risk factors over a longer period of time, since effects may vary with time or may emerge only after a sufficiently long observation period. Effects of hypertension on cognition were found to change over time and were found to be larger after a longer period of exposure compared to a short period of exposure.

A second recommendation is to consider treatment or medication use as a factor in case of vascular disease, since we found that effects of hypertension on cognition were only robust for those participants that were not treated with anti-hypertensive medication.

\subsubsection{Clinical implications}

The clinical implications of our findings in this thesis lie in the identification of MCI subjects and in the health-related risk factors that we investigated. We established that testing multiple cognitive domains improves the diagnostic accuracy of MCI to detect preclinical $\mathrm{AD}$, compared to testing only one single cognitive domain, such as memory. We showed that the instability of MCI over time is inherent to the neuropsychological nature of the MCI definition itself. MCI is defined based on subjective cognitive performance and objective cognitive performance. Cognitive performance, as measured with neuropsychological tests, is influenced by regression-to-the-mean and test-retest effects. These effects cause variability in neuropsychological test scores over time, even in the absence of an actual change in cognitive functioning. Simply using cut-off scores 
on the same test at multiple moments in time would therefore result in an underestimation of the stability of MCI over time.

Hypertension affects cognition after long-term exposure, while effects may remain undisclosed when individuals are tested just once. In addition, treatment of hypertension was proven to be beneficial in terms of cognitive fitness (Hanon \& Forette, 2004), so it appears to have long-term cognitive consequences as well.

Multimorbidity was found to predict conversion to dementia in CIND cases. Therefore persons with multimorbidity should not only be followed closely with respect to their medical condition but doctors should be aware that the cognitive performance of their patients could be influenced by their conditions as well. The very recently developed Test Your Memory (TYM) (Brown et al., 2009) was found to be a useful tool to detect Alzheimer's Disease in a general practice setting, and could serve as a quick and easy standard test to apply when cognitive decline is suspected.

\subsection{Conclusion}

Based on results from our studies executed in two large population-based samples, we may conclude that this thesis has contributed to our understanding of how to define prodromal cognitive decline. This work has provided new insight into the relevance of specific health-related risk factors that were isolated from previous research for both cognitive decline and dementia. Indeed, predicting who will and who will not be suffering from chronic diseases such as dementia in the future is one of the main challenges of aging research today. A first step in this direction is that we found that cognitive decline and dementia can be predicted from cognitive performance even years before diagnosis. This prediction may be improved when genetic, vascular and other health-related risk factors would be taken into account as well. In other studies, hippocampal atrophy has been identified as a predictor of conversion of MCI to dementia (Eckerstrom et al., 2008; Jack et al., 2002) and in recent studies Positron emission tension (PET) imaging using Pittsburgh compound B (PiB) has been suggested to study the spread of senile plaques in persons with MCI and Alzheimer's Disease (Klunk et al., 2004; Shoghi-Jadid et al., 2002). A $\beta$ peptides and hyperphosphorylated tau in cerebrospinal fluid (Hansson et al., 2006; Hulstaert et al., 1999) have been related to conversion as well. A truly comprehensive model that may efficiently predict future cognitive decline or dementia will ultimately be based on not only cognitive, but also psychosocial and biological markers. 


\section{References}

Amieva, H., Jacqmin-Gadda, H., Orgogozo, J. M., Le Carret, N., Helmer, C., Letenneur, L., et al. (2005). The 9 year cognitive decline before dementia of the Alzheimer type: a prospective population-based study. Brain, 128(Pt 5), 1093-1101.

Arnett, D. K., Boland, L. L., Evans, G. W., Riley, W., Barnes, R., Tyroler, H. A., et al. (2000). Hypertension and arterial stiffness: the Atherosclerosis Risk in Communities Study. ARIC Investigators. Am J Hypertens, 13(4 Pt 1), 317-323.

Artero, S., Petersen, R., Touchon, J., \& Ritchie, K. (2006). Revised criteria for mild cognitive impairment: validation within a longitudinal population study. Dement Geriatr Cogn Disord, 22(5-6), 465-470.

Birkenhager, W. H., Forette, F., Seux, M. L., Wang, J. G., \& Staessen, J. A. (2001). Blood pressure, cognitive functions, and prevention of dementias in older patients with hypertension. Arch Intern Med, 161(2), 152156.

Brown, J., Pengas, G., Dawson, K., Brown, L. A., \& Clatworthy, P. (2009). Self administered cognitive screening test (TYM) for detection of Alzheimer's disease: cross sectional study. Bmj, 338, b2030.

Busse, A., Hensel, A., Guhne, U., Angermeyer, M. C., \& Riedel-Heller, S. G. (2006). Mild cognitive impairment: long-term course of four clinical subtypes. Neurology, 67(12), 2176-2185.

Caracciolo, B., Palmer, K., Monastero, R., Winblad, B., Backman, L., \& Fratiglioni, L. (2008). Occurrence of cognitive impairment and dementia in the community: a 9-year-long prospective study. Neurology, $70(19 \mathrm{Pt}$ 2), $1778-1785$.

Cerhan, J. R., Folsom, A. R., Mortimer, J. A., Shahar, E., Knopman, D. S., McGovern, P. G., et al. (1998). Correlates of cognitive function in middle-aged adults. Atherosclerosis Risk in Communities (ARIC) Study Investigators. Gerontology, 44(2), 95-105.

de Groot, J. C., de Leeuw, F. E., Oudkerk, M., van Gijn, J., Hofman, A., Jolles, J., et al. (2000). Cerebral white matter lesions and cognitive function: the Rotterdam Scan Study. Ann Neurol, 47(2), 145-151.

Di Carlo, A., Baldereschi, M., Amaducci, L., Maggi, S., Grigoletto, F., Scarlato, G., et al. (2000). Cognitive impairment without dementia in older people: prevalence, vascular risk factors, impact on disability. The Italian Longitudinal Study on Aging. J Am Geriatr Soc, 48(7), 775-782.

Dubois, B., Feldman, H. H., Jacova, C., Dekosky, S. T., Barberger-Gateau, P., Cummings, J., et al. (2007). Research criteria for the diagnosis of Alzheimer's disease: revising the NINCDS-ADRDA criteria. Lancet Neurol, 6(8), 734-746.

Duff, K., Beglinger, L. J., Van Der Heiden, S., Moser, D. J., Arndt, S., Schultz, S. K., et al. (2008). Short-term practice effects in amnestic mild cognitive impairment: implications for diagnosis and treatment. Int Psychogeriatr, 1-14.

Eckerstrom, C., Olsson, E., Borga, M., Ekholm, S., Ribbelin, S., Rolstad, S., et al. (2008). Small baseline volume of left hippocampus is associated with subsequent conversion of MCI into dementia: the Goteborg MCI study. J Neurol Sci, 272(1-2), 48-59.

Elias, M. F., Elias, P. K., Sullivan, L. M., Wolf, P. A., \& D'Agostino, R. B. (2003). Lower cognitive function in the presence of obesity and hypertension: the Framingham heart study. Int J Obes Relat Metab Disord, 27(2), 260-268.

Farlow, M. R., He, Y., Tekin, S., Xu, J., Lane, R., \& Charles, H. C. (2004). Impact of APOE in mild cognitive impairment. Neurology, 63(10), 1898-1901.

Frerichs, R. J., \& Tuokko, H. A. (2006). Reliable change scores and their relation to perceived change in memory: implications for the diagnosis of mild cognitive impairment. Arch Clin Neuropsychol, 21(1), 109115.

Gustafson, D., Rothenberg, E., Blennow, K., Steen, B., \& Skoog, I. (2003). An 18-year follow-up of overweight and risk of Alzheimer disease. Arch Intern Med, 163(13), 1524-1528.

Hanon, O., \& Forette, F. (2004). Prevention of dementia: lessons from SYST-EUR and PROGRESS. J Neurol Sci, 226(1-2), 71-74.

Hansson, O., Zetterberg, H., Buchhave, P., Londos, E., Blennow, K., \& Minthon, L. (2006). Association between CSF biomarkers and incipient Alzheimer's disease in patients with mild cognitive impairment: a follow-up study. Lancet Neurol, 5(3), 228-234.

Helzner, E. P., Luchsinger, J. A., Scarmeas, N., Cosentino, S., Brickman, A. M., Glymour, M. M., et al. (2009). Contribution of vascular risk factors to the progression in Alzheimer disease. Arch Neurol, 66(3), 343-348. 
Hulstaert, F., Blennow, K., Ivanoiu, A., Schoonderwaldt, H. C., Riemenschneider, M., De Deyn, P. P., et al. (1999). Improved discrimination of AD patients using beta-amyloid(1-42) and tau levels in CSF. Neurology, 52(8), 1555-1562.

Intiso, D., Di Rienzo, F., Rinaldi, G., Zarrelli, M. M., Giannatempo, G. M., Crociani, P., et al. (2006). Brain MRI white matter lesions in migraine patients: is there a relationship with antiphospholipid antibodies and coagulation parameters? Eur J Neurol, 13(12), 1364-1369.

Jack, C. R., Jr., Dickson, D. W., Parisi, J. E., Xu, Y. C., Cha, R. H., O’Brien, P. C., et al. (2002). Antemortem MRI findings correlate with hippocampal neuropathology in typical aging and dementia. Neurology, 58(5), 750-757.

Jelicic, M., van Boxtel, M. P., Houx, P. J., \& Jolles, J. (2000). Does migraine headache affect cognitive function in the elderly? Report from the Maastricht Aging Study (MAAS). Headache, 40(9), 715-719.

Kalaydjian, A., Zandi, P. P., Swartz, K. L., Eaton, W. W., \& Lyketsos, C. (2007). How migraines impact cognitive function: findings from the Baltimore ECA. Neurology, 68(17), 1417-1424.

Kivipelto, M., Helkala, E. L., Hanninen, T., Laakso, M. P., Hallikainen, M., Alhainen, K., et al. (2001). Midlife vascular risk factors and late-life mild cognitive impairment: A population-based study. Neurology, 56(12), 1683-1689.

Klunk, W. E., Engler, H., Nordberg, A., Wang, Y., Blomqvist, G., Holt, D. P., et al. (2004). Imaging brain amyloid in Alzheimer's disease with Pittsburgh Compound-B. Ann Neurol, 55(3), 306-319.

Kruit, M. C., Launer, L. J., van Buchem, M. A., Terwindt, G. M., \& Ferrari, M. D. (2005). MRI findings in migraine. Rev Neurol (Paris), 161(6-7), 661-665.

Kruit, M. C., van Buchem, M. A., Hofman, P. A., Bakkers, J. T., Terwindt, G. M., Ferrari, M. D., et al. (2004). Migraine as a risk factor for subclinical brain lesions. Jama, 291(4), 427-434.

Kurian, A. K., \& Cardarelli, K. M. (2007). Racial and ethnic differences in cardiovascular disease risk factors: a systematic review. Ethn Dis, 17(1), 143-152.

Larrieu, S., Letenneur, L., Orgogozo, J. M., Fabrigoule, C., Amieva, H., Le Carret, N., et al. (2002). Incidence and outcome of mild cognitive impairment in a population-based prospective cohort. Neurology, 59(10), 1594-1599.

Launer, L. J., Ross, G. W., Petrovitch, H., Masaki, K., Foley, D., White, L. R., et al. (2000). Midlife blood pressure and dementia: the Honolulu-Asia aging study. Neurobiol Aging, 21(1), 49-55.

Le Pira, F., Lanaia, F., Zappala, G., Morana, R., Panetta, M. R., Reggio, E., et al. (2004). Relationship between clinical variables and cognitive performances in migraineurs with and without aura. Funct Neurol, 19(2), 101-105.

Marengoni, A., von Strauss, E., Rizzuto, D., Winblad, B., \& Fratiglioni, L. (2009). The impact of chronic multimorbidity and disability on functional decline and survival in elderly persons. A community-based, longitudinal study. J Intern Med, 265(2), 288-295.

Pearson, A. J., Chronicle, E. P., Maylor, E. A., \& Bruce, L. A. (2006). Cognitive function is not impaired in people with a long history of migraine: a blinded study. Cephalalgia, 26(1), 74-80.

Peila, R., White, L. R., Petrovich, H., Masaki, K., Ross, G. W., Havlik, R. J., et al. (2001). Joint effect of the APOE gene and midlife systolic blood pressure on late-life cognitive impairment: the Honolulu-Asia aging study. Stroke, 32(12), 2882-2889.

Qiu, C., Winblad, B., \& Fratiglioni, L. (2005). The age-dependent relation of blood pressure to cognitive function and dementia. Lancet Neurol, 4(8), 487-499.

Riedel-Heller, S. G., Busse, A., Aurich, C., Matschinger, H., \& Angermeyer, M. C. (2001). Prevalence of dementia according to DSM-III-R and ICD-10: results of the Leipzig Longitudinal Study of the Aged (LEILA75+) Part 1. BrJ Psychiatry, 179, 250-254.

Shoghi-Jadid, K., Small, G. W., Agdeppa, E. D., Kepe, V., Ercoli, L. M., Siddarth, P., et al. (2002). Localization of neurofibrillary tangles and beta-amyloid plaques in the brains of living patients with Alzheimer disease. Am J Geriatr Psychiatry, 10(1), 24-35.

Staekenborg, S. S., Koedam, E. L., Henneman, W. J., Stokman, P., Barkhof, F., Scheltens, P., et al. (2009). Progression of mild cognitive impairment to dementia: contribution of cerebrovascular disease compared with medial temporal lobe atrophy. Stroke, 40(4), 1269-1274.

Stenset, V., Hofoss, D., Berstad, A. E., Negaard, A., Gjerstad, L., \& Fladby, T. (2008). White matter lesion subtypes and cognitive deficits in patients with memory impairment. Dement Geriatr Cogn Disord, 26(5), 424-431.

Swartz, R. H., \& Kern, R. Z. (2004). Migraine is associated with magnetic resonance imaging white matter abnormalities: a meta-analysis. Arch Neurol, 61(9), 1366-1368. 
Van Beijsterveldt, C. E., van Boxtel, M. P., Bosma, H., Houx, P. J., Buntinx, F., \& Jolles, J. (2002). Predictors of attrition in a longitudinal cognitive aging study: the Maastricht Aging Study (MAAS). J Clin Epidemiol, 55(3), 216-223.

Van Boxtel, M. P., Gaillard, C., Houx, P. J., Buntinx, F., de Leeuw, P. W., \& Jolles, J. (1997). Can the blood pressure predict cognitive task performance in a healthy population sample? J Hypertens, 15(10), 1069 1076.

Visser, P. J., Verhey, F. R., Scheltens, P., Cruts, M., Ponds, R. W., van Broeckhoven, C. L., et al. (2002). Diagnostic accuracy of the Preclinical AD Scale (PAS) in cognitively mildly impaired subjects. J Neurol, 249(3), 312-319.

Waldstein, S. R., \& Katzel, L. I. (2006). Interactive relations of central versus total obesity and blood pressure to cognitive function. Int J Obes (Lond), 30(1), 201-207.

WHO. (1999). World Health Organization, Guidelines Subcommittee, -International Society of Hypertension guidelines for the management of hypertension. J Hypertens, 17, 151-183.

Xu, W., Qiu, C., Gatz, M., Pedersen, N. L., Johansson, B., \& Fratiglioni, L. (2008). Mid- and Late-life Diabetes in Relation to the Risk of Dementia: A Population-based Twin Study. Diabetes. 

The main aim of this thesis was to identify prodromes and risk factors for cognitive decline and dementia, in an epidemiological setting. The first part consisted of three chapters on defining this prodromal stage, on its stability and on neuropsychological profiles of dementia. The second part focused on health-related risk factors for cognitive decline and dementia, such as vascular disease and multimorbidity.

This summary gives an overview of the seven experimental chapters of this thesis. In Chapter 2, the predictive value of Mild Cognitive Impairment (MCI) for dementia is investigated. Several common definitions of MCI are compared with regard to sensitivity and specificity for dementia diagnosis. MCI predicted dementia best when defined according to a broad cognitive criterion, regardless of subjective complaints into account. The predictive value was never high, though, with a maximum sensitivity of 0.73 . Age was found to be an important mediator of the predictive value of MCI for dementia. In old-old (70-84 years old) persons, sensitivity and positive predictive value were higher then in young- old (60-70 years old) individuals.

Since many MCI cases were found to not be diagnosed with dementia over a nineyear interval, Chapter 3 studied stability of MCI for those individuals that did not develop dementia in those nine years. Three techniques of stability measurement were compared to test whether MCI can be viewed as a stable diagnostic entity. Results showed, that, regardless the stability definition used, at least forty percent of the baseline MCI cases reverted to normal cognitive functioning over a period of six years. Even after correcting for practice effects stability did not improve.

Both the predictive value for dementia and the stability of MCI were found to be low, therefore in Chapter 4 we investigated the preclinical phase of dementia by focusing on neuropsychological test performance without using a fixed cut-off such as MCI. Dementia cases were found to show lower neuropsychological test performance, even up to nine years prior to diagnosis. In addition, performance showed increased decline over time, according to a domain-dependent decline pattern. Memory performance showed increased decline in the first test interval after baseline measurement and executive functioning in the second interval.

In the second part of this thesis health-related risk factors for cognitive decline and dementia were investigated, with a focus on vascular risk factors. In Chapter 5, we studied effects of migraine diagnosis and medication use on cognitive decline. Neuropsychological test results for migraineurs and controls were compared at baseline and over an interval of six years. Migraine diagnosis did not influence cognitive performance change over time, and nor did migraine medication use. We split up the medication use into use of specific migraine medication and use of NSAIDs, however, for both types of medication, no effects were found on cognitive performance or decline. 
Chapter 6 was aimed at testing the interaction between waist circumference and hypertension and the effect of this interaction on cognitive performance. In a different study such an interaction was found. We replicated this study in a larger sample and with a more complete set of cognitive tests available. However, we could not replicate the findings of the other study. No interaction effects between waist-circumference and hypertension on cognitive performance could be identified.

Effects of hypertension on cognitive performance were further explored in Chapter 7, in which we investigated effects of exposure to hypertension and type-II diabetes (NID$\mathrm{DM}$ ) on cognitive change over time. Apolipoprotein E (APOE) genotype was included as a co-variate as was use of anti-hypertensive medication. Persons with long-term untreated hypertension were found to show increased cognitive decline over time compared to healthy controls or compared to individuals with hypertension at only one measurement moment in time. NIDDM diagnosis caused cognitive performance to be lower compared to healthy controls, but no exposure effects for NIDDM were found. Effects of hypertension on cognitive decline were increased for persons with at least one APOE-e4 allele.

In Chapter 8 risk of dementia diagnosis was studied for elderly individuals $(75$ years and older) with cognitive impairment, no dementia (CIND) and multimorbidity (having two or more chronic diseases). Multimorbidity resulted in a three-fold risk of dementia diagnosis in individuals with CIND. Vascular disease was the most common disease cluster present in these individuals (38\% prevalence). The predictive value of multimorbidity for dementia in individuals with CIND did not depend on the number of diseases present.

The last chapter of this thesis, Chapter 9, provides a general discussion of the previous seven chapters and methodological considerations and implications of the studies are discussed. 


\section{Samenvatting}

Dit proefschrift heeft als hoofddoel het vinden van voorspellers en risicofactoren voor cognitieve achteruitgang en dementie. Cognitieve problemen, vooral geheugenklachten, komen bij heel veel ouderen voor. De vraag is of deze klachten een voorteken zijn voor dementie op een later tijdstip of dat er sprake is van gewone vergeetachtigheid. Om dit te kunnen vaststellen is het van belang te weten wat bepaalt in welke groep iemand zit en of iemand dus dementie gaat ontwikkelen of niet. In dit proefschrift zijn voorstadia van dementie en risicofactoren voor dementie en cognitieve achteruitgang onderzocht. Tenzij anders vermeld zijn de studies uitgevoerd binnen de Maastricht Aging Study (MAAS), een longitudinale studie naar determinanten van cognitieve veroudering ( $N=1823$, leeftijd 24-84).

De achtergrond van dit onderzoek is besproken in Hoofdstuk 1, evenals de doelen van het proefschrift en de opzet ervan.

Hoofdstuk 2 beschrijft de effecten van diagnostische criteria en leeftijd op de voorspellende waarde van Mild Cognitive Impairment (MCI) voor dementie. MCI is een fase tussen normaal cognitief functioneren en dementie, waarbij cognitie reeds is aangedaan maar er nog geen sprake is van substantiële interferentie in het dagelijks leven. In eerdere studies worden verschillende definities van MCI door elkaar gebruikt en wordt geen rekening gehouden met de leeftijd van de onderzoeksgroep. Deze studie toonde aan dat de voorspellende waarde van MCI voor dementie sterk afhangt van MCI definitie en leeftijd en dat dus met beide rekening dient te worden gehouden bij de interpretatie van deze voorspellende waarde. Overigens is de voorspellende waarde van MCI in alle gevallen, dus met welke definitie ook gebruikt wordt, laag te noemen.

Hoofdstuk 3 ging verder op het voorgaande hoofdstuk en onderzocht de stabiliteit van MCI over tijd. Als de voorspellende waarde voor dementie laag is, wat gebeurt er dan met die mensen met MCI. Blijven ze stabiel? Of functioneren ze een aantal jaar later weer gewoon normaal? Deze studie heeft de stabiliteit van MCI over 6 jaar onderzocht op 3 verschillende manieren. Deze stabiliteit bleek laag te zijn, ook als werd gecorrigeerd voor oefeneffecten (waar neuropsychologische tests gevoelig voor zijn). Veel mensen met MCI scoorden 3 en 6 jaar later weer normaal op cognitie. De instabiliteit was het grootst tussen baseline en 3 jaar.

Hoofdstuk 4 volgde de trajecten van cognitieve achteruitgang over tijd van mensen die gaan dementeren. De studie wijst uit dat we al negen jaar voor de diagnose Alzheimer kunnen voorspellen wie de ziekte krijgt en wie niet. Dit verschil is het duidelijkst voor geheugenprestatie. In het geval van vasculaire dementie is dit onderscheid ook te maken, maar gaat het niet zozeer om verlies van geheugenprestatie als wel om verlies van executief functioneren.

Vanaf hoofdstuk 5 behandelt dit proefschrift een aantal veel voorkomende, veelal vasculaire aandoeningen om te onderzoeken of deze als risicofactor voor dementie gelden. 
Hoofdstuk 5 gaat in op effecten van migraine op cognitieve achteruitgang over tijd. Migraine is een veel voorkomende vorm van hoofdpijn, die in eerdere studies werd gekoppeld aan witte stof afwijkingen in de hersenen. Studies over effecten op cognitie verschillen nogal in hun uitkomsten, variërend van geen effect tot een negatief effect en zelf een beschermend effect. Met behulp van Generalized Estimating Equations hebben we longitudinale effecten van migraine en het gebruik van migraine medicatie onderzocht. Migraine bleek geen effecten op cognitie te hebben en het gebruik van migraine medicatie ook niet.

Obesitas is een bekende oorzaak van hart- en vaatziekten en wordt in Hoofdstuk 6 behandeld. In deze studie vonden wij geen effecten van obesitas, hoge bloeddruk en tailleomtrek op cognitie. Zowel op geheugen als op snelheid en executief functioneren werden dergelijke effecten niet gevonden. In deze studie is gebruik gemaakt van cognitie op een enkel meetmoment, omdat zij is uitgevoerd in respons op een eerdere studie die dergelijke effecten wel rapporteerde, en die zich ook baseerde op cross-sectionele data.

In Hoofdstuk 7 onderzochten we de effecten van langdurige blootstelling aan hoge bloeddruk op cognitieve prestatie over tijd. De invloed van anti-hypertensiva gebruik, type-II diabetes en ApoE genotype op deze relatie is ook onderzocht. De studie wees uit, dat langdurige blootstelling aan onbehandelde hoge bloeddruk zorgt voor een toename in cognitieve achteruitgang over tijd, op het gebied van geheugen, snelheid en executief functioneren. Dit effect is groter voor mensen met het ApoE-e4 genotype. Type-II diabetes heeft een negatief op cognitie, maar dit effect is niet afhankelijk blootstellingduur. Cognitieve achteruitgang over tijd was minder worden door Proefpersonen die met anti-hypertensiva behandeld werden voor hun hoge bloeddruk lieten minder cognitieve achteruitgang over tijd zien.

Hoofdstuk 8 is het resultaat van een onderzoek aan het Karolinska Instituut in Stockholm, Zweden. De prevalentie van multimorbiditeit, ofwel het hebben van meerdere ziekten, neemt toe met leeftijd. Aan de hand van gegevens van het Kungsholmen Project, een Zweedse longitudinale studie naar veroudering en dementie $(\mathrm{N}=1700$, leefijd 75-100), is onderzocht of mensen met multimorbiditeit meer kans hebben op dementie dan gezonde mensen. In een MCI groep bleek, dat mensen met multimorbiditeit een bijna drie keer zo grote kans hebben om dementie te ontwikkelen dan gezonde mensen. De meest voorkomende aandoeningen waren vasculaire ziekten, die veelal te behandelen zijn. Het succesvol behandelen van vasculaire ziekten kan de kans op dementie dus verkleinen.

In Hoofdstuk 9 werden de hoofdstukken van dit proefschrift bediscussieerd, er werd ingegaan op de limitaties en sterke punten van de studies en er werden klinische implicaties en aanbevelingen voor verder onderzoek gegeven. 


\section{Dankwoord}

Tja, en dan komt het einde toch echt in zicht...vier jaar schrijven, testen, analyseren, invoeren, reizen, presenteren, lesgeven en vooral veel samenwerken heeft geleid tot wat u nu voor u heeft liggen... Hoog tijd om mijn medereizigers te bedanken voor de geweldige trip!

Mijn promotieteam: promotoren Jelle Jolles en Frans Verhey en copromotor Martin van Boxtel: dank voor de kans, het vertrouwen en alle vrijheid!

Beste Jelle, fijn dat ik op jouw bagagedrager mocht plaatsnemen! Ik ben je dankbaar voor alles wat je in de afgelopen vier jaar allemaal mogelijk hebt gemaakt! Ik heb veel van je geleerd!

Beste Frans, dank voor je betrokkenheid, je altijd kritische, klinische blik, je support bij mijn praatje in Chicago en de leuke gesprekken! Ik hoop dat we nog lang blijven samenwerken!

Beste Martin, dank voor de vele overleggen, het vertrouwen in mij, wat MAAS betreft, de super uitgebreide en gedegen commentaren op mijn stukken, de fijne gesprekken en de tips over Zweden!

Dr. Dijkstra, beste Jeanette, onofficieel vierde lid van mijn promotieteam, bedankt voor je klinische blik, je goeie commentaren op mijn stukken en vooral voor je luisterend oor!

Dr. Pieter Jelle Visser, fijn dat jij als MCI-deskundige bij mijn studies betrokken wilde zijn! Dr. Frans Tan, dank voor je statistische input en voor het checken of het allemaal wel goed uitgelegd was zo!

My team in Sweden, Professor Laura Fratiglioni, cara Laura, it was and is an honor to work with you and to enjoy your company. You made me feel at home at ARC, as did your fantastic team! Barbara Caracciolo, even though we did not physically work together a lot during my stay, you were always fast in your comments and you helped me get to know the world of epidemiological statistics, thanks!

Mijn geweldige, leuke, lieve collega's bij NP, bedankt voor alle gezellige lunches, (AiO-) uitjes en 'gewone' kletsmomenten! In het bijzonder wil ik Astrid Quist bedanken voor de fijne samenwerking op MAAS en Nico en Ron voor al hun onontbeerlijke en ontzettend gewaardeerde technische steun! Elsa en Els, bedankt voor alle logistieke en planma- 
tige ondersteuning, vooral 'op 't einde'. Floortje, dank voor 't delen van de top-tijd in Stockholm!

My colleagues at ARC, thank you all for making me feel at home in Stockholm! I would especially like to thank Stephanie Paillard-Borg, for being a fantastic room-mate and for being the other stupidest rat in the cage with me (-). Can't wait to get some Thai food again! René en Maureen, bedankt voor jullie gastvrijheid en voor de geweldige Sinterklaasavond!

Een mega-project als MAAS kan niet bestaan zonder de medewerking van geweldige stagiaires: Romanee, Ellen F., Audrey, Eveline, Suzanne, Kim, Amaryllis, Noortje, Sanne, Ellen P., Martine en Helene bedankt! Het was een genot om met jullie te werken en om te weten dat er zulke goede mensen voor de proefpersonen en data zorgden!!

Romanee, jij speciaal bedankt voor al je werk voor hoofdstuk 5 van dit proefschrift! We moeten nu echt eens snel een date plannen in Anvers of Den Bosch (of Mestreech natuurlijk...).

De mensen die voor de inhoud van dit proefschrift hebben gezorgd: alle MAASdeelnemers, bedankt voor de jarenlange inzet!

Mijn kamergenoten...Esther, Lisbeth en Wim, bedankt dat jullie mijn kamergenoten wilden/willen zijn! Bedankt voor alle leuke gesprekken, discussies, reacties op mijn zuchten, dat jullie zelf ook soms zuchtten, en vooral voor dat ik me bij jullie helemaal op mijn gemak voel! Esther, soms komt er iemand op je pad die precies begrijpt wat je bedoelt en hoe je bent zonder dat je dat hoeft uit te leggen, dankjewel!

Mijn MCI maatje van het eerste uur, Inez! Het is me een eer samen met jou de MCImeisjes te zijn en ik vind het super dat we naast onderzoek nog zoveel meer met mekaar delen! Chicago, Stockholm en Lapland (de hondenslee!!) waren tot nu toe de hoogtepunten! Ben benieuwd waar we nog allemaal heen zullen gaan!

Mijn lieve vriendinnen en paranimfen, Esther Hoogenhout en Rosa Drijgers, ik kan me geen beter duo voorstellen als bijstand vandaag. Lieve Esther, wat een reis waren die afgelopen vier jaar!! We zijn samen aan deze aio-ervaring begonnen en hebben veel gelachen en gelukkig iets minder veel gehuild. Dat we nog maar lang vriendinnen mogen blijven en dat we nog maar vaak met Jeroen, Popke Rein en Marit (jongste telg van de Teigetje fanclub!!) etentjes mogen doen!

Rosa, lief vriendinnetje, vanzelfsprekend ben jij mijn paranimf vandaag, ik had het niet anders gewild! Niet alleen vertegenwoordig je WIAN vandaag, maar je bent ook mijn relativerings-punt. Als ik weer eens stress over deadlines, de toekomst of andere 'belangrijke' zaken ben jij altijd degene die mij weer met beide benen op de grond krijgt en me laat inzien dat de wereld niet vergaat als alle major-life-decisions niet in een dag worden genomen!

Meiden, jullie zijn geweldige vriendinnen (en collega's) en ik zal proberen niet om te kiepen vandaag, maar als dat wel gebeurt, heb ik er alle vertrouwen in dat jullie me goed kunnen vervangen $(-)$. Es, succes met de laatste loodjes!! 
Wiet, Rob, Paul, Sas, Ka, Aad, Pat, Sendy: jullie zijn een bijzondere combinatie van hele dierbare vrienden, dankjewel daarvoor! Enne, heb ik nou hiermee eindelijk bewezen dat de bijnaam 'Muts' echt niet verdiend is??

Mijn allerliefste nichie Joke (en Ries), wij zijn al vriendinnetjes sinds jij geboren bent en daar ben ik enorm trots op! Dank voor de supermooie kaft van dit boekje enne...op naar 't volgende BA concert!

Lief What's In A Name, Fleur, Mich, Mieke, Mini, Rosa (alweer (:) en San, mijn 'tweede' studententijd werd door jullie een groot feest en dat was pas het begin! Jullie zijn geweldige vriendinnen! Alle etentjes, stapavonden, uitstapjes, goeie gesprekken en slappe lachmomenten waren onbetaalbaar en onmisbaar als afleiding! Deelie, welkom bij de club!

Mijn familie, allereerst Oop en Oom. Jullie zijn een belangrijk deel van mijn basis en ik wil jullie bedanken voor alle steun en interesse door de jaren heen! Jullie maken het heel makkelijk om van oude mensen te houden en jullie geven voor mij de kleur aan dit onderzoek! Deze is voor jullie!

Mijn schoonfamilie, Marianne, MJ, Sophie, Jan, Marlies, Thom en Robin: bedankt voor de interesse in wat ik de afgelopen vier jaar heb gedaan en voor de gezellige etentjes, theetjes en wijntjes!

Mama en papa, Bram en Hanneke, mijn basis. Jullie hebben me zoveel geleerd, daar ben ik jullie dankbaar voor! Thuis was er altijd ruimte voor discussie, voor goede gesprekken, maar ook voor veel (heel veel) lachen en gezelligheid. De laatste maanden van 't tiepen aan mijn proefschrift woonde ik weer bijna helemaal thuis, en hoewel 't best wennen was, maakten jullie er een feest van, dankjewel daarvoor!

Brammie, wat ben je toch een leuke grote kleine broer en wat ben ik trots op wat je allemaal doet!!

Mam, al mijn hele leven kan ik met werkelijk alles bij jou terecht, je bent met stip de liefste mama van de hele wereld!

Pap, jou wil ik speciaal bedanken, omdat je mij hebt geleerd dat vaderschap niet van biologie afhangt, maar van 'er zijn'. Je bent een kei van 'n papa!

En dan, als allerlaatste, mijn lief, Jeroen. Wie had dat nou gedacht, tien jaar geleden op de Lantaarnstraat, jij en ik, allebei bijna doctor! Het is voor mij niet meer dan logisch dat ik dit boekje opdraag aan jou! Jij bent mijn betere wederhelft, mijn allerliefste. Zonder jou was dit avontuur niet half zo leuk geweest en was dit boekje er nooit gekomen! Bedankt voor alle afleiding, de geweldige reizen, je vele Stockholm- bezoekjes, voor al je liefde en je grenzeloze vertrouwen in mij. Ik wil je op deze plek ook nog even laten weten dat ik vreselijk trots ben op hoe jij je door het afgelopen jaar hebt heen geslagen!! Mij lijkt 't best veel, binnen 1 jaar een nieuwe baan, twee keer verhuizen, het afronden van een proefschrift en vijf keer op een neer vliegen naar Stockholm?! 
Verder vind ik het echt weer typisch iets voor ons dat we het voor elkaar hebben gekregen om 1 dag na elkaar te promoveren, haha...Ik wens je heel veel succes de $18^{\mathrm{e}}$ en kijk al uit naar ons super knalfeest!! (En ook wel naar de heerlijke relaxvakantie daarna...) Nog eventjes en dan kunnen we eindelijk samen doctortje spelen (:). 


\section{Publications}

Van Boxtel MP, Baars L \& Jolles J (2007). Obesity, blood pressure and cognitive function: a reply to Waldstein and Katzel. Int J Obes (Lond)31(7), 187-188

Baars, M.A.E., van Boxtel, M.P.J., Dijkstra, J., Visser, P.J., van den Akker, M.A., Verhey, F.R.J. \& Jolles, J. (2009). Predictive value of Mild Cognitive Impairment for dementia: the influence of case definition and age. Dem Ger Cog Dis, 27(2), 173-181

Baars, M.A.E., van Boxtel, M.P. J. \& Jolles, J. (2009). Migraine does not affect agerelated cognitive decline: results from the Maastricht Aging Study. Headache, in press.

Baars, M.A.E., van Boxtel, M.P.J., Dijkstra, J., Visser, P.J., Verhey, F.R.J. \& Jolles, J Stability of Mild Cognitive Impairment over time: 6 year follow-up results from a population study. (Under review)

Baars, M.A.E., van Boxtel, M.P.J., Tan, F., Bekers, O., Verhey, F.R.J. \& Jolles, J. Hypertension and cognitive decline: mediation by exposure time, treatment and ApoE-e4 genotype. (Under review)

Baars, M.A.E., van Boxtel, M.P.J., Dijkstra, J., Verhey, F.R.J. \& Jolles, J. Neuropsychological trajectories of dementia: nine year follow-up results of the Maastricht Aging Study (Submitted). 



\section{Curriculum Vitae}

Lia Baars werd op 13 januari 1980 geboren te Heerlen. Zij doorliep van 1992 tot 1998 het gymnasium van het Jeanne d'Arccollege in Maastricht. De drie daaropvolgende jaren studeerde zij Economie aan de Universiteit Maastricht om zich vervolgens in $2001 \mathrm{vol}$ overgave te storten op de studie Psychologie aan diezelfde universiteit. Zij koos voor de afstudeerrichting Biologische Psychologie, specialisatie Neuropsychologie. Haar afstudeerstage was de eerste kennismaking met de afdeling Psychiatrie en Neuropsychologie, alwaar zij na het behalen van haar diploma in 2005 startte met haar promotieonderzoek. Gedurende vier jaar onderzocht zij voorspellers en risicofactoren van cognitieve achteruitgang en dementie met gegevens van de Maastricht Aging Study. Het onderzoek dat zij in deze periode heeft uitgevoerd staat beschreven in dit proefschrift. Als onderdeel van haar promotietraject bracht zij in 2008 drie maanden door als 'visiting researcher' aan het Aging Research Center van het Karolinska Institut en Stockholm University, in Zweden.

Momenteel is zij als postdoc onderzoeker verbonden aan het Alzheimer Centrum Limburg en de afdeling Psychiatrie en Neuropsychologie. 